School of Finance

University of St.Gallen

INVESTOR ATTENTION AND SENTIMENT: RISK OR ANOMALY?

MELK BUCHER

WORKING PAPERS ON FINANCE NO. 2017/12

SWISS INSTITUTE OF BANKING AND FINANCE (S/BF - HSG)

JULY 2017 


\title{
Investor Attention and Sentiment: Risk or Anomaly?
}

\author{
MELK C. BUCHER *
}

This version: July 2017

\begin{abstract}
Are stocks' varying sensitivies to changing investor attention and sentiment priced? Employing internet search-based proxies for both, I find novel results that are consistent with theory. Stocks that co-vary negatively with increased investor attention to the stock market outperform in the following months in a behavior consistent with a risk premium. The pricing of co-variation with investor sentiment depends on aggregate mispricing (Baker-Wurgler index), behaving like a risk premium when mispricing is low and like an anomaly when mispricing is high. Sensitivity to both sentiment and attention is strongly related to idiosyncratic volatility and limits to arbitrage: High absolute attention/sentiment loadings are associated with higher volatility, smaller size and other limits to arbitrage. However, the priced attention and sentiment components are clearly distinct from the idiosyncratic risk puzzle and stay significant when controlling for relevant pricing factors and company characteristics. Investor attention is both very robust and highly powerful in pricing a broad variety of test assets. On the other hand, investor sentiment's effect on performance is strongly related to return reversal/momentum and does not add much information on its own.
\end{abstract}

JEL Classification: G12, G02

Keywords: Investor attention, investor sentiment, limits to arbitrage, asset pricing, idiosyncratic risk puzzle

\footnotetext{
${ }^{*}$ Melk Bucher is with the Swiss Institute of Banking and Finance at the University of St.Gallen. I acknowledge the support of the Swiss National Science Foundation in the form of a fellowship. I am grateful to Paul Söderlind, Angelo Ranaldo, Robert Hodrick as well as discussants at the University of St. Gallen and Columbia brownbag seminars for their useful feedback. Author contact: melk.bucher@unisg.ch
} 


\section{Contents}

\begin{tabular}{lll}
\hline Investor attention and sentiment: state variables? & 6
\end{tabular}

A Investor attention . . . . . . . . . . . . . . . . . . . . . 6

B Investor sentiment . . . . . . . . . . . . . . . . . . . . . . 8

C Attention, sentiment and volatility . . . . . . . . . . . . . . 10

II The empirics: Investor attention, investor sentiment and cross-sectional returns 11

A Data . . . . . . . . . . . . . . . . . . . . . . . 11

B The pre-formation regression $\ldots \ldots \ldots \ldots \ldots \ldots$

C Cross-sectional characteristics of attention and sentiment loading . . . . . . . . . 16

D Risk factor or anomaly? . . . . . . . . . . . . . . . . . . . . . . . . 18

E Loadings and expected returns . . . . . . . . . . . . . . . . . . . . . . 21

F Attention, sentiment and limits to arbitrage . . . . . . . . . . . . . . . 21

G Attention, sentiment and the idiosyncratic risk puzzle . . . . . . . . . . . . . 24

IIIIs there a price to investor attention and sentiment?] 25

A Investor attention . . . . . . . . . . . . . . . . . . . . . . 25

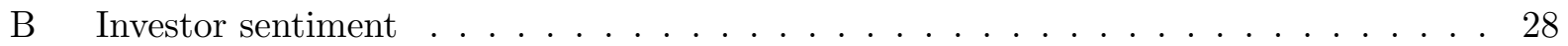

\begin{tabular}{ll}
\hline IV Robustness & 29
\end{tabular}

A Investor attention . . . . . . . . . . . . . . . . . . . . . . . . . . . . 29

B Investor sentiment . . . . . . . . . . . . . . . . . . 36

\begin{tabular}{|l|l}
\hline $\mathrm{V}$ Conclusion & 38
\end{tabular} 
Standard asset pricing theory assumes that investors pay constant attention to and instantly process infinite amounts of information. Furthermore, investors act rationally to maximize utility - not beset by neither sentiment nor cognitive biases. It is no longer a question whether these two assumptions are true; rather, the question is how and when economic agents deviate from these two ideals and what the implications are for asset prices. In this paper, I relax these two standard assumptions one at a time and instead use novel proxies for attention and sentiment to gauge their impact on cross-sectional equity returns. Specifically, I ask: do stocks exhibit varying sensitivity to investor attention and sentiment? And if so, is this sensitivity priced, i.e. are investor attention and sentiment state variables?

Attention is a scarce cognitive resource (Kahnemann and Tversky (1973)). The acknowledgment of this insight has produced a long theoretical and empirical literature on the antecedents and impact of varying attention on both the market and asset-specific levels. On the asset-specific level, attention has been discussed in the context of return pressure following attention-grabbing events (Barber, Odean, and Zhu (2008) \& Da, Engelberg, and Gao (2011)), as a driver of momentum in asset prices (Da, Gurun, and Warachka (2014), Hou, Peng, and Xiong (2009) \& Hirshleifer and $\operatorname{Lim}(2009)$ ), with regards to information demand and stock-level volatility (Vlastakis and Markellos (2012) as well as through its negative impact on stock return predictability (Vozlyublennaia (2014)). On a macro level, investor attention is strongly tied to macroeconomic and information shocks (Peng and Xiong (2006) \& Peng, Xiong, and Bollerslev (2007)), increased correlation (Peng and Xiong (2006)) as well as to uncertainty and volatility (Andrei and Hasler (2015)).

The establishment of investor attention as a relevant factor in the pricing kernel of equity investors is the first major contribution of this paper. While market attention has been shown to be intimately related to the investment opportunity set - in terms of volatility, uncertainty or information shocks -, it is as of yet unanswered whether it can be considered a state variable in its own right 1 . Indeed, in this paper I find that stocks' loading to investor attention is associated negatively with cross-sectional performance, as expected from theory. I present strong evidence that stocks that perform badly in times of increased market attention are rewarded with higher crosssectional returns. The finding is economically significant, to the tune of around $-0.60 \%$ monthly in terms of a quintile high-minus-low portfolio, and survives a myriad of robustness tests.

While investor attention is theoretically meaningful, one of the major empirical challenges has long been the absence of a direct measure of attention, particularly on the market level. Consequently, empiricists have relied upon countless indirect proxies arguably related to attention: these have encompassed extreme returns (Barber et al. (2008)), trading volume (Barber et al. (2008) or Gervais, Kaniel, and Mingelgrin (2001)), news and headlines (Yuan (2015)), advertising expense (Grullon, Kanatas, and Weston (2004)) or price limits (Seasholes and Wu (2007)). These proxies make the critical assumption that the effects considered in fact were associated with a change

\footnotetext{
${ }^{1}$ Somewhat related, Ang, Hodrick, Xing, and Zhang (2006b) have established that volatility, often associated with attention, is a priced state variable. However, given that volatility can be considered endogenous to changing trading behavior and to a change in the information set, I argue that investor attention should be considered a more fundamental state variable.
} 
in attention, an unprovable and noisy proposition. In this paper I employ a direct and revealed measure of investor attention - the Google search frequency in the 'DJIA' (shorthand for the Dow Jones Industrial Index) within the United States. This builds on a relatively recent stream of the literature that has employed Google search queries to measure a myriad of factors, such as car sales or unemployment numbers to impressive accuracy (Varian and Choi (2009)). More specifically, searches of stock tickers and whole indices have successfully been employed as attention proxies (i.e., Vlastakis and Markellos (2012); Da et al. (2011) or Da, Engelberg, and Gao (2015)).

'DJIA' shows behavior which is intuitively consistent with a salient measure of aggregate market attention. It peaks during times of increased volatility, negative market returns and/or information shocks. For instance, it is heightened in the Financial Crisis of 2008-09 and reaches its peak in October 2008 - in times of enormous economic and financial uncertainty and turmoil. It also increases in the fall of 2011 during the downgrade of Treasury securities and in parallel with the Greece debt crisis. Furthermore, 'DJIA' is correlated strongly with alternative search query proxies for investor attention, such as 'NYSE', 'NASDAQ', 'FTSE', 'DAX' or 'Stocks', for instance. At the same time, on a daily level it is near-orthogonal to known asset pricing factors, such as the Fama-French five factors (2015), momentum, liquidity or (idiosyncratic) volatility. This increases the likelihood it measures novel information that is not to date employed in known asset pricing models.

My second main contribution is the analysis of (high-frequency) sentiment as a direct risk factor in an alternative asset pricing model. Sentiment's impact on cross-sectional return spreads is part of a growing literature stream. However, the focus has so far been on mispricing and return anomalies, employing sentiment as a conditioning variable, rather than a risk factor in its own right. Baker and Wurgler (2006)'s seminal paper is indicative of this: they construct a monthly sentiment index and show that it can predict characteristics-sorted (Daniel and Titman (1997)) portfolio returns in the next year. When sentiment is high (low), small, volatile and otherwise hardto-arbitrage stocks underperform (outperform) their safer and bigger peers. This relative return predictability is ascribed to cross-sectional over- (under-) valuation of such stocks in times of high (low) sentiment, consistent with a model featuring noise traders (De Long, Shleifer, Summers, and Waldmann (1990)) and limits to arbitrage (Shleifer and Vishny (1997)). Recently, Stambaugh and Yuan (2016) form an asset pricing model including two explicit misvaluation factors based on an underlying set of eleven return anomalies. They find that it prices assets better than alternatives (such as the Fama-French three factor model) and can relate the performance in the misvaluation factors to sentiment.

Employing sentiment as a (conditional) risk factor implies a different perspective than the orthodox one focused on behavioral misvaluation. I am agnostic as to what sentiment really captures - whether it is purely irrational or also contains a rational measure of uncertainty regarding the health of the economy and business cycl $2^{2}$. I take the perspective of a rational market participant

2 Sibley, Wang, Xing, and Zhang (2016) for instance argue that the predictability from the Baker-Wurgler sentiment index really stems from business cycle risk. 
in terms of pricing sentiment-affected assets. As a rational investor, I argue, it makes sense that you want to be compensated for holding assets that are correlated with noise traders' whimsical sentiment. On the other hand, if sentiment rather captures rationally expected economic uncertainty, it can be considered a state variable all the more. There is no reason as to why sentiment in its classical role as a conditioning/misvaluation variable and as a risk factor could not coexist with each other in 'efficiently inefficient' financial markets (Pedersen (2015)).

To measure market-level sentiment, I obtain a novel daily measure of the prevalence of household concerns across the United States. Specifically, I employ Da et al. (2015)'s Financial and Economic Attitudes Revealed by Search (FEARS) index, which is based on the U.S. internet search volume in panic words, such as 'recession' or 'bankruptcy', for instance. As Da et al. (2015) show, the FEARS index successfully predicts negative contemporaneous returns, return reversal, excessive volatility as well as return spreads related to limits to arbitrage. Furthermore, it correlates with existing lower-frequency sentiment proxies - all of this lending to its instrument validity as a sentiment variable.

I demonstrate that the absolute loading (beta) of stocks to FEARS is skewed towards smaller, less liquid and more volatile stocks. Furthermore, the relationship between FEARS beta and next month's returns is conditional upon the sentiment state of the world: in times of low sentiment, companies with negative FEARS loading underperform - consistent with increased limits to arbitrage; in months of high-sentiment, however, they outperform, consistent with a rational risk premium. That FEARS-performance relationship at the monthly level is separate from the discussed sentiment-based conditional return differentials based on stock characteristics (Baker and Wurgler (2006) \& Baker and Wurgler (2007)).

In summary, I thus find a strong unconditional negative impact of DJIA loading on crosssectional returns, consistent with an attention premium. Furthermore, I find a conditional impact of FEARS loading on cross-sectional returns, depending on the sentiment state of the world. How important are these effects in pricing a large array of different assets? In exhaustive FamaMacBeth(1973) testing over my time sample from 2004 to 2015, I find that investor attention is an important pricing factor across a variety of different test assets (portfolios, stocks) and model specifications (rolling versus constant time-series betas) and is robust to the inclusion of many known cross-sectional factors. In fact, across my sample period it is arguably one of the two most robust factors considered. On the other hand, investor sentiment seems to be far more limited in power to explain unconditional or conditional cross-sectional returns.

Given bigger absolute DJIA and FEARS betas are associated with more idiosyncratically volatile stocks, the question arises whether attention or sentiment can partly explain the idiosyncratic risk puzzle. Ang et al. (2006b) and Ang, Hodrick, Xing, and Zhang (2009) have documented than in the U.S. and internationally, stocks with higher idiosyncratic achieve lower, rather than higher cross-sectional returns over long time samples, which contradicts both theory and earlier evidence (e.g., Malkiel and Xu (2002). In this paper, I find strong evidence that neither can in fact account for the other - rather, they seem orthogonal effects remarkably robust from each other. 
Apart from controlling for company characteristics, I perform a wide battery of robustness tests of (un)conditional attention and sentiment cross-sectional performance. The negative relationship between DJIA beta and performance is robust across equally- and value-weighted returns and company size, survives return reversal and momentum, is robust across samples and really is due to directional, rather than absolute factor loading. However, I document that the relationship has become significantly weaker in the past few years, perhaps as market participants have begun to trade in the factor. Furthermore, while the performance spread of pre-sorted attention portfolios is remarkably robust, the post-formation exposure of the portfolios to attention is less so and seems interacted with company size. On the other hand, the cross-sectional return differential due to investor sentiment all but disappears when controlling for last month's stock returns. This implies that over the sample considered, the FEARS-performance effect is mostly due to return predictability at the one-month-horizon, rather than sentiment loading.

The paper is structured as follows: Section 1 introduces the theoretical framework for pricing attention and sentiment in the cross-section. In section III I discuss the proxies for attention and sentiment as well as the cross-sectional (un)conditional patterns between attention, sentiment and stock returns. In particular, I document robust performance of attention and partly of sentiment over what is company characteristics related to limits to arbitrage Section III creates tradable attention and sentiment factors and tests them for pricing various test assets in the equities markets. Lastly, section IV discusses a battery of robustness tests.

\section{Investor attention and sentiment: state variables?}

\section{A. Investor attention}

Asset pricing theory postulates that expected stock returns are related cross-sectionally to their sensitivities to state variables which impact on investors' utility or welfare. Assets whose lowest returns tend to occur precisely in times of unfavorable shifts in that welfare must offer additional compensation for investors to be willing to hold them. Classical theory also assumes that investors are unbounded with regards to obtaining and processing information and do so at lightning speed. I depart from the standard theory in one key point: I assume that economic agents obtain and process

information not automatically, but only by deliberately placing attention. They are bounded in their ability to both collect and process information - they can only pay attention to a subset of available information at a time and learning is not immediate. In other, words, following Da et al. (2011), Da et al. (2015) and in the vein of Kahnemann and Tversky (1973), I thus assume that attention is a scarce cognitive resource.

How, then, investors decide to allocate their scarce attention across the universe of financial market information? I assume that investors can pay attention to information on various levels relevant to the economy or financial markets as a whole, to a certain industry or just to specific companies. I further posit that during times of higher aggregate uncertainty or information shocks impacting financial markets as a whole, investors pay relatively more attention to the market than 
in calmer periods where more attention is directed to industry and/or company levels. Specifically, I follow the model of Peng and Xiong (2006) who posit that economic agents emphasize category learning (the whole market) rather than idiosyncratic company information following an uptick in uncertainty.

I propose investor attention to the stock market to be a good candidate for a state variable. Investor attention to the whole market is systematic - it affects the covariance structure of a broad swath of the investment universe. As Peng and Xiong (2006) and Peng et al. (2007) show, macroeconomic shocks and increased uncertainty about future market returns lead to categorylearning behavior as limited investor attention is focused on the whole market rather than specific assets. Ensuing this redirection of attention towards the market, both market volatility as well as the comovement of individual stocks with the market increase contemporaneously. Assuming meanvariance preferences of the representative agent, such an increase in investor attention towards the market is undesirable as a diversified portfolio is likely to achieve a lower Sharpe ratio due to both higher market volatility as well as higher correlation between the invested assets (assuming constant returns).

However, not only is higher market attention positively related to volatility (Vlastakis and Markellos (2012)), there is also theoretical and empirical evidence that it is negatively related to market returns. Ozoguz (2009) finds that investors' uncertainty about the state of the economy has a negative impact on aggregate market valuations as well as leads to significant variation across portolios sorted by size, book-to-market, and past returns. The investment opportunity set of our representative agent is thus hurt in the wake of increased uncertainty and investor attention by (i) increased volatility, (ii) increasing correlations and (iii) lower valuation levels/negative returns all lending credence to investor attention as a candidate state variable. An asset which performs better (worse) in this scenario should thus command a lower (higher) expected return.

In the vein of multifactor models, such as from Merton (1973) and Ross (1976), and inspired by more recent research on the role of aggregate volatility (Ang et al. (2006b) and Chen (2002)) or liquidity (Pastor and Stambaugh (2003)), I test whether investor attention is a state variable. More specifically, I study whether and how exposure to market investor attention is priced in the cross-section of stock returns. The underlying multifactor representation of expected returns in the cross-section takes the following form:

$$
r_{t+1}^{i}=a_{t}^{i}+\beta_{m, t}^{i}\left(r_{t+1}^{m}-\gamma_{m, t}\right)+\beta_{a_{t}}^{i}\left(a_{t+1}-\gamma_{a, t}\right)+\sum_{k=1}^{K} \beta_{k, t}^{i}\left(f_{k, t+1}-\gamma_{k, t}\right)
$$

where $r_{t+1}^{i}$ is the excess return on stock $i, \beta_{m, t}^{i}$ is the loading on the excess market return, $\beta_{a, t}^{i}$ is the asset's sensitivity to investor attention, and the $\beta_{k, t}^{i}$ coefficients for $k=1, \ldots, K$ represent loadings on other risk factors. In the full conditional form in equation (1), both the conditional means in the factors as well as their factor premia can vary over time. The model is thus written in terms of factor innovations: $r_{t+1}^{m}-\gamma_{m, t}$ denotes the innovation in market return, $a_{t+1}-\gamma_{a, t}$ denotes the innovation in investor attention and $f_{k, t+1}-\gamma_{k, t}$ represents innovations in the other factors. The 
conditional means of market returns, investor attention and factor $k$ are denoted by $\gamma_{m, t}, \gamma_{a, t}$ and $\gamma_{k, t}$, respectively. In equilibrium, the conditional mean of stock $i$ is represented by

$$
a_{t}^{i}=E_{t}\left(r_{t+1}^{i}\right)=\beta_{m, t}^{i} \lambda_{m, t}+\beta_{a, t} \lambda_{a, t}+\sum_{k=1}^{K} \beta_{k, t}^{i} \lambda_{k, t}
$$

where $\lambda_{m, t}$ is the price of risk of the market factor, $\lambda_{a, t}$ is the price of market attention risk and the $\lambda_{k, t}$ are the prices of the other factors. Only if a factor is traded, its conditional mean $\gamma_{k, t}$ is equal to its conditional price of risk $\lambda_{k, t}$.

The main prediction of the model is that stocks with different loadings on aggregate investor attention risk have different average returns. Specifically, as increased investor attention is related to increased uncertainty and thus 'bad' states of the economy, I assume that stocks that co-vary positively with investor attention have lower average returns. That is, I predict $\lambda_{a, t}$ to be negative. It has to be noted that the conditional multifactor model in equation (1) does not lend itself to direct examination as the true set of factors is unknown and the true conditional factor loadings are not observable. Thus, I do not use equation (1) in my empirical work directly, but rather use an appropriate simplification. The empirical framework employed - encompassing the concrete empirical proxies as well as regression-based tests of the model used - is outlined in section II.

\section{B. Investor sentiment}

Apart from investor attention, I also analyze cross-sectional pricing of investor sentiment in an asset pricing framework. Broadly defined, investor sentiment is a belief about future cash flows and investment risks that are not justified by the facts at hand (Baker and Wurgler (2007)). Investor sentiment thus departs further from standard asset pricing theory than investor attention. In this view, at least part of the market participants are irrational noise traders (De Long et al. (1990) ) whose actions cannot be fully offset by rational participants due to noise trader risk and limits to arbitrage (Shleifer and Vishny (1997)). The unpredictability of noise traders' erroneous stochastic beliefs affects prices systematically and over multiple time periods, thus deterring rational arbitrageurs from aggressively betting against them. Even if prices eventually were to converge to their rational price, limits to arbitrage in the form of market- and security-level imperfections make arbitrage costly and risky.

Baker and Wurgler (2006) and Baker and Wurgler (2007) find that there are essentially two plausible channels through which investor sentiment can lead to cross-sectional mispricing: either through variation in (i) relative sentiment or (ii) relative difficulty of arbitrage between different types of stocks. Empirically, these two channels are hard to distinguish and lead to similar hypotheses. What makes some stocks more vulnerable to broad shifts in the propensity to speculate? Baker and Wurgler (2006) suggest that the main factor is the subjectivity of their valuations - empirically proxied by measures such as young, unprofitable, extreme growth and highly idiosyncratically volatile stock. These same characteristics also makes these stocks harder and more expensive to arbitrage. In the following, I will refer to these cross-sectional characteristics as Baker-Wurgler 
(BW) characteristics.

What is the cross-sectional effect of noise trader sentiment, then, on speculative, hard-toarbitrage stocks? Baker and Wurgler (2006) hypothesize that speculative stocks are valued lower than their safe, easy-to-arbitrage stocks during times of lower sentiment, while the opposite is true in high-sentiment periods. This is shown schematically in figure1. This then leads to positive (negative) cross-sectional outperformance of speculative-vs-safe stocks in the coming twelve months if sentiment is low, with the opposite true for high sentiment. More specifically, Baker and Wurgler (2006) find cross-sectional predictability in a 'conditional characteristics model' based on Daniel and Titman (1997).

While investor sentiment has thus been analyzed in a (conditional) cross-sectional context, it has so far not been considered as a state variable. I argue that similarly to investor attention, this is partly due to the difficulty to measure sentiment on a higher-frequency basis. This, however, is a precondition to calculate assets' varying sensitivities to it (sentiment $\beta$ s) and thus open sentiment to analysis within an asset pricing framework. In my analysis, I obtain a novel and daily measure of investor attention - the FEARS index (Da et al. (2015)), which now makes this possible (see section II.A on the employed investor sentiment proxy).

Specifically, as for investor attention, I analyze investor sentiment in a multifactor pricing model. Thereby I simply replace investor attention with investor sentiment, as can be seen from equations (3) and (4) below.

$$
\begin{gathered}
r_{t+1}^{i}=a_{t}^{i}+\beta_{m, t}^{i}\left(r_{t+1}^{m}-\gamma_{m, t}\right)+\beta_{s t}^{i}\left(s_{t+1}-\gamma_{s, t}\right)+\sum_{k=1}^{K} \beta_{k, t}^{i}\left(f_{k, t+1}-\gamma_{k, t}\right) \\
a_{t}^{i}=E_{t}\left(r_{t+1}^{i}\right)=\beta_{m, t}^{i} \lambda_{m, t}+\beta_{s, t} \lambda_{s, t}+\sum_{k=1}^{K} \beta_{k, t}^{i} \lambda_{k, t}
\end{gathered}
$$

where $\beta_{s_{t}}$ is the asset's sensitivity to investor sentiment, $s_{t+1}-\gamma_{s, t}$ denotes the innovation in investor sentiment and $\lambda_{s, t}$ is the price of investor sentiment risk.

Again, the main prediction of the model is that stocks with different exposure to investor sentiment have different average returns. However, other than for investor attention, the sign of $\lambda_{s, t}$ is not clear ex ante. Rationally, low sentiment can be considered a 'bad' state of the economy which would justify that assets that perform badly during negative sentiment have higher average returns. On the other hand, the sentiment literature is built on the premise of irrational noise traders and limits to arbitrage - meaning that in the short-to-medium run, the opposite could be the case. Specifically, if limits to arbitrage prevent rational economic agents from correcting mispricing, positive covariation with sentiment could in fact lead to lower returns relative to more sentimentally-stable assets.

From an aggregate financial markets standpoint, there is evidence that the difficulty of arbitrage varies with sentiment over time. This is for instance captured in the Baker-Wurgler (BW) sentiment index that is based among other things on the closed-end fund discount or first-day IPO 
returns. This makes it likely that $\lambda_{s, t}$ conditionally varies with aggregate sentiment. In the analysis to follow, I will thus explicitly model $\lambda_{s, t}$ conditionally based on whether in period $t$ we are in positive or negative BW sentiment state. That is, apart from estimating (3) on the whole sample (unconditionally), I will also estimate it separately for subsamples based on (positive, negative) BW sentiment. Ultimately, the question is whether there exists a priced (un)conditional sentiment risk factor over and above the conditional performance differentials based on company characteristics associated with difficulty of arbitrage (BW characteristics).

\section{Attention, sentiment and volatility}

As discussed, both investor attention and sentiment are associated to volatility. In the former case, an increase in investor attention is often associated with increased contemporaneous and future volatility (e.g., Peng and Xiong (2006) or Vlastakis and Markellos (2012)). In the investor sentiment literature, idiosyncratic company volatility presents a limit to arbitrage. Thus, the analysis of investor attention and sentiment will contribute to better understand the idiosyncratic volatility puzzle whereby stocks with higher idiosyncratic volatility internationally and over long time periods have received lower average returns and alphas in the cross-section. This puzzle has held true over long time periods and in capital markets internationally (Ang et al. (2006b) or Ang et al. (2009) ). It is is inconsistent with standard risk models which would require stocks with higher idiosyncratic volatility to be compensated by higher rather than lower average returns due to the undesirability and risk associated with higher volatility (Malkiel and Xu (2002)).

The idiosyncratic risk puzzle has received a lot of attention in the recent behavioral and asset pricing literature and has produced a list of potential explanations. Baker and Wurgler (2006)'s findings that negative (positive) sentiment can predict positive (negative) outperformance of highminus-low volatility portfolios is a partial explanation associated with difficulty of arbitrage. Furthermore, the negative unconditional relationship of idiosyncratic volatility is for instance explained through non-standard preferences (i.e. the seeking of lottery-like payoffs), biases such as anchoring/comparing to benchmarks or uneven frictions for different kinds of market participants (i.e. with regards to leverage). Most recently, Stambaugh, Yu, and Yuan (2015) find that the idiosyncratic volatility-return relation is negative among overpriced and positive among underpriced stocks. However, the former effect dominates due to an arbitrage asymmetry between buying and shorting (buying is easier and less risky) which leads to the observed overall negative relationship ${ }^{3}$.

Controlling for idiosyncratic volatility, together with other limits to arbitrage, thus has two ultimate aims. For one, it helps answer the question whether there exists a priced (un)conditional attention and/or sentiment risk factor over and above the conditional performance differentials based on company characteristics associated with difficulty of arbitrage (BW characteristics). For

\footnotetext{
${ }^{3}$ For an explanation and literature review of lottery-like payoffs or prospect theory, see Bali and Cakici (2008), Bali, Cakici, and Whitelaw (2011), Ilmanen (2012), for a review of biases i.e. Baker, Bradley, and Wurgler (2011), for a review of relatively different leverage constraints Frazzini and Pedersen $(2014)$ and for a review of the arbitrage asymmetry Stambaugh, Yu, and Yuan (2012), Stambaugh, Yu, and Yuan (2014), Stambaugh et al. (2015), Stambaugh and Yuan (2016).
} 
two, it might deliver a partial explanation as to the idiosyncratic risk puzzle that is still not completely resolved in the literature.

\section{The empirics: Investor attention, investor sentiment and cross-sectional returns}

\section{A. Data}

\section{A.1. Measuring investor attention}

As a proxy for aggregate investor attention, I employ the daily Google search queries in the keyword 'DJIA' from within the United States between January 2004 and December 2015, obtained through Google Trends This follows a recent literature stream which employs Google search-based measures to identify various theoretical variables of interest (i.e., Choi and Varian (2009), Choi and Varian (2012)) with hardly any lag time ('nowcasting') and with relatively high daily frequency. In an asset pricing context, Da et al. (2011), Vlastakis and Markellos (2012) and Vozlyublennaia (2014) have similarly gauged investor attention in specific stocks (i.e., stock tickers or company names) or the stock market as a whole (i.e., index names). While the choice of specific keyword is somewhat arbitrary, I have chosen 'DJIA' as I argue it to be (i) a relevant proxy (it is the acronym for one of the most well-known stock indices to retail investors in the United States) as well as ii) non-ambiguous (many search terms, such as 'DowJones' or 'Apple' are polluted by searches that do not capture the variable of interest here). However, in the robustness section, I show that the search interest in 'DJIA' is related strongly to alternative proxies, such as 'NYSE' or 'Stocks', for instance (figure 20p.

The value of the search-based measure becomes clear when compared to its alternatives - empiricists have long faced the challenge that there were no direct measures of investor attention. Consequently, they have relied on indirect proxies such as extreme returns, trading volume, news and headlines or advertising expense (i.e, Barber et al. (2008) or Hou et al. (2009)). On the other hand, Google searches are a direct and 'revealed' aggregate attention measure of millions of households throughout the United States. As Da et al. (2011) put it succinctly, 'if you search for a stock in Google, you are undoubtedly paying attention to it (p.1462)'. As a measure of investor attention, it is arguable that it will be biased towards retail investors. More sophisticated investors are likely to use other means to obtain information on potential or made investments, such as professional databases. I argue that this in the context of aggregate investor attention as a state variable this is non-problematic - retail investors are arguably 'marginal' attention payers to stock markets: they pay attention during specific times of exogenous shocks or increased uncertainty in the market while professional investors are likely to cover the markets more consistently (Vozlyublennaia (2014)). The search pattern in 'DJIA' at first glance confirm just that - it spikes in times of increased uncertainty as in the financial crisis of 2008/09 or during the Treasury downgrade of 2011,

\footnotetext{
${ }^{4}$ https://trends.google.com/
} 
for instance (top panel of figure 3).

Concretely, I construct the proxy for investor attention as the average out of ten daily Google Trends series of the query in 'DJIA'. I do this as the series are each time a random subsample of DJIA queries - all ten, however, correlated to each other by more than 0.9. Furthermore, Google Trends only allows for daily granularity in the data for time periods equal to or below 3 months, and for each time period rebases the maximum search query to 100. I stitch together three monthsintervals of the search query 'DJIA' at a time while I use a one-month overlap to rebase units back to the units of the first three months-interval of January to March 20045. This allows for a consistent daily measure of 'DJIA' searches in the United States, from January 2004 to December 2015.

What I am interested in is the 'abnormal' part of investor attention through time, that is investor attention without confounding effects of a long-term time or seasonal trend. For this reason, I use a seasonal-trend decomposition procedure based on Loess as in Cleveland, Cleveland, McRae, and Terpenning (1990) to obtain seasonal (daily granularity) as well as long-term trend. The remainder of the raw attention time series minus seasonal and trend components is the DJI $A_{t}$ investor attention proxy used throughout the analysis (as shown in figure 3).

$$
D J I A_{t}^{\text {remainder }}=D J I A_{t}^{\text {raw }}-D J I A_{t}^{\text {seasonal }}-D J I A_{t}^{\text {trend }}
$$

Furthermore, DJI $A_{t}^{\text {remainder }}$ is z-standardized for the analysis.

$$
D J I A_{t}=\left(D J I A_{t}^{\text {remainder }}-\mu_{D J I A}\right) / \sigma_{D J I A}
$$

whereby $\mu_{D J I A}$ and $\sigma_{D J I A}$ are mean and standard deviation of $D J I A_{t}^{\text {remainder }}$, respectively.

Following Breeden, Gibbons, and Litzenberger (1989) and Lamont (2001), I also create a daily factor-mimicking portfolio in attention $F-D J I A$ to mimick abnormal attention in the equities markets:

$$
D J I A_{t}=c+b^{\prime} X_{t}+u_{t},
$$

where $X_{t}$ represents the returns on the base asset: ${ }^{6}$. Since the base assets are excess returns, the coefficient $b$ can be interpreted as weights in a zero-cost portfolio. The return on the portfolio $b^{\prime} X_{t}$ is the factor $F-D J I A$ that mimicks abnormal daily investor attention.

\section{A.2. Measuring investor sentiment}

What is sentiment, and how can it be measured? Sentiment is an elusive concept - its 'soft' quality makes measurement tricky and has produced a long literature on the best way to do so. The proxies suggested in the literature include investor surveys, investor mood, retail investor trades,

\footnotetext{
${ }^{5}$ Concretely, for a given three months-interval I multiply the DJIA by the inverse of the ratio of new over old data in the one-month overlap.

${ }^{6}$ In this case, $\beta_{D J I A}$-sorted portfolios based on NYSE/AMEX stocks.
} 
mutual fund flows, trading volume, dividend premia, closed-end fund discounts, option-implied volatility, IPO first-day returns or volumes, the relative share of equity in capital issues as well as insider trading activity 7 .

Given the plethora of proxies and the lack of definitive measure, Baker and Wurgler (2006) then form a composite index of sentiment based on six underlying proxies - the closed-end fund discount, NYSE share turnover, the number and average first-day returns on IPOs, the the equity share in new issues, and the dividend premium. The Baker-Wurgler sentiment index has the advantage that it encompasses multiple of the potential proxies of investor sentiment. Given its top-down nature it builds on the two fundamental assumptions of sentiment and limits to arbitrage to explain which stocks are likely to be most affected by sentiment. This broad nature makes it a strong medium-term (month-by-month) conditioning variable to understand 'baseline sentiment' and ensuing characteristics-based returns 8

Da et al. (2015) have devised a daily measure of investor sentiment that aggregates across millions of Google searches to reveal negative market-level sentiment related to household economic concerns - the Financial and Economic Attitudes Revealed by Search (FEARS) index 9 . The index strongly predicts U-shaped returns (negative contemporaneous market returns as well as a partial recovery in the following days) across their sample as well as an uptick and subsequent meanreversal in volatility. The index is strongly related to limits to arbitrage - highly volatile stocks or stocks particularly exposed to downside beta (Ang, Chen, and Xing (2006a)) are affected more by the return patterns than the cross-section. Furthermore, the FEARS index is strongly correlated to, but contains additional information to alternative measures of investor sentiment, such as the VIX, the 'ADS' index of Aruoba, Diebold, and Scotti (2009) or the economic policy uncertainty index ('EPU') of Baker, Bloom, and Davis (2015).

I use the FEARS index as a proxy for daily noise trader sentiment in this analysis. More specifically, I use the 30 search terms that have the statistically most significant negative correlation to equity markets over Da et al. (2015)'s full sample of 2004 - 2011. The words (shown in figure 2) are intuitively related to negative economic sentiment and increased uncertainty and comprise inter alia 'recession', 'unemployment' or 'bankruptcy'. I then perform the same data-cleaning recipe as Da et al. (2015), except for de-seasoning differently ${ }_{10}$, for each time series, I take daily log-differences,

${ }^{7}$ See for instance Baker and Wurgler (2000), Qiu and Welch (2006), Lee, Shleifer, and Thaler (1991), Neal and Wheatley (1998), Baker and Stein (2004), Scheinkman and Xiong (2003), Baker and Stein (2004), Brown, Goetzmann, Hiraki, Shirishi, and Watanabe (2003), Lemmon and Portniaguina (2006), Brown and Cliff (2004).

${ }^{\circ}$ While the Baker-Wurgler (2006) index is arguably the most prominent sentiment index, it has also received its share of criticism. Perhaps the most problematic aspect of the index is that its proxies are the product of an equilibrium outcome in the markets and thus depend on a myriad other potential sources other than sentiment alone. As Qiu and Welch (2006) put it: 'How does one test a theory that is about inputs $\rightarrow$ outputs with an output measure?' Furthermore, Sibley et al. (2016) find that the predictive quality of the index is largely due to its correlation with business-cycle variables (i.e., interest rates) that largely disappears when controlling for them.

${ }^{9}$ Based on words in the Harvard IV-4 and Lasswell Value dictionaries (words of 'positive/negative' and 'economic' content), they employ backward rolling regressions on market returns to identify the thirty words with the statistically strongest contemporaneous correlation to create the index for the subsequent six months. They find that nearly all of the strong relationships of search terms to market returns are negative and concur with Tetlock (2007) that negative terms are better at identifying sentiment than their positive counterparts.

${ }^{10}$ The complete process is outlined on pages $6-10$ of Da et al. (2015). The only difference in my approach is that I 
winsorize at the $2.5 \%$ level, take out seasonality and finally standardize by dividing through its standard deviation. FEARS $S_{t}$ is then the sum of the thirty log-differences of standardized search terms $\triangle A S V I_{t}$ at a given date.

$$
F E A R S_{t}=\sum_{i=1}^{30}\left(\Delta A S V I_{t}\right)
$$

Similarly to $F-D J I A$, I also form a daily factor-mimicking portfolio in sentiment $F-F E A R S$. Furthermore, I use the Baker-Wurgler (2006) index ${ }^{11}$ as a monthly conditioning variable to see whether the cross-sectional dynamics around sentiment loadings is different in different 'sentiment states of the world Baker and Wurgler (2006) find that their sentiment index predicts alphas and returns of characteristics-sorted portfolios, but that their results are incompatible with a systematic risk story. More specifically, they analyze whether (i) market beta loadings or (ii) their risk premium vary with changing market sentiment and refute this. In a similar vein, I analyze whether there is a premium to stocks on FEARS loading as our noise trader proxy and whether it varies between positive and negative Baker-Wurgler sentiment states as discussed in section I.B.

\section{A.3. Company characteristics}

As discussed, in this paper, I seek to analyze whether investor attention (DJIA) or sentiment $(F E A R S)$ as factors can explain cross-sectional returns over and above company characteristics related to limits to arbitrage. I thus recreate the proxies for difficulty of arbitrage/valuation on the company level as in Baker and Wurgler (2006). In specific, the proxies relate to market capitalization $(M C a p)$, idiosyncratic volatility $\left(\sigma_{i}\right)$, return-on-equity $(R o E)$, dividends-to-book equity $(D B E)$; property, plant and equipment over assets $(P P E / A)$; research and development expenses over assets $(R \& D / A)$; book-to-market equity $(B E / M E)$; external finance over assets $(E F / A)$; and lastly, sales growth in the last year relative to the year before $(G S)$. The exact definitions are discussed in Baker and Wurgler (2006, p.1653ff.). All data is from Compustat or the Center for Research on Security Prices (CRSP).

\section{A.4. Further data}

I obtain daily security prices of U.S. stocks (all available) and the monthly value-weighted excess returns of Pastor and Stambaugh (2003)'s illiquid-minus-liquid stocks through CRSP. Furthermore, I obtain the Fama-French five factors, the momentum factor as well as the performance data of various double-sorted portfolios from Kenneth French's website $€^{12}$.

As for the factor-mimicking portfolios in attention and sentiment, I create a daily mimicking portfolio in liquidity $(L I Q)$ based on the monthly correlation of base assets to the Pastor-Stambaugh

follow Loess decomposition as for DJIA instead of weekday dummies which additionally takes out a long-term time trend.

${ }^{11}$ Obtained through Jeffrey Wurgler's website: http://people.stern.nyu.edu/jwurgler/.

12 http://mba.tuck.dartmouth.edu/pages/faculty/ken.french/data_library.html 
excess returns over the past twelve months on a rolling basis.

Lastly, I create a factor-like portfolio in idiosyncratic volatility by creating a high-minus-low (HML) portfolio in idiosyncratically volatile stocks (Sigma). Thereby, each month I use a stock's idiosyncratic volatility $\left(\sigma_{i}\right)$ in the previous month $m$ (daily data). As in Ang et al. (2006b), idiosyncratic volatility is defined as the standard deviation of the residual within a regression of stock returns on the Fama-French three factors (FF-3).

$$
\begin{gathered}
r_{t}^{i}=\beta_{0}^{i}+\beta_{M K T}^{i} M K T_{t}+\beta_{S M B}^{i} S M B_{t}+\beta_{H M L}^{i} H M L_{t}+u_{t}^{i} \\
\sigma_{i}=\sqrt{\operatorname{var}\left(u_{t}^{i}\right)}
\end{gathered}
$$

where $t \in$ month $m$.

Concretely, I calculate Sigma as the $30 \%$ stocks with highest, minus the $30 \%$ stocks with lowest $\sigma_{i}$ over the past month.

\section{B. The pre-formation regression}

My goal is to test whether stocks with different sensitivities to investor attention (or investor sentiment) have different average returns. As companies' sensitivities to investor attention and sentiment are potentially changing over time, I use monthly-rolling pre-formation regressionsTo ex ante measure this sensitivity, I reduce the full model specification to two, namely the market factor $M K T$ and the investor attention (sentiment) DJIA (FEARS) proxies discussed above. Hence, the empirical model I examine each month $m$ is

$$
\begin{gathered}
r_{t}^{i}=\beta_{0}^{i}+\beta_{M K T}^{i} M K T_{t}+\beta_{D J I A}^{i} D J I A_{t}+\epsilon_{t}^{i} \\
r_{t}^{i}=\beta_{0}^{i}+\beta_{M K T}^{i} M K T_{t}+\beta_{F E A R S}^{i} F E A R S_{t}+\epsilon_{t}^{i}
\end{gathered}
$$

for $t \in$ month $m$ and where $i$ denotes the stock in question.

Vast prior research has shown that there are many other cross-sectional factors that have explanatory power for the cross-section of returns, such as the Fama and French (2015) five factors (hereafter FF-5), momentum, liquidity (Pastor and Stambaugh (2003)) and idiosyncratic volatility Ang et al. (2006b)). In order to reduce noise in the presence of the low number of data points per stock-month regression (on average around 21 trading days), however, I remove these control factors from the pre-formation regression 13 . However, in order to control for these known other cross-sectional factors in assessing how investor attention/sentiment is priced, I do include them in all post-formation regression tests.

I construct a set of test assets that are sufficiently disperse in exposure to aggregate attention (sentiment) exposure by sorting all firms on their DJIA (FEARS) loadings in the past month (equations 11 and 12 into five quintile portfolios. Firms in quintile 1 have the lowest (negative) coefficients while firms in quintile 5 have the highest $\beta_{D J I A}\left(\beta_{F E A R S}\right)$ loadings. Within each quintile

\footnotetext{
${ }^{13}$ The formed portfolios and results are robust to including further control variables - results available upon request.
} 
portfolio, I equally weight (daily rebalancing) or value weight (monthly rebalancing) the stocks to obtain daily portfolio returns. I link the returns across time to form one series of post-formation returns for each quintile portfolio.

I run the pre-formation regression for all stocks on the AMEX or NYSE stock exchanges with at least 17 observations in month $m$. The choice of a 1-month window with daily data is a compromise to allow for a reasonable degree of precision while allowing for conditional coefficients in an environment with time-varying factor loadings. It follows two methodologically strongly related studies of Pastor and Stambaugh (2003) and Ang et al. (2006b) who introduced aggregate liquidity and volatility as pricing factors.

\section{Cross-sectional characteristics of attention and sentiment loading}

Table I (II) reports various characteristics for the equally-weighted (value-weighted) investor attention- $\left(\beta_{D J I A}\right)$ sorted quintile portfolios as well as for the high-minus-low ('5-1') portfolio. Table III shows the value-weighted investor sentiment- $\left(\beta_{F E A R S}\right)$ sorted quintile portfolios. The first two columns report mean and standard deviation of monthly total (not excess) simple returns. Columns 3 to 5 show average characteristics of the companies within the five quintile portfolios - specifically, idiosyncratic volatility as defined in Ang et al. (2006b) $\left(\sigma_{i}\right)$, market capitalization in millions of USD (MCap) as well as book-to-market ratio (B/M). The next three columns show Jensen's alphas $\alpha^{i}$ (monthly, based on daily data) of portfolio returns relative to the Capital asset pricing model (CAPM), the three Fama-French factors (Fama and French (1993)) (FF-3), as well as the full model specification. The full model specification controls for FF-5, momentum as well as daily factor-mimicking portfolios of Pastor-Stambaugh liquidity and idiosyncratic volatility as shown in equation 13 below.

$$
r_{t}^{i}=\alpha^{i}+\beta_{M K T}^{i} M K T_{t}+\sum_{k=1}^{K} \beta_{k}^{i} f_{k, t}+\zeta_{t}^{i},
$$

for $t \in T$ and where $i$ denotes the portfolio in question. $K$ encompasses the FF-5 factors $S M B$, $H M L, C M A, R M W$, momentum MOM, (high-minus-low) Pastor-Stambaugh liquidity LIQ as well as (high-minus-low) idiosyncratic volatility Sigma.

The last four columns show pre- and post-formation factor loadings of portfolio returns to investor attention $\left(\beta_{D J I A}\right)$ or sentiment $\left(\beta_{F E A R S}\right)$ as well as to their respective factor-mimicking portfolios $\left(\beta_{F-D J I A}\right.$ or $\left.\beta_{F-F E A R S}\right)$. The pre- and post-formation betas are estimated based on daily quintile portfolio returns on the full model specification, as shown in equation f14 for the example of $\beta_{D J I A}$. By construction, since the portfolios are formed by ranking on past loadings, the pre-formation betas are monotonically increasing in the pre-formation period (for instance, from -0.41 to 0.79 for the equally-weighted DJIA portfolios).

$$
r_{t}^{i}=\beta_{0}^{i}+\beta_{M K T}^{i} M K T_{t}+\beta_{D J I A}^{i} D J I A_{t}+\sum_{k=1}^{K} \beta_{k}^{i} f_{k, t}+\epsilon_{t}^{i}
$$


for $t \in T$ and where $i$ denotes the portfolio in question. $K$ encompasses the FF-5 factors $S M B$, $H M L, C M A, R M W$, momentum MOM, (high-minus-low) Pastor-Stambaugh liquidity LIQ as well as (high-minus-low) idiosyncratic volatility Sigma.

\section{C.1. Investor attention}

Tables 1 and II document a lot of interesting cross-sectional results of attention-sorted stocks. First of all, the portfolios exhibit near-strict monotonically decreasing patterns of returns and alphas. The simple monthly returns range from $1.19 \%(0.83 \%)$ to $0.75 \%(0.15 \%)$ for the equal(value-) weighted portfolios, producing ' $5-1$ ' range of $-0.43 \%$ (-0.67\%). In terms of return volatility, you can observe a U-shape pattern: standard deviation is highest for the low (1) and high (5) $\beta_{D J I A}$ portfolios. It is lowest for the medium portfolio 3 which exhibits no significant loading to investor attention. Equally-weighted portfolios produce higher average returns and volatility across the sample, arguably because the returns of smaller stocks have been higher and more volatile on average across the sample from 2004 to 2015.

Similar U- or N- shaped patterns can be observed for the average company characteristics of quintile portfolios 1 through 5 . Average idiosyncratic volatility and book-to-market ratio is highest, while market capitalization is lowest for the companies in the extreme portfolios. This suggests that high absolute $\beta_{D J I A}$ loading (either negative or positive) is associated with smaller stocks that exhibit more volatile returns whose shares are valued less highly with regards to their book-marketvalue. With regards to average returns, however, there is a monotonic negative relationship not to absolute, but directional $\beta_{D J I A}$ loading.

Does this negative relationship persist when we control for (i) the market, (ii) FF-3 factors or even (iii) FF-5, liquidity and idiosyncratic volatility? In one word, yes. Both for the equal- and value-weighted quintile portfolios the negative monotonic relationship between $\beta_{D J I A}$ and alphas persist. The spread of alphas between the '5-1' portfolios is statistically significant and the GibbonsRoss-Shanken (GRS) test (Gibbons, Ross, and Shanken (1989)) for alphas to be equal to zero can be rejected at the 0.01 level. Moreover, the spread between the '5-1' portfolios in terms of Jensen's alphas (around 0.5 for equally weighted, $>0.6$ for value-weighted portfolios) is around the same as in terms of raw returns. This implies that the return differential of sorting to $\beta_{D J I A}$ is hardly affected by the vast array of control variables employed.

\section{C.2. Investor sentiment}

Table III exhibits the cross-sectional characteristics of $\beta_{F E A R S}$ sentiment-sorted stocks (valueweighted). Are they similar to the ones found for $\beta_{D J I A}$ ? Yes and no. For one, the cross-sectional characteristics of companies associated with high absolute beta loadings are similar. Companies in portfolios 1 and 5 similarly exhibit higher idiosyncratic volatility, higher book-to-market ratios and lower market capitalization. However, we cannot document any unconditional relation between preformation $\beta_{F E A R S}$ and subsequent returns or Jensen's alphas. The relationship is non-monotonic 
(portfolio 4 has highest raw returns and alphas) and the '5-1' difference in alphas and raw returns is very slim.

Enter the Baker-Wurgler (BW) sentiment index. While unconditionally, there is a null-relationship between pre-formation $\beta_{F E A R S}$ and portfolio returns, this changes when conditioning on the BW index. More specifically, it diametrically changes the sign of the relationship between $\beta_{F E A R S}$ and cross-sectional returns: in months where the BW index is negative (positive) at the outset, a lower $\beta_{F E A R S}$ is associated with higher (lower) average cross-sectional returns. This striking relationship is shown in figures 9 and 11. They show Jensen's alphas (first row; all control variables) and raw returns (second row) of the equally-weighted (figure 9) and value-weighted (figure 11) quintile and '5-1' portfolios. The first column thereby shows the lack of unconditional relationship while as the second (third) column displays the positive (negative) $\beta_{F E A R S}$-return relationship in negative (positive) BW states.

While the sign of the ' 5 -1' spread is the same for equally- and value-weighted quintile portfolios, the relationship is still quite different. For equally-weighted portfolios, the positive (negative) relationship in negative/positive BW months is near-monotonic; the '5-1' spread in Jensen's alphas is around $0.6(-0.3)$. On the other hand, for value-weighted portfolios the relationship is nonmonotonic in negative BW months; the ' $5-1$ ' alpha spreads are at 0.25 (-0.7), which is quite different from equally-weighted portfolios. As figures 4 and 6 show, there is no such conditioning effect of BW sentiment on investor attention-sorted portfolios.

\section{Risk factor or anomaly?}

\section{D.1. Investor attention}

While the unconditional (conditional) differences in average returns and alphas corresponding to different $\beta_{D J I A}$ loadings are impressive, I cannot as yet claim them to be due to systematic investor attention risk. I examine the premium for aggregate attention loading within the framework of an unconditional factor model. There are two requirements that must hold to argue for a factor riskbased explanation. First, a factor model implies that there should be a contemporaneous pattern between factor loadings and average returns. Second is that the investor attention risk exposure of assets is robust to controlling for various characteristics and other factor loadings.

In a standard CAPM setting stocks that covary strongly positively with the market factor should, on average, earn high returns over the same period. In a similar vein, in our setting stocks that covary strongly negatively with investor attention $(D J I A)$ should receive higher returns in the cross-section. To test a factor model, Black, Jensen, and Scholes (1972), Fama and French (1992), Fama and French (1993), Jagannathan and Wang (1996), Pastor and Stambaugh (2003) or Ang et al. (2006b), among others, form portfolios using various pre-formation criteria, but examine post-ranking factor loadings over the full sample period. While the $\beta_{D J I A}$ loadings show strong patterns of future results, they represent past covariation with investor attention. To argue for a factor-based explanation, the $\beta_{D J I A}$-sorted portfolios must show contemporaneous loading with 
investor attention over the same period used to compute the alphas. Furthermore, this loading has to be robust to the inclusion of various known risk factors and stock characteristics affecting cross-sectional returns.

To test for contemporaneous and robust investor attention loading, I observe the post-formation

$\beta_{D J I A}$-factor loading of the quintile portfolios in the same period over which the Jensen's alphas are calculated. The daily portfolio returns are regressed on the full model specification (FF-5, MOM, LIQ and Sigma) as shown in equation 14. The results are shown in table I for equally-weighted and table II for value-weighted portfolios. Furthermore, in sections II.F and IV, I also control for various known company characteristics known to affect cross-sectional returns.

The last four columns in table $\mathbb{1}$ show the pre- and post-formation loadings to $\beta_{D J I A}$ and its factor-mimicking portfolio $\beta_{F-F E A R S}$. By construction, since the portfolios are formed by ranking on past loadings, the pre-formation betas are monotonically increasing in the pre-formation period (for instance, from -0.41 to 0.79 for the equally-weighted $D J I A$ portfolios). There exists a statistically significant and monotonically post-formation $\beta_{D J I A}$ loading of the equally-weighted quintile portfolios, contemporaneously with the pattern in performance observed before. While the order of magnitude relative to pre-formation loading is strongly reduced, '5-1' spread in loading has a $t$-statistic of 3.05 and is therefore statistically significant at the $1 \%$ level. The contemporaneous loading to the factor-mimicking portfolio $\beta_{F-D J I A}$ is economically stronger. The 0.15 loading of the ' 5 -1' portfolio indicates that a $1 \%$ return in the contemporaneous factor-mimicking portfolio is accompanied by a $0.15 \%$ return of the ' $5-1$ ' portfolio.

While there is a modest, but statistically significant contemporaneous $\beta_{D J I A}$ loading in equallyweighted portfolios, this loading disappears for value-weighted portfolios. Instead of monotonically increasing $\beta_{D J I A}$ loading over portfolios 1 to 5 , you can observe a U-shaped pattern: portfolios 1 and 5 are positively loaded while as portfolio 3 has the most negative loading. A similar pattern exists also for $\beta_{F-D J I A}$ loadings.

A partial explanation for this is that there seems to be an interaction between the size (market capitalization) of a company and the stability of the loading from pre-formation to post-formation $\beta_{D J I A}$. Figure 8 shows the post-formation $\beta_{D J I A}$ loadings of double-sorted portfolios - first by market capitalization, second by pre-formation investor attention loading. As you can see, small and large stocks (MCap quintiles 1 and 5) show a monotonically increasing post-formation loading in investor attention. On the other hand, the medium-sized stocks (MCap quintiles 2 and 3) does not follow this pattern. I lend further credence to this explanation in the robustness section where I show the '5-1' portfolio performance and post-formation loadings across different MCap quintiles.

\section{D.2. Investor sentiment}

Similarly as for investor attention, I analyze whether the cross-sectional patterns detected around investor sentiment are due to factor exposure or not. However, as we have seen in the last section there is no clear unconditional relationship between $\beta_{F E A R S}$-loading and subsequent 
performance - rather, it is conditioned on beginning-of-month Baker Wurgler (BW) sentiment 14 . Consequently, I also split the samples for the post-formation factor loading test in two, depending on whether the BW index is positive or negative at the beginning of period. This is shown in the two equations below:

$$
r_{t}^{i, n e g}=\beta_{0}^{i, n e g}+\beta_{M K T}^{i, n e g} M K T_{t}+\beta_{F E A R S}^{i, n e g} F E A R S_{t}+\sum_{k=1}^{K} \beta_{k}^{i, n e g} f_{k, t}+\epsilon_{t}^{i, n e g},
$$

for $t \in B W<0$ and where $i$ denotes the portfolio in question. $K$ encompasses the FF-5 factors $S M B, H M L, C M A, R M W$, momentum $M O M$, (high-minus-low) Pastor-Stambaugh liquidity $L I Q$ as well as (high-minus-low) idiosyncratic volatility Sigma.

$$
r_{t}^{i, p o s}=\beta_{0}^{i, p o s}+\beta_{M K T}^{i, p o s} M K T_{t}+\beta_{F E A R S}^{i, p o s} F E A R S_{t}+\sum_{k=1}^{K} \beta_{k}^{i, p o s} f_{k, t}+\epsilon_{t}^{i, p o s},
$$

for $t \in B W>=0$.

Figures 10 and 12 show the pre- and post-formation factor loadings in investor sentiment across the entire sample $\left(\beta_{F E A R S}\right)$ as well as in negative and positive Baker Wurgler states, separately $\left(\beta_{F E A R S}^{\text {pos }} \& \beta_{D J I A}^{\text {pos }}\right)$. It also shows the loadings in the factor-mimicking portfolio to investor sentiment. Figure 10 shows the loading for the equally-weighted portfolio, while figure 12 shows the case of value-weighted portfolios.

Across the whole sample, we have seen that the pre-formation $\beta_{F E A R S}$ does not predict subsequent performance. On an equally-weighted basis, there is some persistence in factor loadings of portfolios: the '5-1' portfolio has slim positive loading on post-formation $\beta_{F E A R S}$ of 0.02 (robust tstat of 1.83) and on the post-formation factor-mimicking portfolio $\beta_{F-F E A R S}$ of 0.09 (robust t-stat of 4.35) (see top row of figure 10). However, the loading is not strictly monotonic. On a valueweighted basis, without taking into account the size- $\beta_{F E A R S}$, the portfolios exhibit no significant post-formation loading as for the $\beta_{D J I A}$ portfolios before (see top row of figure 12).

What about months where the BW sentiment index is positive? The loading seems more persistent than in the unconditional case. Both equally- as well as value-weighted portfolios 1-5 load nearly strictly monotonically on $\beta_{F E A R S}$ (bottom row of figures 10 and 12 ). In terms of statistical significance, the equal-weighted ' $5-1$ ' portfolio loading is significant for both $\beta_{F E A R S}$ (tstat of 1.92) and $\beta_{F-F E A R S}$ (t-stat of 3.98). The value-weighted '5-1' portfolio significantly loads on $\beta_{F-F E A R S}$ (t-stat of 2.87) while missing significance for $\beta_{F E A R S}$ (t-stat of 1.48 ) at the $5 \%$ level.

In negative BW sentiment index months, there seems little persistence in loading on FEARS. Neither the equally- nor the value-weighted '5-1' portfolios significantly load on post-formation $\beta_{F E A R S}$. In terms of loading on the factor-mimicking portfolio $\beta_{F-F E A R S}$, only the equallyweighted ' 5 -1' portfolio achieves statistically significant positive loading at the $5 \%$ level (t-stat of 1.91).

\footnotetext{
${ }^{14}$ In negative BW states, the $\beta_{F E A R S}$-performance relationship is positive, while it is the reverse in positive BW states.
} 


\section{E. Loadings and expected returns}

To recap, I have documented impressive monotonically decreasing returns and alphas associated with pre-formation $\beta_{D J I A}$ loading as expected from theory and intuition. This pre-formation

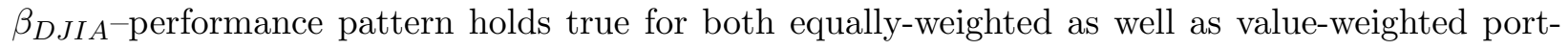
folios. As for factor persistence, there is a pattern of monotonically increasing and statistically significant post-formation $\beta_{D J I A}$ loadings between equally-weighted portfolios 1 and 5 . This disappears for value-weighted portfolios, presumably due to an interaction between company size (market capitalization) and $\beta_{D J I A}$ loading. When forming robust $\beta_{D J I A}$ portfolios that are roughly equal in average company size, I find monotonically increasing and statistically significant post-formation $\beta_{D J I A}$ loadings as for equal-weighted portfolios.

The joint occurrence of the negative $\beta_{D J I A}$-performance pattern as well as the persistence of robust $\beta_{D J I A}$ loadings is a first indication for an investor attention risk factor that prices equities markets. More specifically, there is indication that investors demands higher expected returns for stocks that performs poorly in times of increased noise trader (retail) investor attention. Or, vice versa, investors accept to pay a premium for stocks that perform better during times of increased retail attention.

While Da et al. (2015) document a negative contemporaneous relationship between FEARS and market-level returns, I do not find an unconditional cross-sectional pattern between $\beta_{F E A R S}$ and average returns. Rather, I document that both the $\beta_{F E A R S}$-performance relationship as well as the persistence of factor loading is conditioned by the Baker-Wurgler (2006) index. In times of positive BW sentiment, I find a monotonically decreasing performance between portfolios 1 and 5 as well as some persistence of $\beta_{F E A R S}$ betas. In times of negative BW sentiment, the pre-formation $\beta_{F E A R S}$-performance is positive, but misses statistical significance. The post-formation loadings are mostly insignificant.

The conditional $\beta_{F E A R S}$-performance patterns indicate that in times of positive BW sentiment, noise trader sentiment (FEARS) is priced as anticipated. Investors demand compensation to hold stocks with very negative $\beta_{F E A R S}$ that perform poorly when retail sentiment worsens (FEARS increases). There is some persistence of $\beta_{F E A R S}$ loading in the stocks. On the other hand, in times of negative BW sentiment, stocks with higher $\beta_{F E A R S}$ loadings outperform stocks with negative

$\beta_{F E A R S}$ loadings. Investor sentiment thus performs as expected in positive BW sentiment months ('insurance' premium of high-minus-low $\beta_{F E A R S}$ portfolios), while it presents a puzzle in negative BW sentiment months. Given that portfolios 1 (low) and 5 (high) consist strongly of small and volatile stocks, a potential reason is that limits to arbitrage in negative BW states are partly behind this puzzle. However, at this point, this is mere speculation.

\section{F. Attention, sentiment and limits to arbitrage}

So far, we have found a clear negative $\beta_{D J I A}$-performance link across the whole sample as well as a similar $\beta_{F E A R S}$-performance relationship in times of positive Baker-Wurgler sentiment. 
The relationship is robust to a broad array of cross-sectional pricing factors. However, as seen in tables II II and III, stocks with high absolute $\beta_{D J I A}$ or $\beta_{F E A R S}$ loadings (quintiles 1 and 5) are on average smaller, more volatile on less strongly valued relative to their book market. The $H M L$ or ' 5 -1' portfolio is thus exposed to particular stock characteristics that make the stocks harder to value or arbitrage (i.e. Baker and Wurgler (2006)). This begets the question whether the identified investor attention factor is in fact robust or whether the performance pattern is rather due do these characteristics (i.e., Daniel and Titman (1997)).

Table IV] shows a comprehensive list of the time-series average of average company characteristics of $\beta_{D J I A}$-sorted and $\beta_{F E A R S}$-sorted portfolios that Baker and Wurgler (2006) identify to be associated with difficulty to value or arbitrage (BW characteristics) ${ }^{15}$. As discussed before, stocks in portfolios 1 and 5 (both $\left.\beta_{D J I A} \& \beta_{F E A R S}\right)$ are on average smaller $(M C a p)$, more volatile $\left(\sigma_{i}\right)$ and less highly valued relative to book value $(B E / M E)$. This pattern is confirmed when looking at other BW characteristics: companies in the extreme $1 / 5$ portfolios are on average less profitable $(R o E$, Prof $D)$, pay less dividends $(D / B E$, DivD) and have higher relative R\&D expenses $(R \& D / A)$. Furthermore, they are more dependent on external capital $(E F / A)$ and experience somewhat lower growth $(G S)$. Only in terms of tangibility of capital $(P P E / A)$ there does not seem to be a big difference between the given portfolios.

Figures 13 and 14 plot the average BW characteristics of $\beta_{D J I A}$ portfolios $1-5$ through time 16 . The average characteristics of portfolios $1-5$ share interesting time-series variation. For instance, the effect of the financial crisis of 2008-2009 clearly manifests itself in higher volatility (Sigma) as well as lower profitability $(\operatorname{Prof} D)$, valuations $(B E / M E)$, access to capital $(E F / A)$ as well as sales growth $(G S)$. Still, for most characteristics the difference between characteristics in portfolios 1 and 5 relative to the rest is large fairly consistent over time. For $M C a p, \sigma_{i}$, Prof $D$ and DivD the difference between portfolios $(1,5)$ and portfolios $(2,3,4)$ is particularly easy to distinguish.

\section{F.1. Investor attention}

I now test whether the identified return patterns are really due to my novel $D J I A$ risk factor or whether they can be explained by Baker-Wurgler characteristics. Each month, I perform a double sort of my sample stocks, first sorting into five quintiles based on a given BW characteristic, and then, within each quintile, based on sensitivity to investor attention $\beta_{D J I A}$. The five investor attention portfolios are then averaged over each of the five characteristic portfolios. Hence, they represent investor attention quintile portfolios controlling for the given characteristic.

After forming these robust portfolios, I check whether the documented pattern in $\beta_{D J I A}$ and performance persists, or is changed now. Specifically, for each robust $\beta_{D J I A}$ portfolio $i \in\{1,5\}$, I calculate the Jensen's alpha $\alpha^{i}$ as shown in equation $(13)$. I then test whether there remains a statistically significant '5-1' spread in the alphas.

Table VI shows the Jensen's alphas of equally-weighted $\beta_{D J I} A_{\text {-sorted portfolios } 1-5 \text { as well }}$

\footnotetext{
${ }^{15}$ The data are explained in section II.A

${ }^{16}$ The plots look very similar for $\beta_{F E A R S}$-sorted portfolios and are available upon request.
} 
as the ' $5-1$ ' portfolio controlling for BW characteristics. First to note is that indeed the average '5-1' alpha spread is somewhat reduced with regards to the single-sorted $\beta_{D J I A}$ portfolios. The ' 5 -1' spreads are between $-0.30 \%$ to $-0.40 \%$ monthly for the double-sorted portfolio alphas while they were $-0.50 \%(-0.63 \%)$ for the equally-weighted (value-weighted) single-sorted portfolios. Some part of the return differential associated with $\beta_{D J I A}$ can thus seemingly be explained by BW characteristics alone. However, for most characteristics the '5-1' alpha spread stays statistically significant at the $5 \%$ level with t-stats of over 1.6. The only exceptions are MCap (t-stat of 1.5) which we have identified as an interaction variable before as well as $P P E / A$ (t-stat of 1.52). Given the relatively short sample period of less than twelve years and the broad array of control variables, this is pretty remarkable.

Apart from the scale and significance of the ' 5 -1' spread, it is worth to further look at whether the $\beta_{D J I A^{-}}$alpha relationship stays monotonic or not. For most BW characteristics, again, the negative monotonic relationship between the alphas of portfolios 1-5 is kept. The notable exceptions are size $(M C a p)$ and idiosyncratic volatility $\left(\sigma_{i}\right)$ which are less-than-monotonic. It is thus worth to have a closer look at how the '5-1' spread varies by first size and volatility.

\section{F.2. Size and volatility}

Figure 15 shows the Jensen's alphas of the $5 \times 5$ double-sorted $M C a p / \beta_{D J I A}$ (top chart) and $\sigma_{i} / \beta_{D J I A}$ (bottom chart) portfolios. As a first take-away, you can see that despite controlling for the $S M B$ (small-minus-big) and Sigma (factor-mimicking portfolio of idiosyncratic volatility) cross-sectional factors, the average size of a company (MCap) and its idiosyncratic volatility $\left(\sigma_{i}\right)$ still impacts Jensen's alpha. Across all the MCap quintiles, the '5-1' spread is negative - however, not always monotonically. For smaller stocks (MCap quintiles 1-3), the highest Jensen's alphas are achieved by $\beta_{D J I A}$ loadings that are closer to zero (DJIA quintiles 2-4) rather than very negative. The relationship becomes more monotonic as stocks become bigger and is strictly so for MCap quintile 5 - this is a positive indication for our DJIA factor, as bigger stocks are presumably more liquid and more efficiently traded.

For $\sigma_{i} / \beta_{D J I A}$ portfolios, too, the '5-1' spread is consistently negative, which speaks to the reliability of the $\beta_{D J I A}$-performance relationship. However, the relationship becomes less orderly the higher the $\sigma_{i}$ quintile: while for less idiosyncratically volatile stocks (quintiles 1-3) the relationship is near-monotonic, this is not the case for $\sigma_{i}$ quintiles 4 and 5 . A valid interpretation, similarly to $M C a p$, could be that the less idiosyncratically volatile stocks are more efficiently priced and thus the impact of $D J I A$ on performance can be more reliably estimated.

Strikingly in my sample from 2004 to 2015, I find a positive effect of idiosyncratic volatility on Jensen's alpha which superficially contradicts the negative relationship documented in the literature (i.e., Ang et al. (2006b) or Stambaugh et al. (2015)) over sample periods which are admittedly going back much longer. This can be explained with the conditional effect that the Baker-Wurlger sentiment index has on the relationship between idiosyncratic volatility and average performance. The top row of figure 16 shows Jensen's alphas while the bottom row shows raw monthly returns of 
$5 \times 5$ double-sorted $\sigma_{i} / \beta_{D J I A}$ portfolios across the whole sample (first column) as well as in positive (second) and negative (third) BW sentiment months. Indeed, the somewhat positive directional relationship between $\sigma_{i}$ and Jensen's alphas/returns can be decomposed into a negative (positive) relationship in months with positive (negative) BW index. However, while the BW index in our sample directionally impacts the relationship between $\sigma_{i}$ quintile and performance, the '5-1' spread in terms of $\beta_{D J I A}$ loading is remarkably robust against that. This is another indication of the robustness of the $\beta_{D J I A}$ 's power to explain cross-sectional return differential.

\section{F.3. Investor sentiment}

Similarly as for investor attention, I control for the effect of Baker-Wurgler characteristics on $\beta_{D J I A}$-sorted portfolio performance by double-sorting. As shown, the performance impact is conditioned by the Baker-Wurgler sentiment index, which is why the analysis is split between positive and negative index months.

Table VII shows the Jensen's alphas for $\beta_{F E A R S^{-}}$sorted portfolios 1-5 in times of positive BW sentiment (Panel A) as well as negative BW sentiment (Panel B). It is immediately apparent that the statistically significant negative '5-1' spread in Jensen's alphas during times of positive BW sentiment shrinks further from $-0.3 \%$ monthly (figure 9 to roughly in half for most characteristics. While the $-0.3 \%$ monthly Jensen's alpha missed statistical significance at the $5 \%$ level (t-stat of 1.32 ), the new measures are further away.

Strikingly, the opposite happens with regards to Jensen's alphas of the $\beta_{F E A R S}{ }^{- \text {sorted portfolios }}$ $1-5$ in times of negative BW sentiment. The '5-1' portfolio alpha spread of around $0.5 \%$ monthly (figure 9) stays put or increases when controlling on most BW characteristics - the exception being $R \& D / A$. At the same time, the standard error often decreases so that most t-stats are above 1.6, making the estimate statistically significant at the $5 \%$ level. The BW characteristics thus cannot explain the positive ' 5 -1' spread, quite to the contrary.

\section{G. Attention, sentiment and the idiosyncratic risk puzzle}

So far, I have documented that idiosyncratic volatility is associated with extreme $\beta_{D J I A}$ and $\beta_{F E A R S}$ loadings: portfolios 1 and 5 contain stocks with above-average volatility in the crosssection. On the other hand, idiosyncratic volatility cannot explain the (un)conditional alphas due to investor attention and sentiment loading. This is clear from table VI for investor attention, where controlling for $\sigma_{i}$ slightly impacts, but cannot eliminate the negative monotonic relationship between $\beta_{D J I A}$ and Jensen's alpha. Similarly, table VII documents that controlling for $\sigma_{i}$ does not eliminate the conditional $\beta_{F E A R S}$-performance relationship.

Given that idiosyncratic volatility cannot explain the performance effect of attention or sentiment, does it function vice versa? That is, can the tradable risk factors in investor attention or sentiment 17 explain the expected returns due to idiosyncratic volatility? To answer this, I first

\footnotetext{
${ }^{17}$ The tradable risk factors here are simply the $\beta_{D J I A}\left(\beta_{F E A R S}\right)$ '5-1' portfolios discussed in tables I II and III
} 
construct 5 quintile portfolios based on last month's idiosyncratic volatility. Idiosyncratic risk is defined as in Ang et al. (2006b) as the volatility of the remainder term of a stock's return and the FF-3 factors. I then regress these (equally- and value-weighted) quintile portfolios on the discussed control variables (FF-5, momentum \& liquidity), except for the mimicking-factor of idiosyncratic volatility itself, of course. I then add the $\beta_{D J I A}$ and $\beta_{F E A R S}$ '5-1' portfolios and see whether the $\sigma_{i}$-alphas are changed.

Figure 18 shows the $\sigma_{i}$-alphas for equal- and value-weighting in the first and second row, respectively. The first column shows the Jensen's alphas with respect to the full control variables, except for DJIA or FEARS. The second (third) column then adds the $\beta_{F E A R S}\left(\beta_{D J I A}\right)$ tradable '5-1' portfolio to the mix, respectively. As can be seen from the leftmost column, stocks with higher idiosyncratic volatility have actually outperformed in the cross-section, rather than underperformed as postulated by the idiosyncratic risk puzzle. This is mainly due to a time period of strong outperformance in Sigma (HML portfolio of $\sigma_{i}$ ) in early 2009 (see figure 19). Adding the DJIA and FEARS tradable factors has practically no impact on the Jensen's alphas with respect to $\sigma, 18$,

As for the reverse case, attention and sentiment can thus not account for the idiosyncratic risk puzzle. Rather, they seem to be orthogonal to and robust from each other. Another indication for this is the is the near-zero correlation between the raw investor attention $(D J I A)$ and sentiment (FEARS) factors to Sigma (table $\mathrm{V}$ ). This is in contrast to the BW sentiment index, which does quite a good job at predicting the relationship between $\sigma_{i}$ and subsequent performance (see, for instance figures 16 and 17 which display $\sigma_{i} / \beta_{D J I A}$ and $\sigma_{i} / \beta_{F E A R S}$ double-sorted portfolios in positive and negative BW states).

\section{Is there a price to investor attention and sentiment?}

\section{A. Investor attention}

I have so far found evidence for a relationship between sensitivity to investor attention and subsequent returns. I have also shown that the effect is robust to known asset pricing factors as well as characteristics relating to difficulty of arbitrage/valuation (Baker-Wurgler characteristics). There are also statistically significant ex-post spreads in factor exposure. While this is interesting in its own right, it begets the question whether investor attention is pervasive enough to be a useful risk factor in pricing different kinds of assets in the cross-section. Also, if yes, what is its price of risk? To conclusively answer, I perform Fama-MacBeth(1973) analysis (FMB) on different portfolios as well as stock levels (Fama and MacBeth (1973)).

As a risk factor, I use the returns on the value-weighted ' $5-1$ ' portfolio based on pre-formation loadings to investor attention across all stocks in the sample $\left(\beta_{D J I A}\right)$. As demonstrated, there is some persistence in factor loadings, which means that this risk factor reflects contemporaneous investor attention. While the contemporaneous factor-mimicking portfolio or raw DJIA search

\footnotetext{
${ }^{18}$ Similarly, controlling for sentiment and attention by first sorting on $\beta_{F E A R S}\left(\beta_{D J I A}\right)$ and only subsequently by $\sigma_{i}$, does not materially impact the results.
} 
index may be an even better proxy of current investor attention, it is relies on ex-post information and is impacted by noise. The ' $5-1$ ' portfolio, on the other hand, is ex-ante investible and is thus easier to interpret in the context as a risk factor with risk/return characteristics to which individuals can voluntarily expose themselves to.

\section{A.1. Test assets}

To estimate the factor premium $\lambda_{D J I A}$ on the pre-formation '5-1' $D J I A$ portfolio, I construct various test assets on different levels. First, I construct 25 investible portfolios sorted by idiosyncratic volatility $\left(\sigma_{i}\right)$ and sensitivity to investor attention $\left(\beta_{D J I A}\right)$ as follows. At the end of each month, I first sort stocks by $\sigma_{i}$ over the past month. As in Ang et al. (2006b), idiosyncratic volatility is defined as the standard deviation of the residual within a regression of stock returns on FF-3 factors as in equations $(9)-10$. Secondly, within each $\sigma_{i}$ quintile, I sort stocks into five quintiles based on their past months' $\beta_{D J I A}$. The $\beta_{D J I A}$ is calculated based on daily stock-level regression of excess returns on the market factor $M K T$ as well as DJIA as shown in equation (11). The thus-constructed test assets thus reflect an overall level of riskiness $\left(\sigma_{i}\right)$ that reflects the idiosyncratic risk puzzle (i.e., Ang et al. (2006b), Stambaugh et al. (2015) as well as different exposures to investor attention risk $D J I A$.

Apart from the thus-formed $25 \sigma_{i} / \beta_{D J I A}$-portfolios, I also employ stocks themselves as well as typical Fama-French portfolios as test assets. While a significant price of risk in custom-built portfolios is one thing, our identified risk factor $D J I A$ is more impressive and robust the more it can price a wider variety of assets that are not pre-formed to reflect sensitivity to attention risk. Also, by using various Fama-French double-sorted portfolios sorted by different kinds of FF- 5 factors, we can perhaps gain a better understanding what characteristics our DJIA risk factor is most related to.

\section{A.2. Estimation procedure}

To estimate the unconditional price of attention risk $\lambda_{D J I A}$, I perform two-step FMB analysis with monthly returns on the test assets. Jagannathan and Wang (1996) show that a conditional factor model like equation 1 has the form of a multifactor unconditional model. The original factors enter together with additional factors which proxy the time-varying information set. Similarly to the post-formation regression for the five $\beta_{D J I A}$ portfolios (equation (14)), I thus control for other cross-sectional asset pricing factors in the FMB analysis. This reflects the fact that in addition to my aggregate attention factor $D J I A$, there are additional factors that may affect the unconditional return of a stock. The full FMB specification thus includes FF-5, momentum as well as the highminus-low portfolios of liquidity as well as idiosyncratic volatility:

$$
r_{t}^{i}=c_{t}^{i}+\beta_{M K T, t}^{i} \lambda_{M K T}+\beta_{D J I A, t}^{i} \lambda_{D J I A}+\sum_{k=1}^{K} \beta_{k, t}^{i} \lambda_{k}+\epsilon_{t}^{i}
$$


for months $t \in 1 \ldots T$ where the $\lambda$ s reflect the unconditional prices of risk of the included risk factors and $i$ denotes the test asset in question. $K$ encompasses the FF-5 factors $S M B, H M L$, $C M A, R M W$, momentum $M O M$, (high-minus-low) Pastor-Stambaugh liquidity $L I Q$ as well as (high-minus-low) idiosyncratic volatility Sigma.

With regards to the first-stage time-series estimation, I perform monthly rolling regressions based on daily data. This allows the factor loading betas to change through time. However, I also employ a single time-series estimation of factor exposure across the whole sample which may less well explain the cross-sectional dispersion in returns, but be more reliable in terms of beta estimates. Having different kinds of estimation procedures will allow to contrast the findings and make the results more robust. This, of course, means that the factor loadings are the same across all months for a given test asset $i$ : $\beta_{k, t}^{i}=\beta_{k}^{i}$. In the second stage, I then use monthly crosssectional regressions incorporating these factor loadings as shown in equation (17). Of course, I am particularly interested in the price of attention risk $\lambda_{D J I A}$ and its statistical significance.

\section{A.3. Results}

Table VIII shows the estimated market premia of DJIA and the other risk factors as well as the cross-sectional fit (adjusted $R^{2}$ ) under different model specifications - with different risk factors, different estimation procedures and different test assets. The sample period is from January 2004 to September 2015 (N: 141 months). Specification I shows the results of the regression for the 25 $\sigma_{i} / \beta_{D J I A}$-portfolios on FF-3 as well as our DJIA factor with monthly rolling first-stage regression. Strikingly, over the relatively short time horizon, none of the FF-3 risk premia are estimated to be statistically significant. $\lambda_{D J I A}$ on the other hand, achieves a market price of risk of $-0.50 \%$ per 1 unit increase $\beta_{D J I A}$ and is comfortably significant at the $5 \%$ level. The sign the risk premium is in-line with expectations, meaning that the portfolios that perform better during times of increased attention achieve on average lower returns. However, the FF-3 model together with DJIA is not very good at pricing my 25 test portfolios $\sigma_{i} / \beta_{D J I A}$, achieving a somewhat disappointing $13 \%$ in $R^{2}$.

Specification II further to specification I includes the other two FF-5 factors $R M W$ and $C M A$ as well as the factor-mimicking portfolio of high-minus-low idiosyncratic volatility-stocks Sigma. The estimated DJIA factor premium increases in absolute size to - 0.72 and achieves an even higher t-statistic. In particular, it seems that the inclusion of the $R M W$ factor helps prices assets better - it achieves a factor price of risk of 0.36 that is highly significant at the $1 \%$ level. Furthermore, its inclusion leads to higher precision in the estimates of $\lambda_{M K T}$ and $\lambda_{H M L}$. Lastly, the cross-sectional fit improves dramatically: the $R^{2}$ is increased to 0.49 .

Specification III further includes momentum and the factor-mimicking portfolio on PastorStambaugh liquidity. Both $M O M$ and $L I Q$ do not achieve statistical significance on their own and they do not overly strongly impact the estimate on $\lambda_{D J I A}$. With -0.64 , it remains statistically significant at the $2 \%$ level. However, the inclusion of $M O M$ and $L I Q$ leads to a higher and seemingly more precise estimate in $\lambda_{M K T}$ which now achieves statistical significance $(\mathrm{p}<0.05)$. On 
the other hand, the estimates on $S M B$ and $H M L$ are pushed to zero while $R M W$ stays significant. Interestingly, despite $M O M$ and $L I Q$ missing statistical significance, the cross-sectional fit further improves to an impressive $R^{2}$ of 0.83 .

As in III, specification IV uses the full model. However, I change the first-stage so that the time-series betas to the risk factors are estimated not be monthly rolling, but a single time series regression. First thing to note is that $D J I A$ stays significant in this specification, too. As the average absolute $\beta_{D J I A} \sqrt{19}$ are less disperse (closer to zero), the price of 1 unit change in $\beta_{D J I A}$ increases to -1.93 and the t-stat rises to 2.79. Some other risk factors change behavior quite strongly. While the $M K T$ and $R M W$ factors lose statistical significance, the $S M B$ and $H M L$ factors newly become significant at the $5 \%$ and $1 \%$ levels, respectively. Lastly, the $R^{2}$ in this specification decreases - perhaps unsurprisingly given the lower flexibility - to 0.47.

Lastly, specification V uses the full model specification with all NYSE and AMEX stocks (N:3096) as test assets and with monthly rolling time-series estimation. Again, I find a statistically significant price of attention risk of $-0.54 \%$ monthly (t-stat of 2.26 , significant at the $1 \%$ level). This is further indication that the $\beta_{D J I A}$ captures return-relevant sensitivity on securitylevel, not just in a pre-sorted portfolio context. Further to DJIA, the $M K T$ and $R M W$ portfolios gain statistical significance - all in all similar to the results as for specification III on portfolio level. The cross-sectional fit is slightly lower, but still impressive given the test assets are individual stocks. The adjusted $R^{2}$ is 0.67 .

Further to the results on the level of $\sigma_{i} / \beta_{D J I A^{-}}$-portfolios and stocks, table IX] displays the results of FMB on the level of Fama-French portfolios. More specifically, columns I - VI show the factor premia for different double-sorted portfolios based on different criteria. The estimations are based on monthly rolling regressions based on the full model (all control variables). Strikingly, the $D J I A$ factor is significant (at the $5 \%$ and mostly $1 \%$ level) for all six different types of Fama-French portfolios. Furthermore, for most specifications only $R M W$ achieves statistical significance while most pricing factors do not achieve t-stats high enough to be considered significant at the $5 \%$ level. Only the $M K T$ level achieves statistical significance at the $5 \%$ level for operating profitability- \& investment-sorted portfolios. When it comes to the $D J I A$ factor premium, it achieves a particularly high risk premium for size- \& operating profitability-sorted portfolios (column V), as well as on book-to-market \& operating profitability (column II) and book-to-market \& investment (column II).

\section{B. Investor sentiment}

Analogously to investor attention, in this section I analyze investor sentiment in an FMB framework. However, I analyze investor sentiment both for the whole sample as well as in two subsamples - months with positive and months with negative Baker-Wurgler (BW) sentiment. This is motivated by the fact that BW sentiment seems to diametrically change the relationship between $\beta_{F E A R S}$ loading and subsequent performance (as shown in previous sections). In terms of test assets, I

\footnotetext{
${ }^{19}$ Results available upon request.
} 
restrict the analysis here on my $25 \sigma_{i} / \beta_{D J I A}$ baseline portfolios.

Table $\mathrm{X}$ shows the results of the FMB analysis across the whole sample (Panel A) as well as across only positive (Panel B) or negative (Panel C) BW months. For each sample, I use the full model specification with all asset pricing factors. In specifications I, III and V I use a monthly rolling regression for estimating the $\beta$ s to the asset pricing factors, while as in specifications II, IV and VI I use a single time-series regression.

As Panel A shows, there is no statistically significant unconditional risk premium $\lambda_{F E A R S}$. In the monthly rolling regression (I), the $M K T$ and $R M W$ are the only factors to achieve statistical significance, both with positive risk premia. The point estimate of $\lambda_{F E A R S}$ is nearly exactly 0 . In the case of a single time-series regression, none of the risk factors reach statistical significance when all employed jointly 20

Panel B shows the subsample of months with positive BW sentiment. While the point estimate in $\lambda_{F E A R S}$ is negative in both estimation cases III and IV, it does not reach statistical significance in either case. In specification III (1m rolling estimation), there are significant positive risk premia in $R M W, M O M, L I Q$, meaning that robustness, momentum and illiquidity carried higher average returns. In specification IV with a single first-stage time series regression, only $H M L$ comes close to reaching statistical significance with a negative risk premium, meaning that low book-to-market outperformed higher book-to-market. Given the relatively short sample period, there is a definite danger of multicollinearity.

Panel $\mathrm{C}$ lastly shows the FMB risk premia in months with negative BW sentiment. The point estimate in $\lambda_{F E A R S}$ is positive in both estimation cases $\mathrm{V}$ (1m rolling estimation) and VI (1 time series), but only reaches statistical significance in the latter. In specification $\mathrm{V}$ only $M K T$ receives a significant risk premium (positive), while in specification VI $S M B$ and $M O M$ receive a significant negative and $L I Q$ and FEARS receive a significant positive loading. The cross-sectional fit across all three subsamples, similarly as for investor attention, is significantly higher for monthly rolling first stage regressions than when employing a single time-series regression.

In summary, thus, the point estimates of investor sentiment go in the direction anticipated from the section before - they are negative (positive) during positive (negative) BW sentiment. However, there is less evidence for them to be priced in a (un)conditional sense than for investor attention in the section before. This could of course be the result that FEARS is a less cross-sectionally pervasive phenomenon than $D J I A$, that there is less stability in factor loading or there is simply less directional impact of $\beta F E A R S$ on returns.

\section{Robustness}

\section{A. Investor attention}

I have shown investor attention to be strongly related to monotonic return patterns as would be predicted from a risk factor that is priced as an unconditional state variable. On an equally-

\footnotetext{
${ }^{20}$ In a simple CAPM/FF-3 setting, the $\lambda_{M K T}$ is statistically significant.
} 
weighted basis, there is significant factor persistence - portfolios sorted by prior months' $\beta D J I A$ continue to load on investor attention $D J I A$ subsequently. On a purely value-weighted basis, the return patterns persist or even become stronger, while as the factor persistence disappears. When controlling for size, some factor persistence again reappears. Furthermore, I have documented that investor attention loading is strongly related to limits of arbitrage, but cannot exclusively be explained by them. The montonic return patterns survive controlling for a host of company proxies for limits of arbitrage (Baker-Wurgler characteristics). Lastly, in the sample period from 2004 to 2015 investor attention $D J I A$ has been a useful empirical factor to cross-sectionally price a wide variety of assets - both on portfolio as well as individual stock level.

While a lot of the analysis up to this point speaks to the generality of the findings, this section aggressively tests the robustness of the return spread as well as factor loading with a battery of tests.

\section{A.1. Does "DJIA" measure investor attention?}

I have defended the choice of $D J I A$ as a proxy of retail investor attention in section II.A $D J I A$ is a direct and unambigous proxy for attention and similar proxies have been employed in the literature (i.e. Da et al. (2011) or Da et al. (2015)). Still, the choice of 'DJIA' as a search string as opposed to other stock market indices or stock-market investment-related keywords is admittedly somewhat arbitrary. It is thus important to understand whether related keywords that reflect retail stock market attention share important characteristics with 'DJIA' in the time series.

Figure 20 shows related the relative frequency of Google keyword searches related to equities through time. More specifically, it plots the time series of U.S.-based Google queries in 'DJIA', 'NYSE' (New York Stock Exchange), 'NASDAQ' (National Association of Securities Dealers Automated Quotations), 'Stocks', 'FTSE' (Financial Times Stock Exchange) as well as 'DAX' (Deutscher Aktienindex).

As apparent on a first glance, the time series of these related stock market searches share important characteristics. For instance, over the roughly 3,000 days in the sample, 4 of the 6 queries (DJIA, Stocks, FTSE, DAX) achieve their maximum on October 10, 2008 during the nadir of the Global Financial crisis, while you see noticeable peaks for the two other ones (NYSE, NASDAQ) as well. October 10 concluded the week with the most negative weekly returns in most U.S. and European stock indices since 1929. It is thus reasonable to assume that investor attention spiked on that day as retail investors scrambled to understand the effects of an enormous flurry of activity, such as the aftermath of the Lehman bankruptcy and the bailout of several U.S. and European lenders. Another noticeable peak across the search queries is visible during August of 2011 as stock markets across the United States and Europe fell in the wake of fears of contagion of the European debt crisis as well as the downgrade of United States treasury securities.

The similarity of DJIA with related keyword searches and the joint occurrence of peaks during significant financial shocks thus lends further robustness to it being a suitable proxy for a meaningful state variable. Indeed, an asset that performed relatively better in October 2008 or August 2011 
definitely would have added valuable insurance to a portfolio. On the other hand, table XI shows that correlation of the search indices is significant, it is also far from perfect on a daily leve ${ }^{21}$. Interestingly, the DJIA is most strongly correlated with the FTSE (0.69) and DAX (0.70), two major non-U.S. stock market indices rather than with NYSE (which is not a directly tradable asset) or NASDAQ. Thus, while all six keywords reflect investor attention, they each share unique variation too. The results discussed are robust to including all six search queries rather than just DJIA 22 .

\section{A.2. The impact of market capitalization}

Having defended the proxy of investor attention, in the following sections I want to dissect the observed return and factor patterns further, focusing in particular on the robustness of the high-minus-low (5-1) portfolio. Tables XII - XVII display various characteristics of the 5-1 $\beta_{D J I A}$ portfolio, controlling for a host of potential interfering effects. More specifically, the tables show the monthly portfolio excess returns, their standard deviation and the Jensen's alphas to the CAPM, the FF-3 as well as all the full model specification. Furthermore, in the last four columns the preformation and post-formation factor loadings to DJI A and its factor-mimicking portfolio $F-D J I A$ are shown.

Given the concentration of smaller and more volatile stocks in the extreme $\beta_{D J I A}$ portfolios 1 (negative) and 5 (positive) (i.e., tables I \& II), the question naturally arises whether the return patterns are observable in only a small part of the stock market by market capitalization. Table XII shows the high-minus-low attention portfolio across five different market capitalization (MCap) quintiles. Stocks are first sorted by MCap as of beginning of month and then, within MCap quintile, by their $\beta_{D J I A}$. Panel A (B) thereby shows value-weighted (equally-weighted) portfolio returns.

The point estimate of monthly excess returns in the 5-1 $\beta_{D J I A}$ portfolio are negative across all MCap quintiles. Strikingly, the return spread is significantly higher within the highest $20 \%$ of stocks in terms of MCap (quintile 5). This becomes even more pronounced when considering Jensen's alphas rather than simple monthly returns. In terms of statistical significance, the 5-1 $\beta_{D J I A}$ spread in Jensen's alphas is only statistically significant at the $5 \%$ level for MCap quintiles 5 and 2 for value-weighted and quintile 5 for equally-weighted returns. Together this is an indication that the negative $\beta_{D J I A}$-performance relationship is not an artifact of small, volatile stocks, but is pervasive and actually becomes stronger for a large part of liquid equities on the NYSE.

On the other hand, when considering factor persistence, the picture reverses. Small and mediumsized stocks in MCap quintiles show a statistically significant persistence in post-formation factor exposure in both value- as well as equally-weighted returns. On the other hand, the post-formation $\beta_{D J I A}$ and $\beta_{F-D J I A}$ of the $5-1$ portfolio in MCap quintiles 4 and 5 is not significantly different from zero. These results present somewhat of a puzzle.

\footnotetext{
${ }^{21}$ On a weekly level, the correlation is higher for all pairs considered.

${ }^{22}$ Results available upon request.
} 


\section{A.3. Bigger sample: including NASDAQ}

To further investigate this apparent puzzle - robustly negative $\beta_{D J I A}$-performance, but lack of stability in factor exposure, I enlarge the sample. Further to the main sample (as in Pastor and Stambaugh (2003)) that includes all active stocks initially listed on the NYSE or AMEX, I now also include all initially NASDAQ-listed stocks 23 . This more than doubles the sample from 3096 to 7662 stocks.

Table XIII shows the same 5-1 portfolio characteristics as in table XII in this enlarged sample. This further corroborates the results discussed. Across all market capitalization quintiles and both for value- and equally-weighted returns, there is a negative 5-1 spread in monthly returns. Other than for the main sample, however, the 5-1 portfolio has significantly negative Jensen's alphas (CAPM, FF-3, full model) in all MCap quintiles, except for the very smallest stocks (the bottom $20 \%$ ). There, the negative 5-1 spread is not statistically significant because of an inflated standard error (in large part due to the higher standard deviation of monthly 5-1 returns).

In terms of post-formation loadings to DJIA and its factor-mimicking portfolio $F-D J I A$, too, the results are more robust than in the smaller main sample, while pointing in the same direction. For MCap quintiles 1-4 post-formation loadings are statistically significant for both value- and equally-weighted returns. For MCap quintile 5, the equally-weighted portfolio returns still load statistically significantly on the factor-mimicking portfolio $F-D J I A$, but not on DJIA itself, while value-weighted returns do not load on either.

In general, table XIII thus demonstrates that return patterns are robust and extend to a larger sample of the stock market encompassing the majority of active CRSP stocks during the sample studied. Furthermore, the factor structure seems to persists for all but the very biggest stocks. Somewhat puzzlingly, the standard deviation of value-weighted 5-1 monthly excess returns are in fact higher for the biggest MCap quintile than for all but the smallest stocks.

\section{A.4. Robustness over time}

So the 5-1 return spread is robust across company size (MCap) and the size of the sample studied. Is it robust, too, across time? Table XIV shows the 5-1 portfolio characteristics in three roughly equally-sized subsamples: i) 2004:01-2007:11, ii) 2007:12-2011:10 and iii) 2011:11-2015:10. Panel A (B) show value- (equally-) weighted portfolio returns, respectively. Panel C shows valueweighted portfolio returns, controlling for MCap. Specifically, in Panel C I double-sort stocks into MCap and subsequently $\beta_{D J I A}$ quintiles. Within each $\beta_{D J I A}$ quintile, I then average across MCap quintiles $1-5$ to arrive at a 5-1 $\beta_{D J I A}$ portfolio that controls for MCap.

First thing to note is that the 5-1 $\beta_{D J I A}$ portfolio spread in simple returns is negative for each of the three subsamples studied and across different return weightings. However, it is also apparent that the return spread is significantly stronger within the first two subsamples in time and is close to zero in the sample from 2011 to 2015 . This pattern is corroborated by the Jensen's alphas. In

\footnotetext{
${ }^{23}$ Specifically, I include exchange codes 3 and 33 to the codes 1, 2, 31, 32 of the main sample in CRSP notation. This adds stocks that were initially listed on NASDAQ on top of those initially listed on the NYSE/AMEX exchanges.
} 
the first time period, the Jensen's alphas to CAPM and FF-3 models are significant, while the alpha to the full model for value-weighted (Panels A \& C) returns does not reach statistical significance. In the second time period from 2007 to 2011, the CAPM and FF-3 alphas do mostly not reach statistical significance because of a strongly increased volatility in monthly excess returns. Despite the short time sample and the high standard deviation, the alphas with respect to all risk factors (full model) reach statistical significance for value-weighted returns (Panels A \& C). In the third and most recent time period, the Jensen's alphas are estimated much closer to zero and the null hypothesis of no 5-1 spread cannot be refuted.

The most unambiguous post-formation loadings in $\beta_{F-D J I A}$ are achieved from 2004 to 2007, where the 5-1 portfolio strongly loads on the factor-mimicking portfolio $F-D J I A$ irrespective of weighting scheme. On the other hand, in the same time period the post-formation loadings in the raw DJIA are close to zero. In the second time period from 2007 to 2011, the post-formation $\beta_{D J I A}$ of the equally-weighted 5-1 portfolio (Panel B) is positive, while the $\beta_{D J I A}$ of the value-weighted 5-1 portfolio (Panels A \& C) is around zero. In the last subsample, the post-formation $\beta_{D J I A}$ and $\beta_{F-D J I A}$ is insignificant for the value-weighted portfolio (Panel A); on the other hand, they are significant or close to significance for the equally-weighted portfolio and for the value-weighted one that controls for company size (MCap).

The interpretation of the above is somewhat of a puzzle. First of all, it is important to note that the three subsamples in time are relatively short (each less than four years). This means that for an effect to achieve statistical significance, it needs to be that much larger in terms of signal-to-noise ratio. However, if you believe in a puzzle rather than a factor explanation behind the $\beta_{D J I A^{-}}$ performance relationship, then the diminishing 5-1 spread could be due to market participants having detected and traded on the anomaly - thereby gradually decreasing its importance. On the other hand, the factor loadings have been persistent in the last subsample if you control for the impact of MCap. While this rather speaks to a factor explanation, it is then a puzzle while the risk premium would have decreased to zero in that period. A potential explanation for this puzzle is the finding that the bulk of the negative 5-1 return/alpha spread is 'paid for' in select and particularly volatile times across the whole sample ${ }^{24}$. It is thus possible that the risk premium on $\beta_{D J I A}$ is only significant in times of sufficient volatility or cross-sectional dispersion. The third time period, on the other hand, has on average seen decreased volatility and increased cross-sectional correlation.

\section{A.5. Is it return reversal and/or momentum?}

The sample period studied, in particular the crisis period 2007-2009, has seen a lot of return reversal on a monthly horizon, particularly for smaller, more volatile stocks. Given the stronger average absolute $\beta_{D J I A}$ loading of harder-to-value stocks (they are more often in portfolios 1 and 5), an alternative hypothesis is that the negative 5-1 alpha spread is really due to return reversal. Table XV shows the 5-1 $\beta_{\text {DJIA }}$ portfolio across the three subsamples discussed, controlling for return

\footnotetext{
${ }^{24}$ Further analysis available upon request.

${ }^{25}$ Analysis available upon request.
} 
reversal. Specifically, at the beginning of each month, I double-sort stocks first by last month's simple return and then by their $\beta_{D J I A}$ loading (equation (11)). Within each $\beta_{D J I A}$ quintile, I then average across return quintiles to arrive at an 'average-return' 5-1 $\beta_{D J I A}$ portfolio. Panel A (B) shows value- (equally-)weighted portfolio returns.

Comparing Panels A (B) with their counterparts in table XIV shows that the excess return and Jensen's alpha patterns of the 5-1 portfolio are on average only modestly affected. All monthly returns and Jensen's alphas across time samples and control factors stay negative. In the first period, the Jensen's alphas for value- and equally-weighted portfolios achieve slightly lower $t$-stats when controlling for return reversal. In the second time sample, the value-weighted portfolio in fact achieves higher $t$-stats while the equally-weighted portfolio achieves less statistical significance relative to no controlling for return reversal. In the third time sample, as in table XIV before, the 5-1 Jensen's alphas are not statistically significant from zero, even though the estimates and $t$-stats are a little higher.

When it comes to post-formation $\beta_{D J I A}$ exposure, the impact of return reversal is somewhat stronger: In the first time subsample, the post-formation factor exposure persists statistically significantly in the direction of pre-formation exposure. However, in the second time subset the value-weighted portfolio in fact achieves a zero post-formation $\beta_{F-D J I A}$ loading and a barely significant negative loading to the factor-mimicking portfolio, meaning that the pre-formation loadings are reversed when controlling for return reversal. For the equally-weighted portfolio, the postformation loadings are generally decreased when incorporating, but $\beta_{F-D J I A}$ is still positive as would be expected intuitively. Similarly, for the third time sample the estimates and $t$-stats for value- and equally-weighted 5-1 portfolio alphas are lower than not incorporating return reversal, and miss statistical significance.

\section{A.6. Infrequent trading}

Dimson (1979) establishes that when shares are traded infrequently, beta estimates can be biased. To circumvent this problem, he suggests an aggregated coefficients (AC) method whereby he considers the regression of observed returns on preceding lags as much as synchronous independent variable: 26 . The coefficient with regards to the factor at question is then aggregated across lags. Shown below is the $\mathrm{AC}$ method for $\beta_{D J I A}$ loading for the example of three lags.

$$
\beta_{D J I A}^{\text {Dimson }}=\sum_{\tau=0}^{3} \beta_{D J I A, t-\tau}
$$

Given that the main sample in this case is of NYSE/AMEX-listed stocks and a recent sample going back to 2004 only, infrequent trading is less of a concern. However, for completeness' sake, table XVI show the 5-1 portfolio performance when $\beta_{D J I A}$ is measured with synchronous information only (baseline) as well as with 1-3 daily lags. On the other hand, if stocks react immediately

\footnotetext{
${ }^{26}$ In fact he also considers future independent variable data, which I refrain here in order not to introduce endogeneity.
} 
to $D J I A$, I expect to see a gradual decrease in the $\beta_{D J I A \text {-performance relationship and factor }}$ persistence.

The top row (Dimson lags: 0 ) shows the baseline case of $\beta_{D J I A}^{\text {Dimson }}$ loading which is estimated with same-day DJIA only. As I increase the lags of the $\beta_{D J I A}^{\text {Dimson }}$ estimate, the value-weighted portfolio (Panel A) has increasingly smaller 5-1 mean returns, which are around 0 for the case of three lags. In the case of equally-weighted returns, the mean returns are more robust as you increase the lag number. In fact, the maximum 5-1 return spread there is when including two lags. This makes intuitive sense, as the equally-weighted portfolio returns lend more weight to smaller, less frequently traded stocks than the value-weighted portfolio in panel A. The same phenomenon - a steep decline in alphas for value-weighted returns and a much more gradual one for equally-weighted returns can be observed in terms of Jensen's alphas.

The last four columns show the traditional pre- and post-formation $\beta_{D J I A}$ and $\beta_{F-D J I A}$ factor loadings with no lags. As columns 1 and 3 show, the 5-1 spread in daily pre-formation loadings to $D J I A$ and $F-D J I A$ is strongly related to the $\beta_{D J I A}^{D i m s o n}$. On the other hand, the daily $5-1$ $\beta_{D J I A}$ spread decreases as you increase the number of lags in $\beta_{D J I A}^{\text {Dimson }}$ and thus shift more weight to lagged sensitivity to $D J I A$. The post-formation $\beta_{D J I A}$ and $\beta_{F-D J I A}$ loadings present somewhat of a puzzle: not only do they decrease, but they actually turn negative as you increase Dimson lags to 2 or 3 . This means that portfolio 5 with the highest $\beta_{D J I A}^{D i m s o n}$ in month $t$ has a significantly lower post-formation $\beta_{F-D J I A}$ in $t+1$ than portfolio 1 with the lowest $\beta_{D J I A}^{\text {Dimson }}$ in $t$ (both for the equaland value-weighted cases).

\section{A.7. Is it absolute factor loading?}

Lastly, I analyze whether it is absolute rather than directional pre-formation $\beta_{D J I A}$ that predicts future performance and loadings. In a rational asset pricing framework this could for instance be the case if investors care about absolute, rather than relative exposure. Or it could . Table XVII shows the 5-1 portfolio formed based on high-minus-low absolute $\left|\beta_{D J I A}\right|$ (rather than directional $\left.\beta_{D J I A}\right)$ loading across MCap quintiles.

The top row shows that the low $\left|\beta_{D J I A}\right|$ portfolio 5 underperforms the low $\left|\beta_{D J I A}\right|$ portfolio 1 in the next month in terms of simple returns, both on value-weighted $(-1.11 \%)$ and equally-weighted basis $(-0.92 \%)$. The effect is robust to inclusion of known asset pricing factors, as the $t$-stats of the Jensen's alphas show. However, this negative 5-1 return differential in terms of absolute preformation is drastically reduced in size for larger stocks: for MCap quintiles 2-5, the mean 5-1 returns are near zero. Jensen's alphas, too, shrink drastically in size and are mostly statistically insignificantly different from zero (with the exception of MCap quintile 3 where they are shrunk strongly, but survive statistical significance).

The $\left|\beta_{D J I A}\right|$ 5-1 portfolio strongly loads on stocks with particularly negative pre-formation $D J I A$ loading - more so than on stocks with particularly positive pre-formation $D J I A$ loading: the pre-formation $\beta_{D J I A}$ is negative for most stocks in most MCap quantiles (exception: MCap quintile 5). However, strikingly, the post-formation $F-D J I A$ is strongly positive and significant 
in all MCap quintiles except for the second one across both value- and equally-weighted portfolios.

As table XVII shows, the performance differential due to absolute sorting on $\beta_{D J I A}$ is less robust than due to directional sorting. Only for the very smallest stocks in MCap quintile 1 there is a significant and economically meaningful performance differential between absolute portfolios 5 and 1 - it mostly disappear for the bigger MCap quintiles; and given the difficulty of arbitrage and the transaction costs to be expected for small and volatile stocks, it might not in effect be possible to trade on the perfomance differential in MCap quintile 1. Somewhat of a puzzle, however, is why pre-formation $\left|\beta_{D J I A}\right|$ sorting seems to predict the positive post-formation 5-1 $\beta_{F-D J I A}$ in the sample studied - better, in fact than pre-formation $\beta_{D J I A}$ sorting.

\section{B. Investor sentiment}

Similarly to investor attention before, in this section I perform a brief robustness test of FEARS

as a sentiment variable. As gets clear from the following pages, FEARS's effects are strongly conditionally tied to the general (Baker-Wurgler) sentiment state. Furthermore, the lion's share of the effect is essentially due to return predictability at the one-month horizon, and is thus not robust.

\section{B.1. The impact of market capitalization}

Table XVIII show the characteristics of the 5-1 $\beta_{F E A R S}$ portfolio of excess returns (valueweighted) across different MCap quintiles. Stocks are first sorted by MCap as of beginning of month and then, within MCap quintile, by their $\beta_{F E A R S}$, that is their sensitivity to investor sentiment. Panel A (B) thereby shows months with positive (negative) Baker-Wurgler (BW) sentiment.

The analysis previously has shown that across all stocks in the sample, the differential of $\beta_{F E A R S}$ portfolios 5 and 1 in monthly returns and alphas is negative (positive) during positive (negative) BW sentiment months, both for value- and equally-weighted returns. As is visible from table XVIII. however, there is a strong dispersion in this effect across MCap quintiles. Actually, the the average 5-1 spread across both positive and negative BW sentiment months decreases near-monotonically with MCap quintiles. The same effect is visible for Jensen's alphas. So while on aggregate there is a negative 5-1 spread in Jensen's alphas during positive BW months, it is actually only significant in MCap quintiles 4 and 5, thus for bigger-than-median stocks. Contrarily, while there is an aggregate positive 5-1 spread in Jensen's alphas during negative BW months, this effect seems to be driven near-exclusively by the smallest $20 \%$ of stocks (MCap quintile 1 ).

When it comes to post-formation factor exposure during the negative BW sentiment months only MCap quintiles 4 and 5 achieve statistical significance, meaning that for these stocks negative 5-1 outperformance coincides contemporaneously with $\beta_{F E A R S}$ exposure. During positive BW months, only MCap quintiles 2 and 3 achieve statistically significant post-formation FEARS exposure. On the other hand, due in part to the high volatility and the short sample, the 5-1 alpha spread is not significantly different from zero. 
The negative 5-1 alpha spread coinciding with positive factor exposure spread for MCap quintiles 4 and 5 during positive BW months (Panel A) makes intuitive economic sense as a sort of insurance premium to be paid for stocks that perform well during times of particularly high FEARS. MCap quintiles 4 and 5 being above-average sized stocks, and the BW sentiment being positive (indicating calm financial markets), the presumption can be that they are more efficiently priced in the financial markets relative to MCap quintiles 1-3. On the contrary, I find an extremely high 5-1 return and alpha spread of around $2 \%$ monthly ( $>24 \%$ annually) in small stocks (MCap quintile 1) based on pre-formation $\beta_{F E A R S}$ sorts during negative BW months. The fact that FEARS is strongly associated with return patterns due to limits to arbitrage (Da et al. $(2015)$ ) combined with the fact that we are looking at small, volatile stocks during turbulent times makes it well conceivable that the month $t+1$ outperformance of $5-1$ alphas is due to behavioral patterns coupled to limits to arbitrage. More specifically, it implies that small stocks that are reacting particularly negatively to increased noise trader fears and uncertainty continue to get sold off relative to the cross-section.

\section{B.2. Bigger sample: including NASDAQ}

Can the findings of the previous section be corroborated in a bigger sample, including all NASDAQ stocks? Table XIX shows the same characteristics of a 5-1 $\beta_{F E A R S}$ portfolio of excess returns (value-weighted) across different MCap quintiles as in table XVIII in this enlarged sample. Panel A (B) thereby shows months with positive (negative) Baker-Wurgler (BW) sentiment.

The results are somewhat different: in positive BW months, all monthly 5-1 spreads in monthly mean returns and alphas are negative, however mostly not statistically significant. Only for MCap quintile 3 do the Jensen's alphas all achieve statistical significance at the $5 \%$ level, as the volatility and thus standard error around the estimate is lower. During negative BW sentiment, we find a similar decrease in mean monthly 5-1 performance as the MCap quintile increases, however only until MCap quintile 3. The point estimate of the 5-1 portfolio's Jensen's alpha is economically large (around $1.2 \%$ monthly), but misses statistical significance due to the large standard error. That way none of the Jensen's alphas (all positive, except for MCap quintile 3) achieve statistical significance.

In terms of post-formation factor loading to raw $F E A R S, 3 / 5 \beta_{F E A R S}$ 's are significant during positive BW sentiment, but only $1 / 5$ is during negative BW sentiment. As for the factor-mimicking portfolio 4/5 (3/5) $\beta_{F-F E A R S}$ 's are significant during positive (negative) BW sentiment, documenting a rather stable factor exposure overall.

\section{B.3. Is it return reversal and/or momentum?}

While the conditional 5-1 performance differentials in table XVIII are rather impressive, I was mostly not able to document a systematic price of FEARS risk in an asset pricing sense. One explanation could be that the FEARS conditional performance effects are really due to return reversal or momentum at the monthly level. Table $\mathrm{XX}$ thus examines the $\beta_{F E A R S}$-performance effect, controlling for monthly return predictability. More specifically, every beginning of month I 
double-sort the stocks according to their simple return as well as their $\beta_{F E A R S}$ loading last month. I then form the 5-1 portfolio in $\beta_{F E A R S}$ across the five different return quintiles, across the whole sample (UC) as well as in positive (Pos) and negative (Neg) BW months, respectively. Panel A (B) shows value-weighted (equally-weighted) results.

In short, the lion's share of the documented $\beta_{F E A R S}$-performance relationship is driven by return predictability. When controlling for last month's return, none of the value-weighted 5-1 return or Jensen's alpha spreads are economically meaningful and fail statistical significance very strongly. Only in terms of equally-weighted returns, there is a marginally significant positive Jensen's alpha for the 5-1 portfolio during negative BW months. Unsurprisingly, the sample of negative BW months is the one where $\beta_{F E A R S}$ achieves a significant state price of risk $\lambda_{F E A R S}$ in 1 of the 2 FMB analysis models (single first-stage time series regression; see table $\mathrm{X}$.

Controlling for return predictability, the value-weighted 5-1 portfolio has a zero unconditional post-formation $\beta_{F E A R S}$ loading - with positive (negative) $\beta_{F E A R S}$ in positive (negative) BW states. Equally-weighted, there remains some post-formation $\beta_{F E A R S}$ persistence unconditionally - with statistically significant positive $\beta_{F E A R S}$ in positive BW states and insignificant loading in negative BW months.

\section{B.4. $\beta_{F E A R S}$ : Time lags and absolute sensitivity}

For completeness' sake, despite having found out that return reversal or momentum at the one-month horizon seems to drive the detected $\beta_{F E A R S}$-performance relationship, I quickly discuss the effect of Dimson (1979)'s aggregated coefficients as well as of absolute FEARS loading below.

Table XXI displays the 5-1 portfolio characteristics based on pre-formation $\beta_{F E A R S}^{\text {Dimson }}$ with varying lags - similarly as in table XVI for DJIA. In short, the performance differential, if any, dissipates quickly when incorporating past lags. This indicates that $\beta_{F E A R S}$ on a daily level captures any investor sentiment of interest - without a requirement to rely on any lagged such sensitivity.

Table XXII displays the 5-1 portfolio characteristics based on absolute pre-formation $\left|\beta_{F E A R S}\right|$ - similarly as in table XVII for DJIA. As can be seen from Panel A, there is a rather large 5-1 spread in monthly returns during positive BW months for small stocks (MCap quintile 1). When controlling for our full model specification (including idiosyncratic volatility, in particular), the Jensen's alpha however is not statistically significant from zero. In negative BW months (Panel B) and in MCap quintiles $(1,2,5)$, however, the Jensen's alpha of the 5-1 $\left|\beta_{F E A R S}\right|$ portfolio is statistically significantly negative. This means that stocks with high absolute exposure to FEARS might in fact underperform in negative financial market conditions - of course, not controlling for return reversal here.

\section{Conclusion}

The attention of investors to the financial markets and their information processing abilities are limited and time-varying. In particular, there is strong theoretical and empirical evidence that 
investor attention increases precisely during times of increased uncertainty or economic shocks (i.e., Andrei and Hasler (2015) or Peng et al. (2007)). In short, investor attention increases during 'bad' economic states, which makes it a natural candidate for a state variable in asset pricing. The problem has long been that investor attention could not directly be measured. In this paper, I follow recent literature to proxy investor attention through a direct measure - the Google search frequency in 'DJIA'.

Indeed, sorting stocks with regards to their last month's sensitivity to 'DJIA' produces a significant performance spread of around $0.60 \%$ monthly in a direction consistent with intuition. This performance spread is robust to a broad array of known asset pricing factors. In an asset pricing exercise, I confirm a significant price of attention risk. Assets loading positively on a tradable portfolio of high-minus-low (pre-formation) investor attention sensitivity pay a significant price for protection to attention risk. The attention risk premium is robust to varying test specifications, a wide array of test assets as well as different model specifications.

Extreme negative or positive investor attention loadings are associated with limits to arbitrage, such as high idiosyncratic volatility, high book-to-market valuation or small company size (proxies developed in Baker and Wurgler (2006)). Still, I show that that the performance spread due to investor attention sensitivity survives controlling for those proxies. In particular, the negative relationship between investor attention beta $\left(\beta_{D J I A}\right)$ and subsequent performance becomes cleaner the bigger and arguably more efficiently traded the stocks in question. In a host of robustness tests, I find that the performance spread due to investor attention neatly extends to a bigger sample, survives momentum and return reversal and works better than alternative specifications based on the sum of contemporaneous and lagged coefficients or absolute rather than directional betas.

While the performance spread over the sample from 2004 to 2015 is very robust, two questions raise questions for future research. For one, in the last part of the sample from 2011 to 2015 the performance spread has diminished considerably. This could be due to a variety of reasons: given the popularity of Google search-based strategies, it is conceivable that market participants have 'traded away' the cross-sectional pricing of the $\beta_{D J I A}$. Another, likelier explanation is that the last period from end of 2011 to 2015 has simply seen less uncertainty and investor attention shocks, making it a sample beset with a Peso problem. Secondly, while the performance spread due to past investor attention is robust, the post-formation loadings are less so. The post-formation loadings of pre-sorted portfolios depend strongly on whether they are equally- or value-weighted, on the sample at hand and on the controls employed. This means that while I have ruled out many alternative sorts of explanations for the observed performance anomaly, a factor explanation remains possible, but not certain.

Further to investor attention, I analyze whether exposure to investor sentiment leads to crosssectional performance differentials. As a measure of investor sentiment, I employ Da et al. (2015)'s FEARS index, which reflects the Google search interest in thirty keywords related to household concerns and has demonstrably been linked strongly to alternative measures of investor sentiment. However, other than in Da et al. (2015)'s paper, I am not interested in the short-term aggregate 
market dynamics around changes in FEARS, but rather in the longer-run cross-sectional pricing implications of differing betas of assets to FEARS.

As opposed to investor attention, I do not find an unconditional performance differential relating to investor sentiment beta $\left(\beta_{F E A R S}\right)$. Rather, I find that $\beta_{F E A R S}$ sorts leads to conditional performance differentials depending on the sentiment state the economy is in. To proxy for sentiment, I use the Baker-Wurgler index, a broad-based measure of investor sentiment (Baker and Wurgler (2006)). When the economy is in a positive (negative) sentiment state, stocks with higher $\beta_{F E A R S}$ - stocks that provide protection to an increase in household concerns - achieve lower (higher) cross-sectional performance, robust to a wide variety of asset pricing factors. While the positive performance differential in times of positive BW sentiment is consistent with a risk premium, the latter presents an anomaly that could be tied to less-than-perfectly efficient markets.

However, as opposed to investor attention, investor sentiment is less robust as a (conditional) asset pricing factor. In a variety of asset pricing tests, a tradable sentiment proxy only achieves a significant price of risk in one instance. Furthermore, the conditional $t+1$ return differential due to sorting on $\beta_{F E A R S}$ is strongly related to return reversal and momentum. This means that while FEARS has interesting cross-sectional implications in the daily to weekly horizon (Da et al. (2015)), it is not a useful state variable in the asset pricing sense: past loading does not predict future return differentials over and above return predictability at the monthly horizon and stock characteristics pertaining to difficulty of arbitrage.

Lastly, while both absolute attention and sentiment loadings are positively related to idiosyncratic volatility, I demonstrate that investor attention and sentiment are orthogonal to the idiosyncratic risk puzzle: neither can account for the other. 


\section{REFERENCES}

Andrei, Daniel, and Michael Hasler, 2015, Investor Attention and Stock Market Volatility, Review of Financial Studies 28, 33-72.

Ang, Andrew, Joseph Chen, and Yuhang Xing, 2006a, Downside risk, Review of Financial Studies 19, 1191-1239.

Ang, Andrew, Robert J Hodrick, Yuhang Xing, and Xiaoyan Zhang, 2006b, The Cross-Section of Volatility, Journal of Finance LXI, 259-299.

Ang, Andrew, Robert J. Hodrick, Yuhang Xing, and Xiaoyan Zhang, 2009, High idiosyncratic volatility and low returns: International and further U.S. evidence, Journal of Financial Economics $91,1-23$.

Aruoba, S. Boraan, Francis X. Diebold, and Chiara Scotti, 2009, Real-Time Measurement of Business Conditions, Journal of Business 8 Economic Statistics 27, 417-427.

Baker, Malcolm, Brendan Bradley, and Jeffrey Wurgler, 2011, Benchmarks as Limits to Arbitrage: \nUnderstanding the Low-Volatility Anomaly, Financial Analysts Journal 67, 40-54.

Baker, Malcolm, and Jeremy C. Stein, 2004, Market liquidity as a sentiment indicator, Journal of Financial Markets 7, 271-299.

Baker, Malcolm, and Jeffrey Wurgler, 2000, The Equity Share in New Issues and Aggregate Stock Returns, The Journal of Finance LV, 2219-2257.

Baker, Malcolm, and Jeffrey Wurgler, 2006, Investor Sentiment and the Cross-Section of Stock Retums, The Journal of Finance 61, 1645-1680.

Baker, Malcolm, and Jeffrey Wurgler, 2007, Investor Sentiment in the Stock Market, Journal of Economic Perspectives 21, 129-151.

Baker, Scott R, Nicholas Bloom, and Steven J Davis, 2015, Measuring Economic Policy Uncertainty, NBER Working Paper Series October, 1-75. 
Bali, Turan G, and Nusret Cakici, 2008, Idiosyncratic Volatility and the Cross Section of Expected Returns, Journal of Financial and Quantitative Analysis 43, 29-58.

Bali, Turan G., Nusret Cakici, and Robert F. Whitelaw, 2011, Maxing out: Stocks as lotteries and the cross-section of expected returns, Journal of Financial Economics 99, 427-446.

Barber, B. M., T. Odean, and N. Zhu, 2008, Do Retail Trades Move Markets?, Review of Financial Studies 22, 151-186.

Black, Fisher, Michael Jensen, and Myron S. Scholes, 1972, The capital asset pricing model: Some empirical tests, in Michael Jensen, ed., Studies in the Theory of Capital Markets (Praeger, New York).

Breeden, Douglas T, Michael R Gibbons, and Robert H Litzenberger, 1989, Empirical Tests of the Consumption-Oriented, Journal of Finance 44, 231-262.

Brown, Gregory W., and Michael T. Cliff, 2004, Investor sentiment and the near-term stock market, Journal of Empirical Finance 11, 1-27.

Brown, Stephen J, William N Goetzmann, Takato Hiraki, Noriyoshi Shirishi, and Masahiro Watanabe, 2003, Investor Sentiment in Japanese and U. S. Daily Mutual Fund Flows, National Bureau of Economic Research Working Paper Series No. 9470.

Chen, Joseph S., 2002, Intertemporal CAPM and the Cross-Section of Stock Returns, SSRN Electronic Journal .

Choi, Hyunyoung, and Hal Varian, 2009, Predicting Initial Claims for Unemployment Benefits, Unpublished Working Paper. .

Choi, Hyunyoung, and Hal Varian, 2012, Predicting the Present with Google Trends, Economic Record 88, 2-9.

Cleveland, Robert B., William S. Cleveland, Jean E. McRae, and Irma Terpenning, 1990, STL: A Seasonal-Trend Decomposition Procedure Based on Loess, Journal of Official Statistics .

Da, Zhi, Joseph Engelberg, and Pengjie Gao, 2011, In Search of Attention, Journal of Finance 66, $1461-1499$. 
Da, Zhi, Joseph Engelberg, and Pengjie Gao, 2015, The sum of all FEARS investor sentiment and asset prices, Review of Financial Studies 28, 1-32.

Da, Zhi, Umit G. Gurun, and Mitch Warachka, 2014, Frog in the pan: Continuous information and momentum, Review of Financial Studies 27, 2171-2218.

Daniel, Kent, and Sheridan Titman, 1997, Evidence in the Characteristics of Cross Sectional Variation in Stock Returns, The Journal of Finance LII, 1-33.

De Long, B, A Shleifer, LH Summers, and R Waldmann, 1990, Noise Trader Risk in Financial Markets, Journal of Political Economy 98, 703-738.

Dimson, Elroy, 1979, Risk measurement when shares are subject to infrequent trading, Journal of Financial Economics 7, 197-226.

Fama, EF, and JD MacBeth, 1973, Risk, return, and equilibrium: Empirical tests, Journal of political economy 81, 607-636.

Fama, Eugene F., and Kenneth R. French, 1992, The Cross-section of Expected Stock Returns, The Journal of Finance 47, 427-465.

Fama, Eugene F., and Kenneth R. French, 1993, Common risk factors in the returns on stocks and bonds, Journal of Financial Economics 33, 3-56.

Fama, Eugene F., and Kenneth R. French, 2015, A five-factor asset pricing model, Journal of Financial Economics 116, 1-22.

Frazzini, Andrea, and Lasse Heje Pedersen, 2014, Betting against beta, Journal of Financial Economics 111, 1-25.

Gervais, Simon, Ron Kaniel, and Dan H. Mingelgrin, 2001, The High-Volume Return Premium, The Journal of Finance LVI, 877-919.

Gibbons, Michael R., Stephen A. Ross, and Jay Shanken, 1989, A Test of the Efficiency of a Given Portfolio, Econometrica 57, 1121.

Grullon, Gustavo, George Kanatas, and James P. Weston, 2004, Advertising, breadth of ownership, and liquidity, Review of Financial Studies 17, 439-461. 
Hirshleifer, David, and Sonya Seongyeon Lim, 2009, Driven to Distraction : Extraneous Events and Underreaction to Earnings News Driven to Distraction : Extraneous Events and Underreaction to Earnings News LXIV, 2289-2325.

Hou, Kewei, Lin Peng, and Wei Xiong, 2009, A Tale of Two Anomalies: The Implications of Investor Attention for Price and Earnings Momentum, Working Paper 43.

Ilmanen, Antti, 2012, Do Financial Markets Reward Buying or Selling Insurance and Lottery Tickets?, Financial Analysts Journal 68, 26-36.

Jagannathan, Ravi, and Zhenyu Wang, 1996, The Conditional CAPM and the Cross-Sectionof, Journal of Finance 51, 3-53.

Kahnemann, Daniel, and Amos Tversky, 1973, Availability: A heuristic for judging frequency and probability, Cognitive Psychology 5, 207-232.

Lamont, Owen A., 2001, Economic tracking portfolios, Journal of Econometrics 105, 161-184.

Lee, Charles M. C., Andrei Shleifer, and Richard H. Thaler, 1991, Investor Sentiment and the Closed-End Fund Puzzle, The Journal of Finance XLVI, 75-109.

Lemmon, Michael, and Evgenia Portniaguina, 2006, Consumer confidence and asset prices: Some empirical evidence, Review of Financial Studies 19, 1499-1529.

Malkiel, Burton G, and Yexiao Xu, 2002, Idiosyncratic Risk and Security Returns, Working Paper

Merton, Robert C, 1973, An Intertemporal Capital Asset Pricing Model 41, 867-887.

Neal, Robert, and Simon M. Wheatley, 1998, Do Measures of Investor Sentiment Predict Returns ? Author ( s ): Robert Neal and Simon M . Wheatley Source : The Journal of Financial and Quantitative Analysis, Vol . 33 , No.4 ( Dec ., 1998 ), pp . Business Administration, Journal of Financial and Quantitative Analys 33, 523-547.

Ozoguz, Arzu, 2009, Good times or bad times? Investors' uncertainty and stock returns, Review of Financial Studies 22, 4377-4422. 
Pastor, L, and Robert Stambaugh, 2003, Liquidity risk and expected stock returns, The Journal of Political Economy 111, 642.

Pedersen, Lasse Heje, 2015, Efficiently Inefficient (Princeton University Press, Princeton, New Jersey).

Peng, Lin, and Wei Xiong, 2006, Investor attention, overconfidence and category learning, Journal of Financial Economics 80, 563-602.

Peng, Lin, Wei Xiong, and Tim Bollerslev, 2007, Investor attention and time-varying comovements, European Financial Management 13, 394-422.

Qiu, Lily, and Ivo Welch, 2006, Investor Sentiment Measures, NBER Working Paper Series .

Ross, Stephen A., 1976, The Theory of Capital Asset Pricing, Journal of Economic Theory 13, $341-360$.

Scheinkman, JoséA., and Wei Xiong, 2003, Overconfidence and Speculative Bubbles, Journal of Political Economy 111, 1183-1220.

Seasholes, Mark S., and Guojun Wu, 2007, Predictable behavior, profits, and attention, Journal of Empirical Finance 14, 590-610.

Shleifer, Andrei, and Robert W. Vishny, 1997, The Limits of Arbitrage, Journal of Finance 52, $35-55$.

Sibley, Steven E., Yanchu Wang, Yuhang Xing, and Xiaoyan Zhang, 2016, The information content of the sentiment index, Journal of Banking and Finance 62, 164-179.

Stambaugh, Robert F., Jianfeng Yu, and Yu Yuan, 2012, The short of it: Investor sentiment and anomalies, Journal of Financial Economics 104, 288-302.

Stambaugh, Robert F., Jianfeng Yu, and Yu Yuan, 2014, The long of it: Odds that investor sentiment spuriously predicts anomaly returns, Journal of Financial Economics 114, 613-619.

Stambaugh, Robert F., Jianfeng Yu, and Yu Yuan, 2015, Arbitrage Asymmetry and the Idiosyncratic Volatility Puzzle, Journal of Finance 70, 1903-1948. 
Stambaugh, Robert F., and Yu Yuan, 2016, Mispricing Factors, Review of Financial Studies (Forthcoming) .

Tetlock, Paul C., 2007, Giving content to investor sentiment: The role of media in the stock market, Journal of Finance 62, 1139-1168.

Varian, Hal, and Hyunyoung Choi, 2009, Predicting the Present with Google Trends, Google Working Paper .

Vlastakis, Nikolaos, and Raphael N. Markellos, 2012, Information demand and stock market volatility, Journal of Banking 86 Finance 36, 1808-1821.

Vozlyublennaia, Nadia, 2014, Investor attention, index performance, and return predictability, Journal of Banking and Finance 41, 17-35.

Yuan, Yu, 2015, Market-wide attention, trading, and stock returns\$, Journal of Financial Economics $116,548-564$. 
Figure 1. Theoretical effect of investor sentiment on different types of stocks (Baker \& Wurgler, 2007).

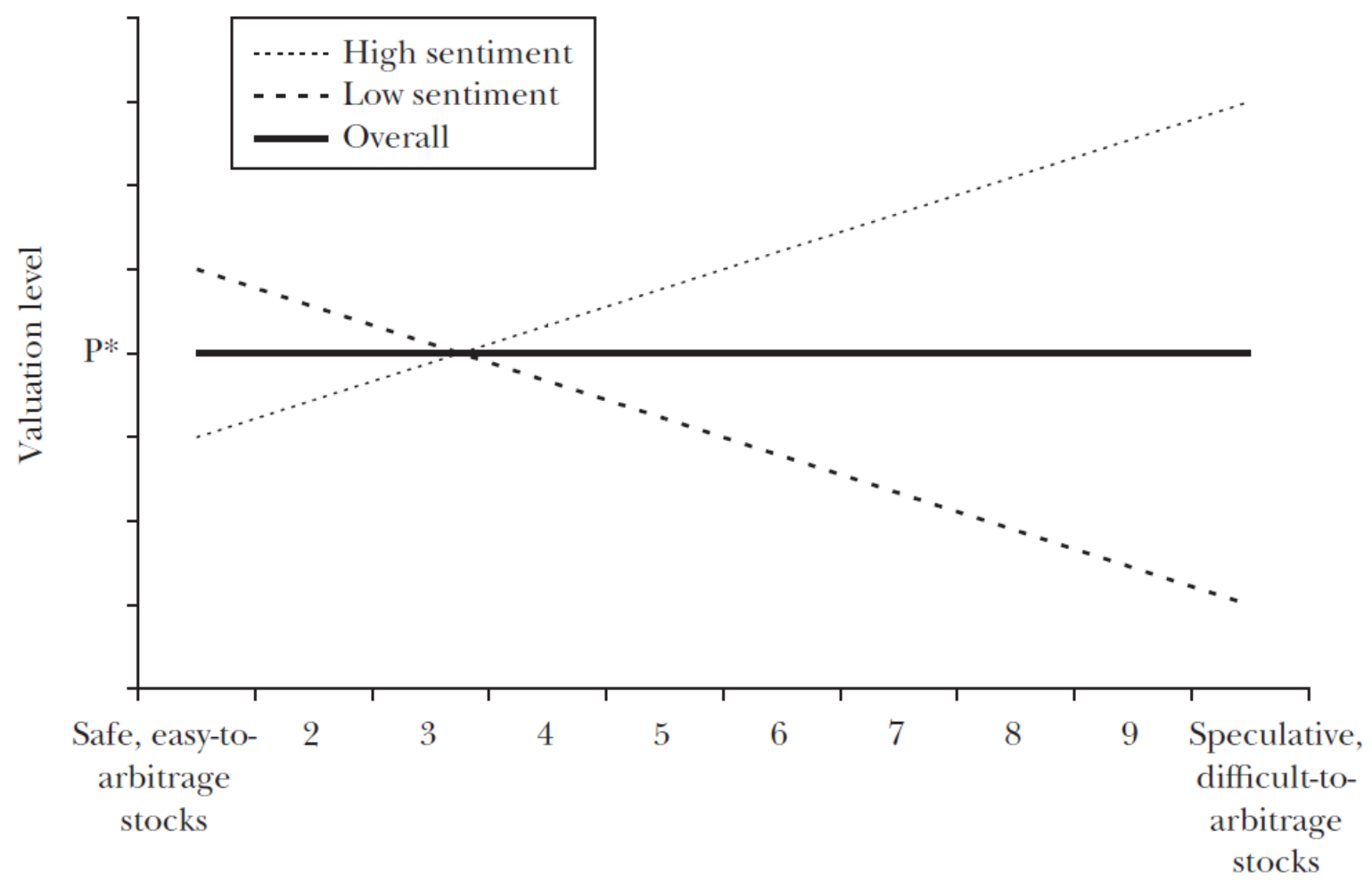

The figure shows the theoretical dependence of valuation level on difficulty to arbitrage in different sentiment states. Source: Baker \& Wurgler (2007, p.133). 
Figure 2. The 30 words in the FEARS index as in Da et al. (2015).

\begin{tabular}{lll} 
& Search Term & T-Statistic \\
\hline 1 & GOLD PRICES & -6.04 \\
2 & RECESSION & -5.60 \\
3 & GOLD PRICE & -4.81 \\
4 & DEPRESSION & -4.56 \\
5 & GREAT DEPRESSION & -4.15 \\
6 & GOLD & -3.98 \\
7 & ECONOMY & -3.52 \\
8 & PRICE OF GOLD & -3.23 \\
9 & THE DEPRESSION & -3.20 \\
10 & CRISIS & -2.93 \\
11 & FRUGAL & -2.87 \\
12 & GDP & -2.85 \\
13 & CHARITY & -2.63 \\
14 & BANKRUPTCY & -2.50 \\
15 & UNEMPLOYMENT & -2.46 \\
16 & INFLATION RATE & -2.32 \\
17 & BANKRUPT & -2.28 \\
18 & THE GREAT DEPRESSION & -2.17 \\
19 & CAR DONATE & -2.11 \\
20 & CAPITALIZATION & -2.10 \\
21 & EXPENSE & -1.97 \\
22 & DONATION & -1.89 \\
23 & SAVINGS & -1.82 \\
24 & SOCIAL SECURITY CARD & -1.71 \\
25 & THE CRISIS & -1.65 \\
26 & DEFAULT & -1.63 \\
27 & BENEFITS & -1.56 \\
28 & UNEMPLOYED & -1.55 \\
29 & POVERTY & -1.52 \\
30 & SOCIAL SECURITY OFFICE & -1.51 \\
\hline
\end{tabular}

This table reports the 30 search terms derived from words of economic sentiment in the Harvard and Lasswell dictionaries (see the description in Section 1.1) that have had the largest negative correlation with the market. The terms are ordered from most negative (GOLD PRICES) to least negative (SOCIAL SECURITY OFFICE).

The list shows the 30 search terms with the most negative correlation with the stock market over the sample (2004-2011) in Da et al. (2015, p.10). 
Figure 3. Loess decomposition of daily Google search frequency of DJIA (1:2004-12:2015; N:4383)

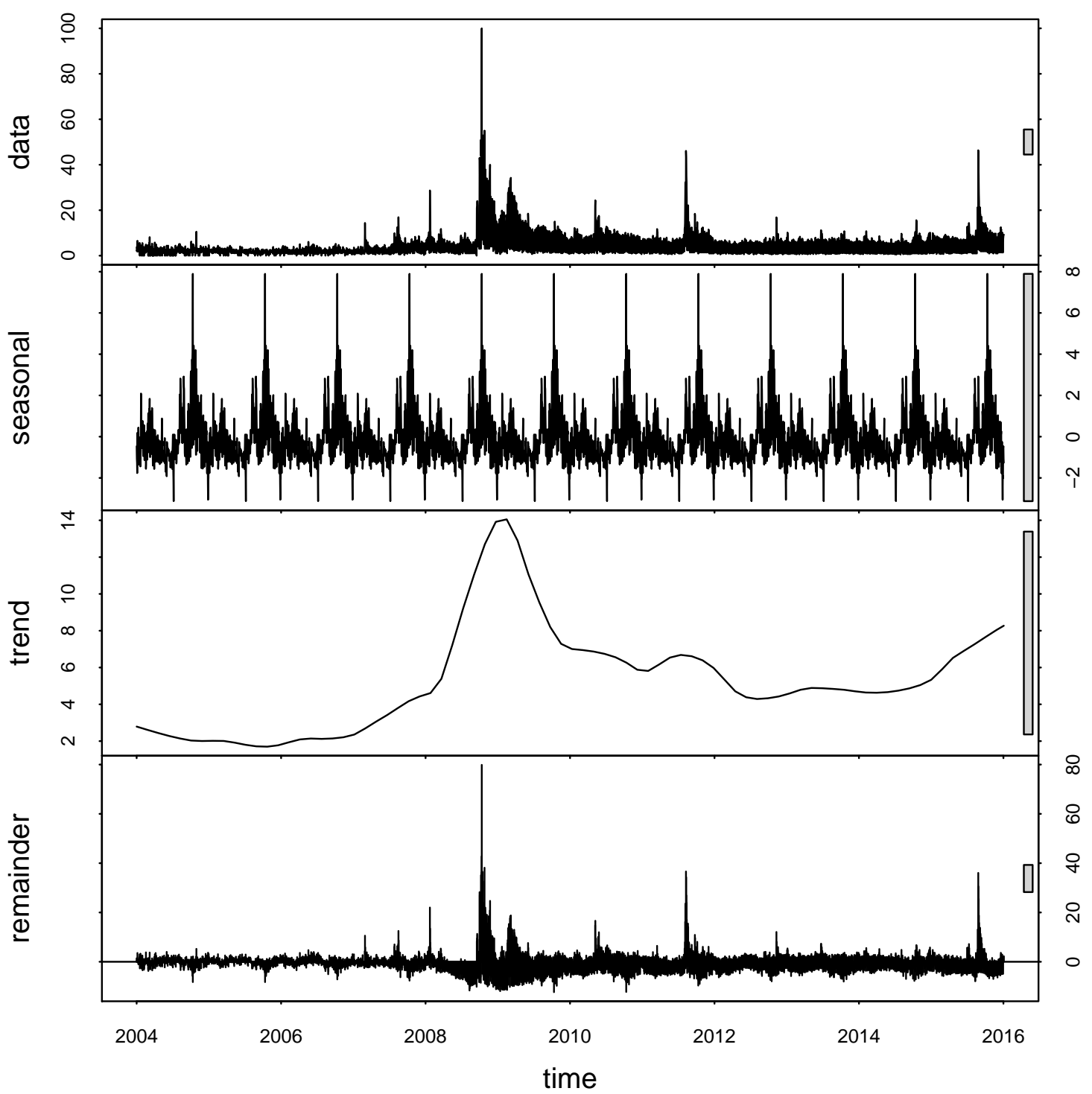

The top graph shows the raw daily Google search frequency of the keyword "DJIA" in the United States from January 2004 to December 2015 (data). It is broken down by Loess decomposition into a yearly-recurring seasonal pattern (seasonal), a long-term trend (trend) as well as a remainder term. The remainder term is used as the main proxy for investor attention in the stock market $(D J I A)$ in this paper. 
Figure 4. Jensen's alphas and average returns of equally-weighted investor attention-sorted portfolios $\left(\beta_{D J I A}\right)(1: 2004-09: 2015)$.
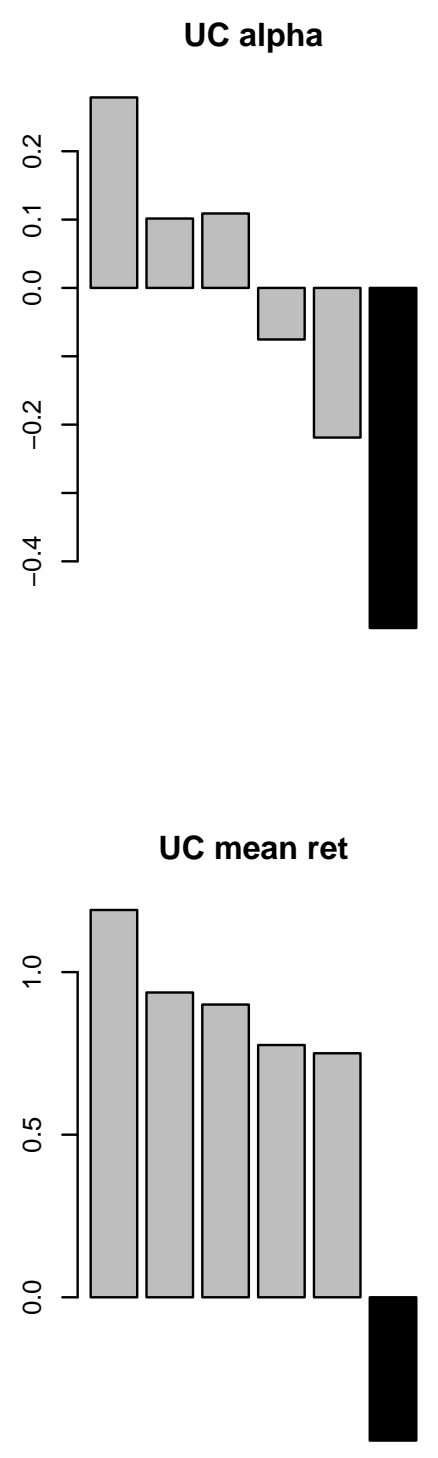
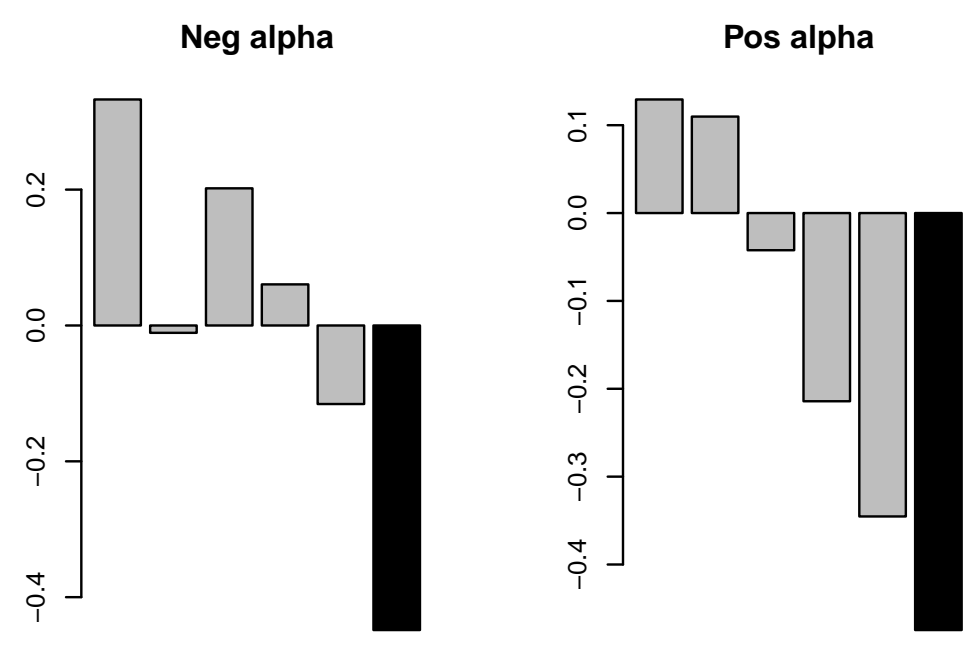

Neg mean ret

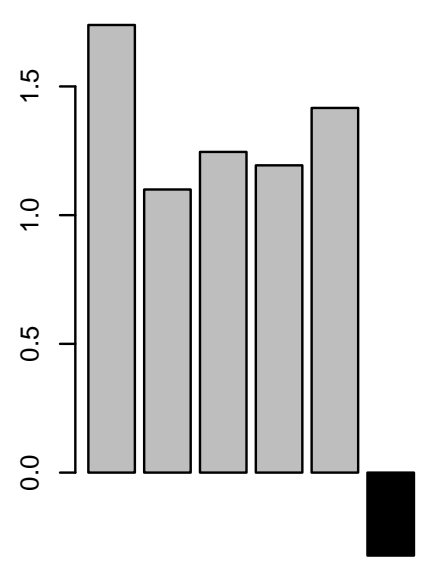

Pos mean ret

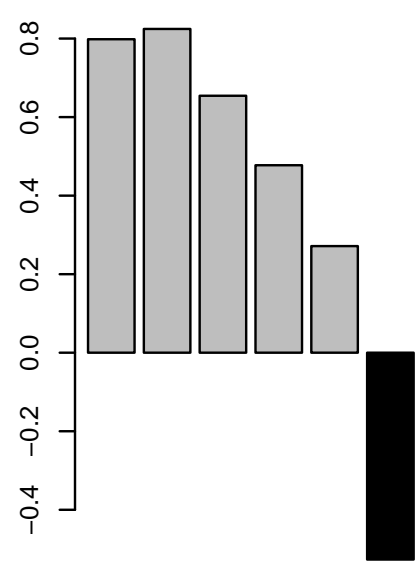

The barplots depict the performance of equally-weighted quintile portfolios sorted by prior month's investor attention beta $\left(\beta_{D J I A}\right)$ (filled grey) as well as the difference between portfolios 5 and 1 (filled black). The top rows the monthly Jensen's alpha across all months as well as in negative and positive Baker-Wurgler (2006) sentiment months. The second row shows raw monthly returns (simple, not excess). 
Figure 5. Pre-and post-formation betas $\left(\beta_{D J I A}\right)$ of equally-weighted quintile portfolios to investor attention and factor-mimicking portfolio (1:2004-09:2015).

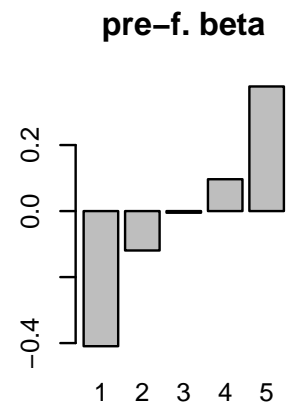

post-f. beta
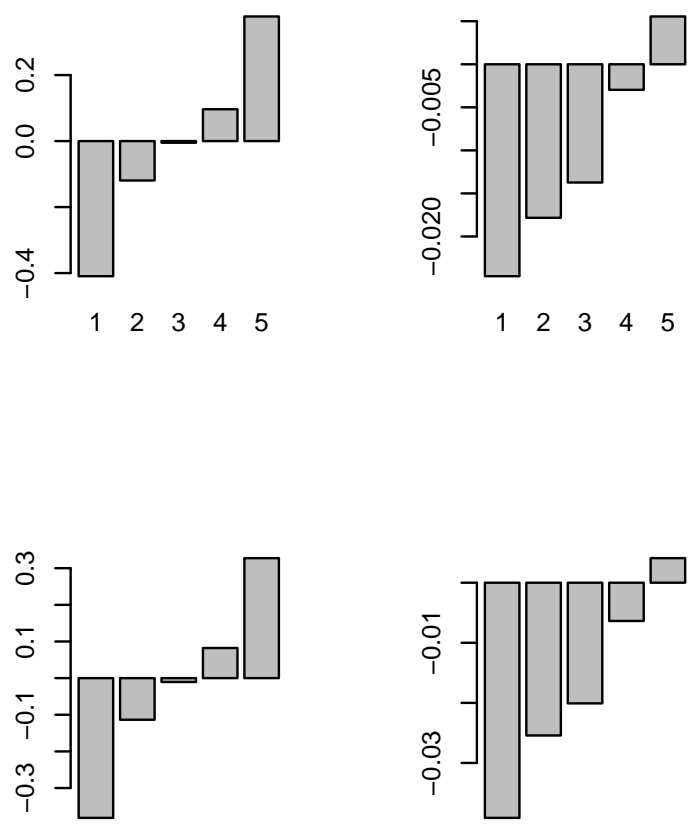

$\begin{array}{lllll}1 & 2 & 3 & 4 & 5\end{array}$

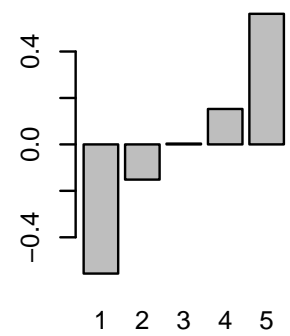

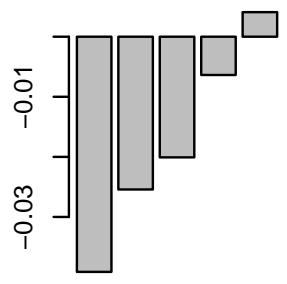

$\begin{array}{lllll}1 & 2 & 3 & 4 & 5\end{array}$

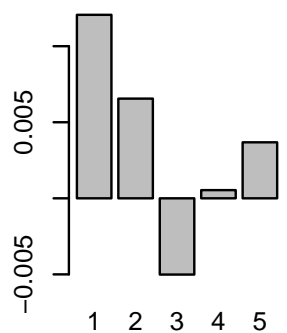

pre-f. FMP beta
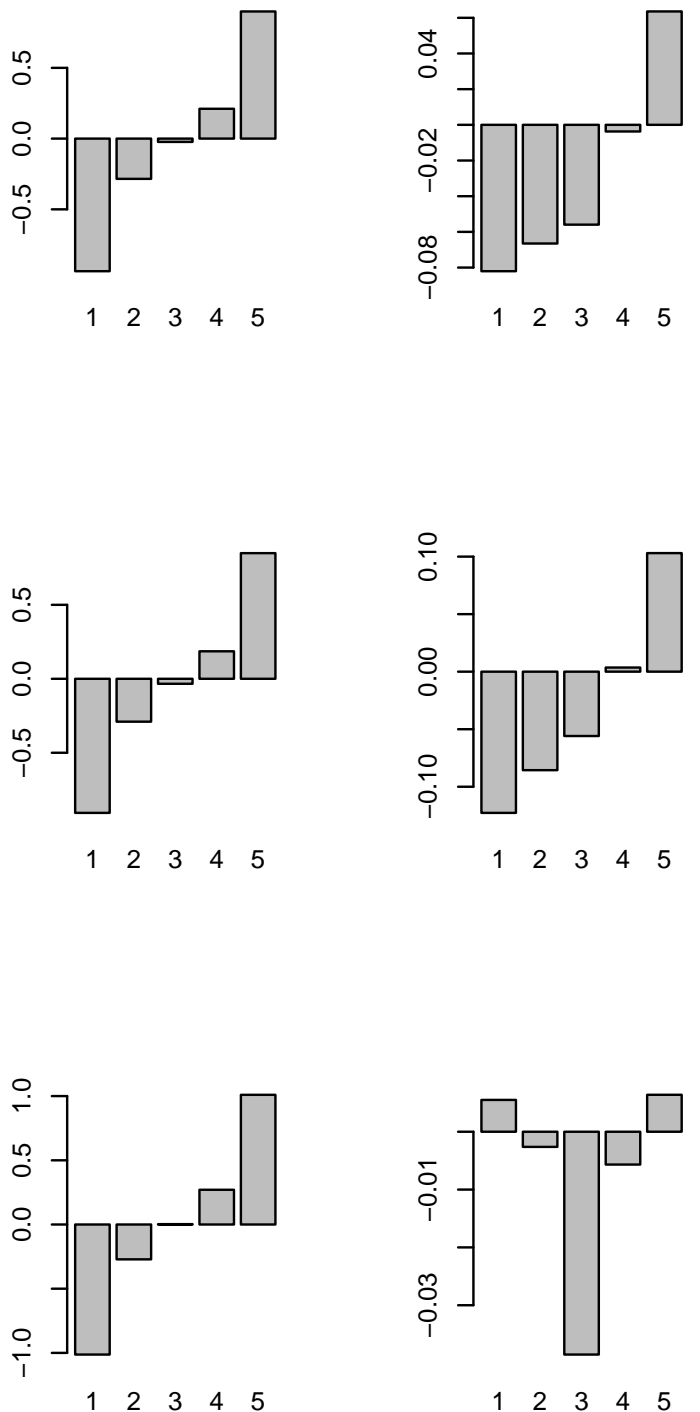

The barplots depicts the pre- and post-formation betas to investor attention (first and second columns) and its factor-mimicking portfolio (third and fourth columns) of equally-weighted quintile portfolios sorted by prior month's beta $\left(\beta_{D J I A}\right)$. The first row shows the pre-and post-formation betas across all months, while the second (third) row shows the post-formation betas in negative (positive) Baker-Wurgler sentiment months. 
Figure 6. Jensen's alphas and average returns of value-weighted investor attention-sorted portfolios $\left(\beta_{D J I A}\right)(1: 2004-09: 2015)$.

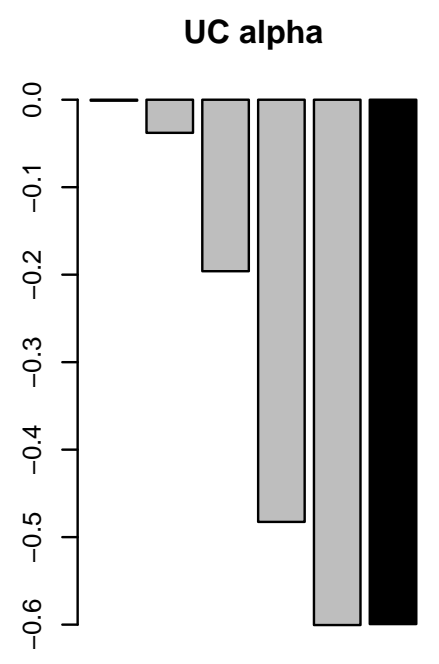

UC mean ret

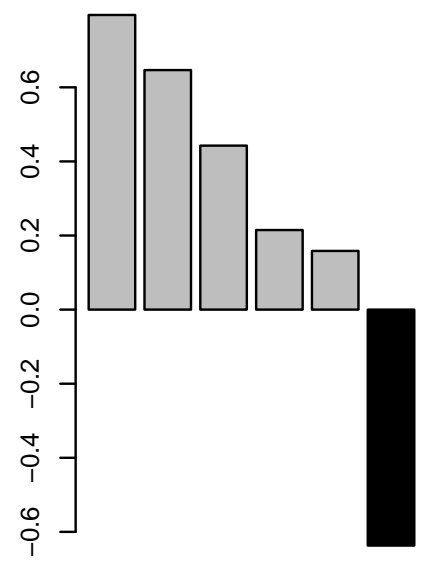

Neg alpha

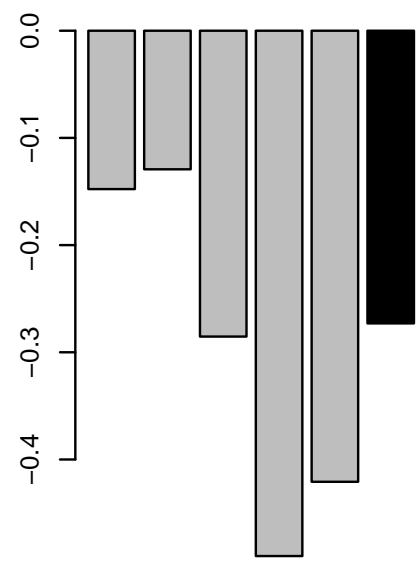

Neg mean ret

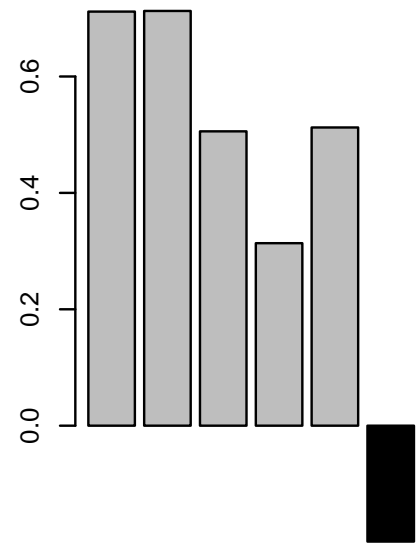

Pos alpha

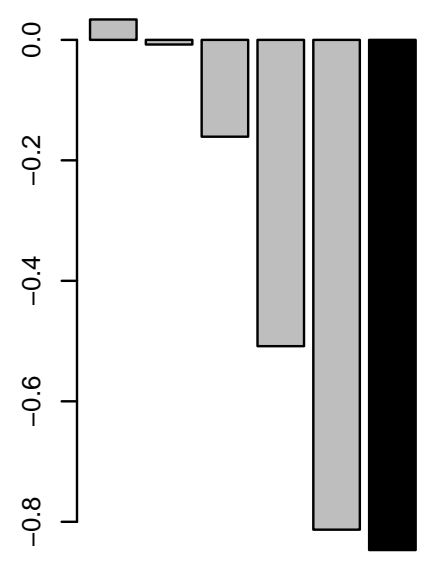

Pos mean ret

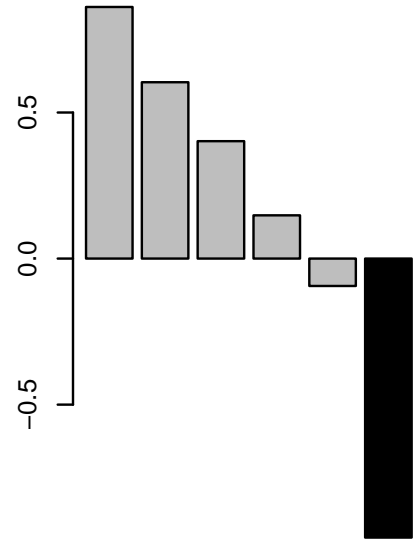

The barplots depict the performance of value-weighted quintile portfolios sorted by prior month's investor attention beta $\left(\beta_{D J I A}\right)$ (filled grey) as well as the difference between portfolios 5 and 1 (filled black). The top rows the monthly Jensen's alpha across all months as well as in negative and positive Baker-Wurgler (2006) sentiment months. The second row shows raw monthly returns (simple, not excess). 
Figure 7. Pre-and post-formation betas $\left(\beta_{D J I A}\right)$ of value-weighted quintile portfolios to investor attention and factor-mimicking portfolio (1:2004-09:2015).
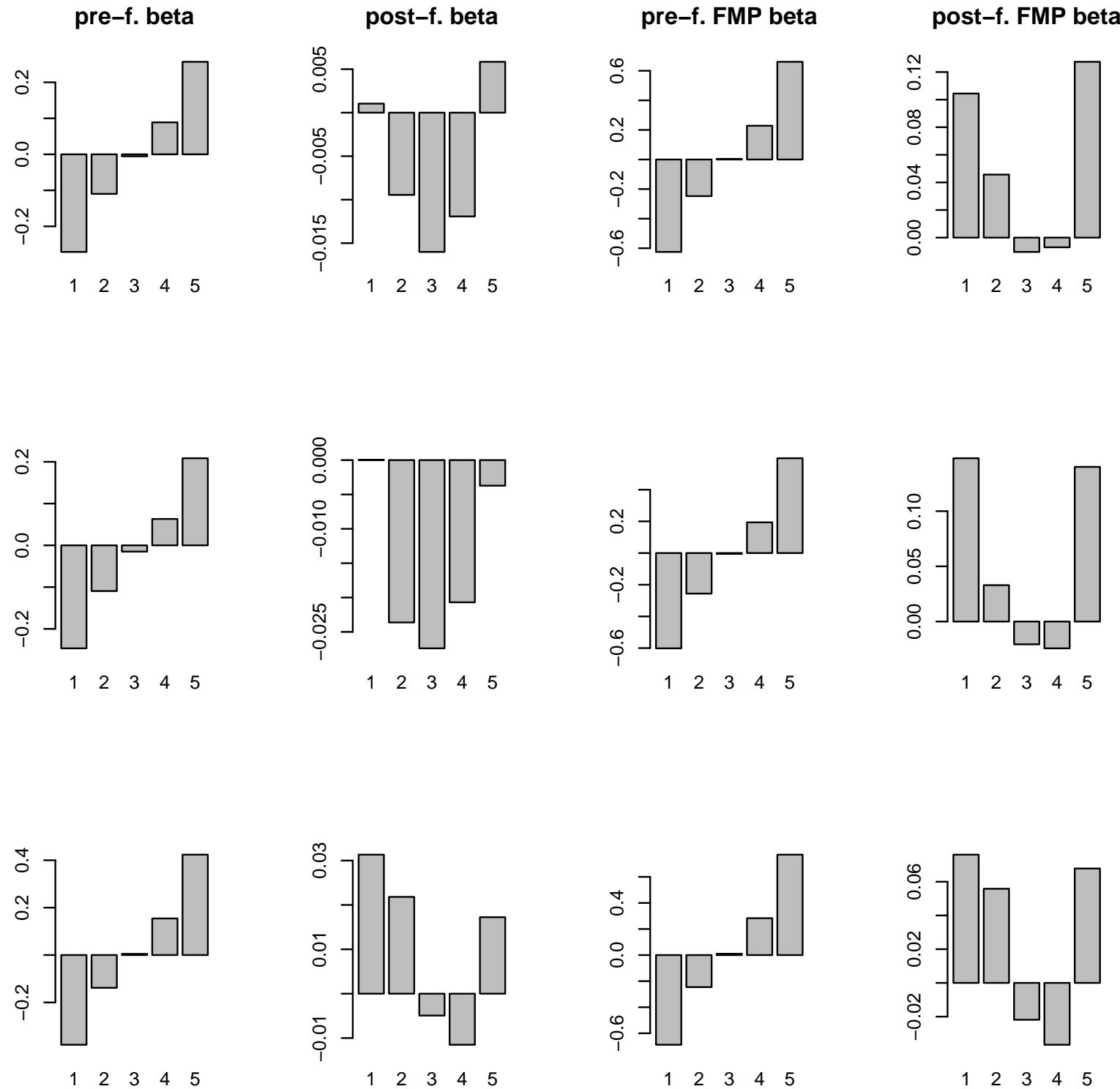

The barplots depicts the pre- and post-formation betas to investor attention (first and second columns) and its factor-mimicking portfolio (third and fourth columns) of value-weighted quintile portfolios sorted by prior month's beta $\left(\beta_{D J I A}\right)$. The first row shows the pre-and post-formation betas across all months, while the second (third) row shows the post-formation betas in negative (positive) Baker-Wurgler sentiment months. 
Figure 8. Interaction of MCap \& DJIA loading.

Loadings of $5 \times 5$ MCap/DJIA portfolios

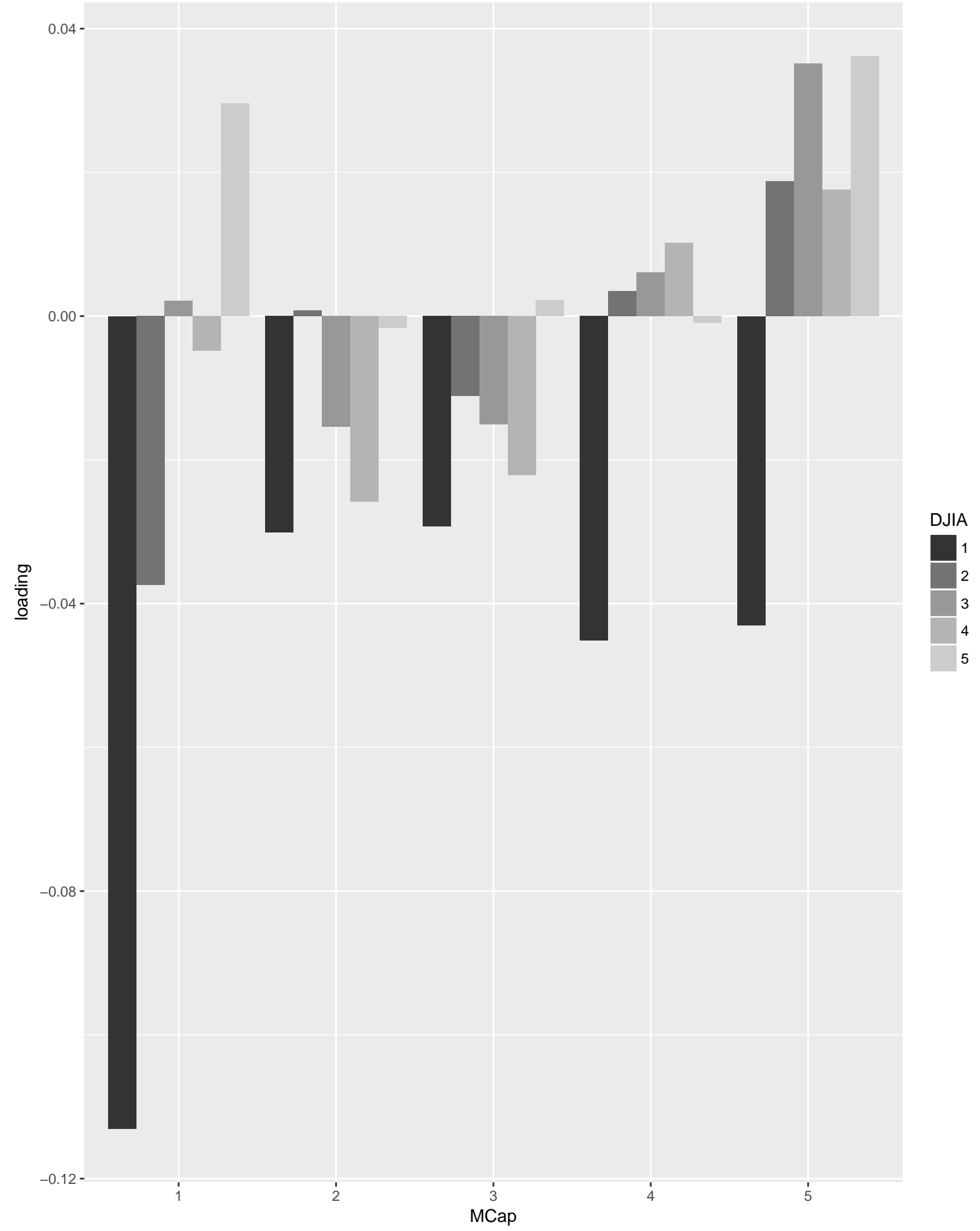

This figures shows the post-formation $\beta_{D J I A}$ of double-sorted MCap/DJIA sorted portfolios (equally-weighted). 
Figure 9. Jensen's alphas and average returns of equally-weighted investor sentiment-sorted portfolios $\left(\beta_{F E A R S}\right)(1: 2004-09: 2015)$.
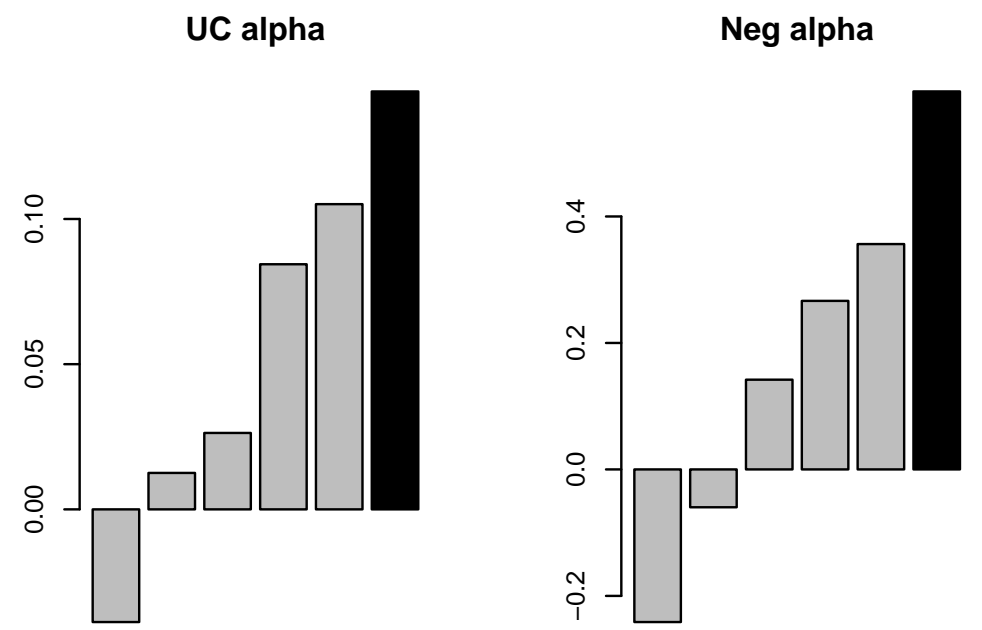

Pos alpha
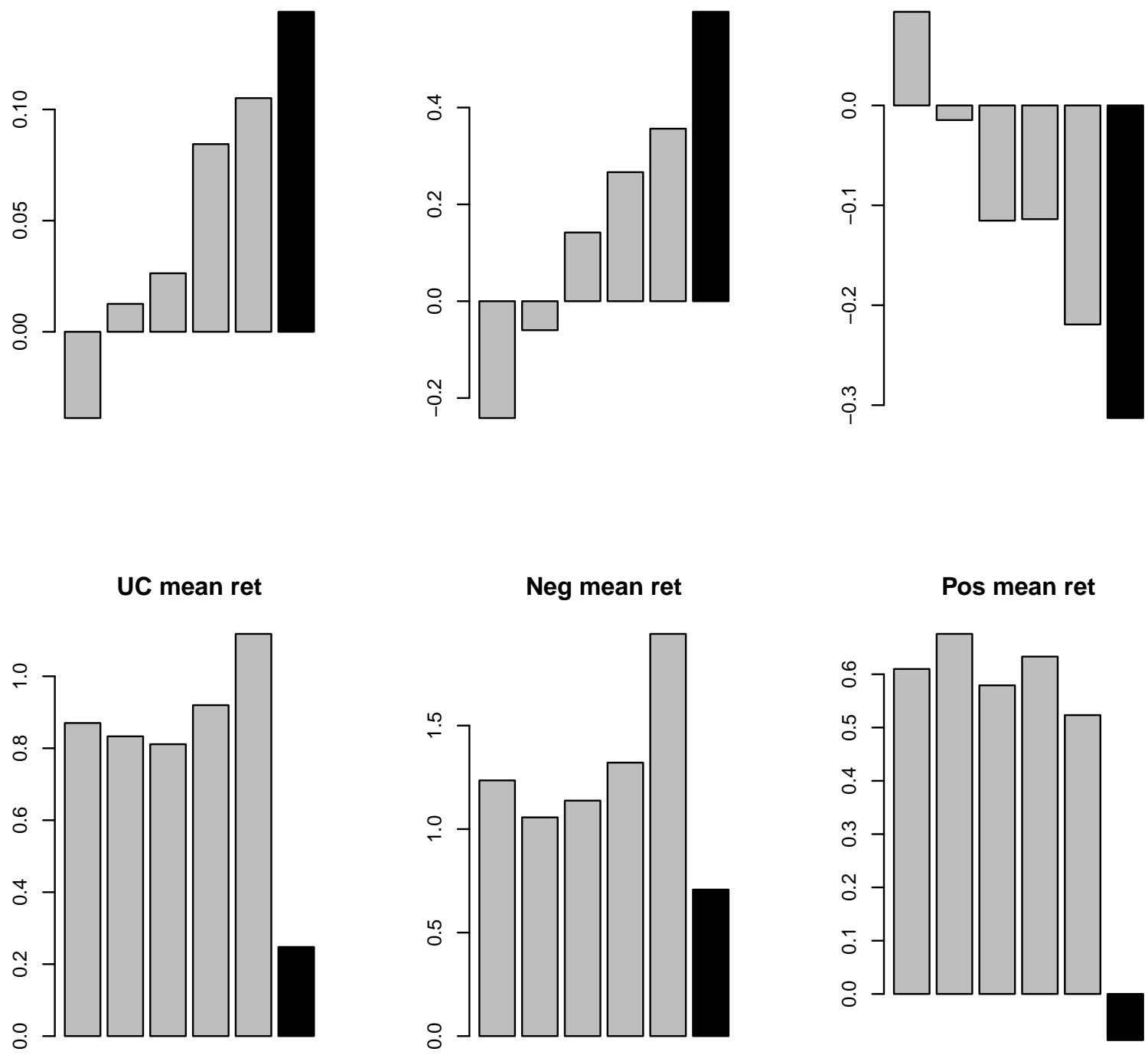

The barplots depict the performance of equally-weighted quintile portfolios sorted by prior month's investor sentiment beta $\left(\beta_{F E A R S}\right)$ (filled grey) as well as the difference between portfolios 5 and 1 (filled black). The top rows the monthly Jensen's alpha across all months as well as in negative and positive Baker-Wurgler (2006) sentiment months. The second row shows raw monthly returns (simple, not excess). 
Figure 10. Pre-and post-formation betas $\left(\beta_{F E A R S}\right)$ of equally-weighted quintile portfolios to investor sentiment and factor-mimicking portfolio (1:2004-09:2015).
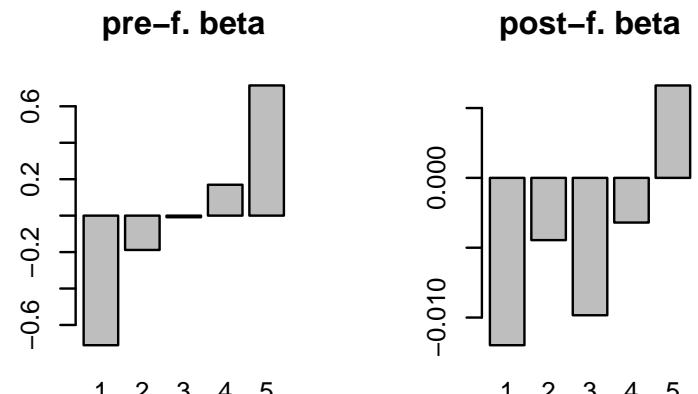

pre-f. FMP beta

post-f. FMP beta

$\begin{array}{lllll}1 & 2 & 3 & 4 & 5\end{array}$

$123 \quad 3 \quad 4 \quad 5$
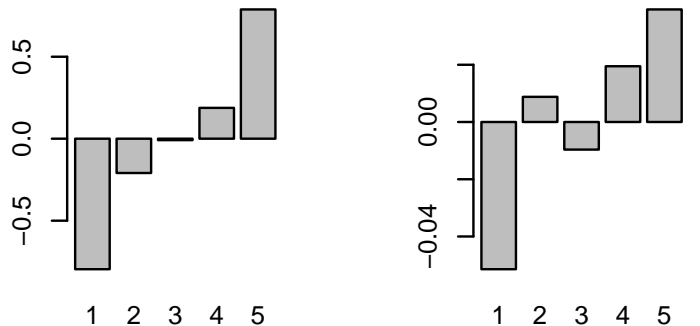

$\begin{array}{lllll}1 & 2 & 3 & 4 & 5\end{array}$

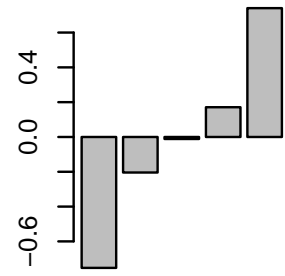

$\begin{array}{lllll}1 & 2 & 3 & 4 & 5\end{array}$

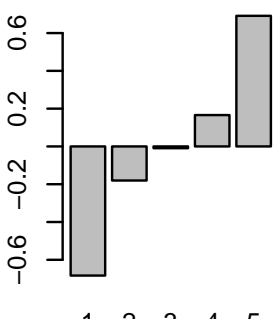

$\begin{array}{lllll}1 & 2 & 3 & 4 & 5\end{array}$
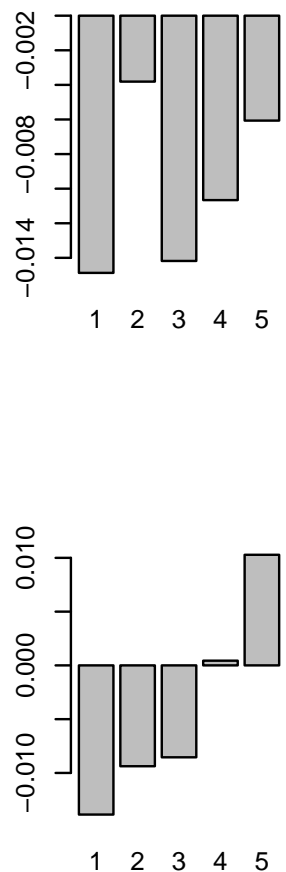
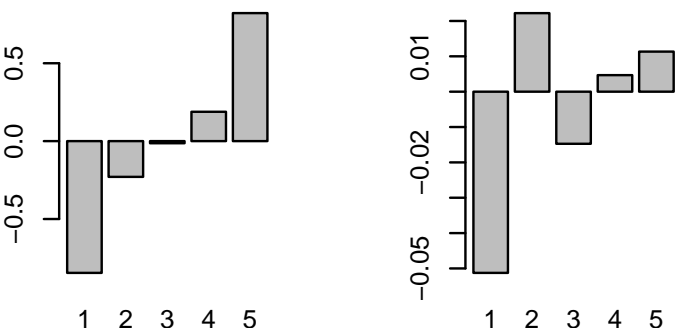

The barplots depicts the pre- and post-formation betas to investor sentiment (first and second columns) and its factor-mimicking portfolio (third and fourth columns) of equally-weighted quintile portfolios sorted by prior month's beta $\left(\beta_{F E A R S}\right)$. The first row shows the pre-and post-formation betas across all months, while the second (third) row shows the post-formation betas in negative (positive) Baker-Wurgler sentiment months. 
Figure 11. Jensen's alphas and average returns of value-weighted investor sentiment-sorted portfolios $\left(\beta_{F E A R S}\right)(1: 2004-09: 2015)$.

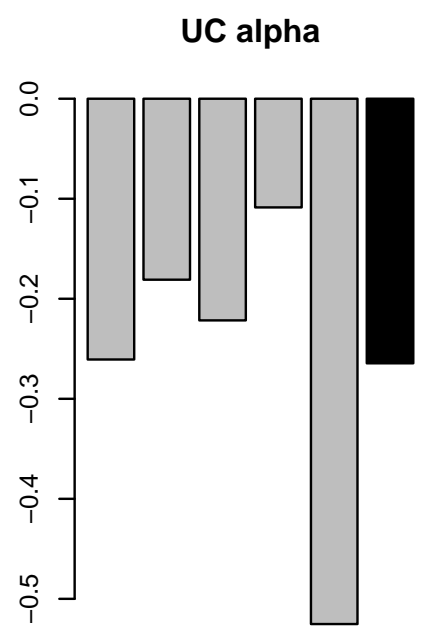

UC mean ret

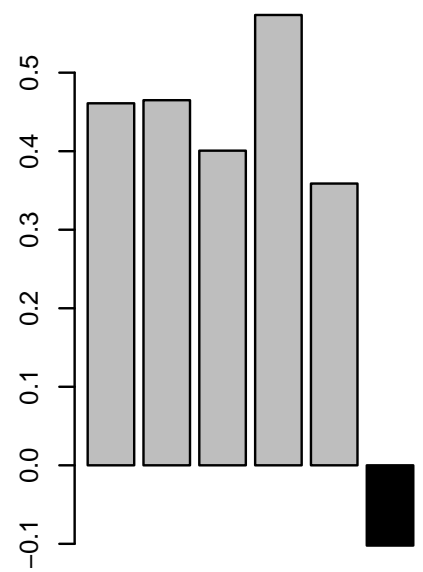

Neg alpha

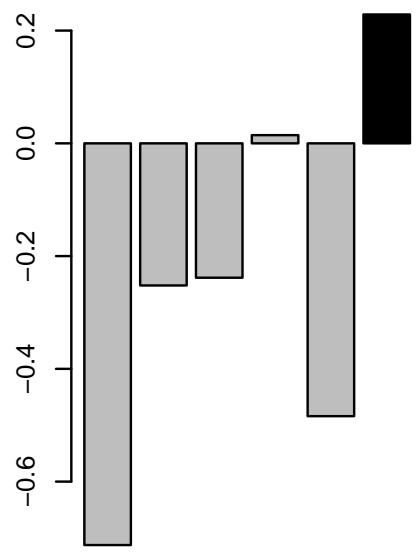

Neg mean ret

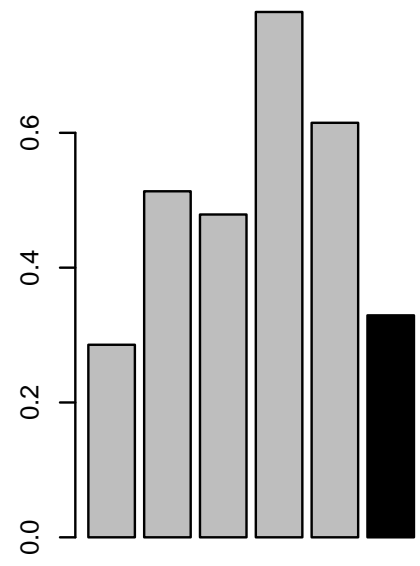

Pos alpha

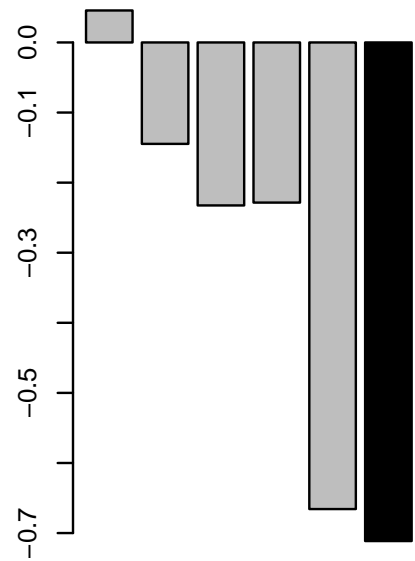

Pos mean ret

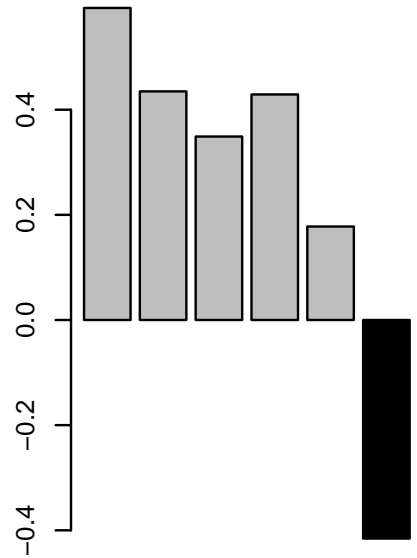

The barplots depict the performance of value-weighted quintile portfolios sorted by prior month's investor sentiment beta $\left(\beta_{F E A R S}\right)$ (filled grey) as well as the difference between portfolios 5 and 1 (filled black). The top rows the monthly Jensen's alpha across all months as well as in negative and positive Baker-Wurgler (2006) sentiment months. The second row shows raw monthly returns (simple, not excess). 
Figure 12. Pre-and post-formation betas $\left(\beta_{F E A R S}\right)$ of value-weighted quintile portfolios to investor sentiment and factor-mimicking portfolio (1:2004-09:2015).
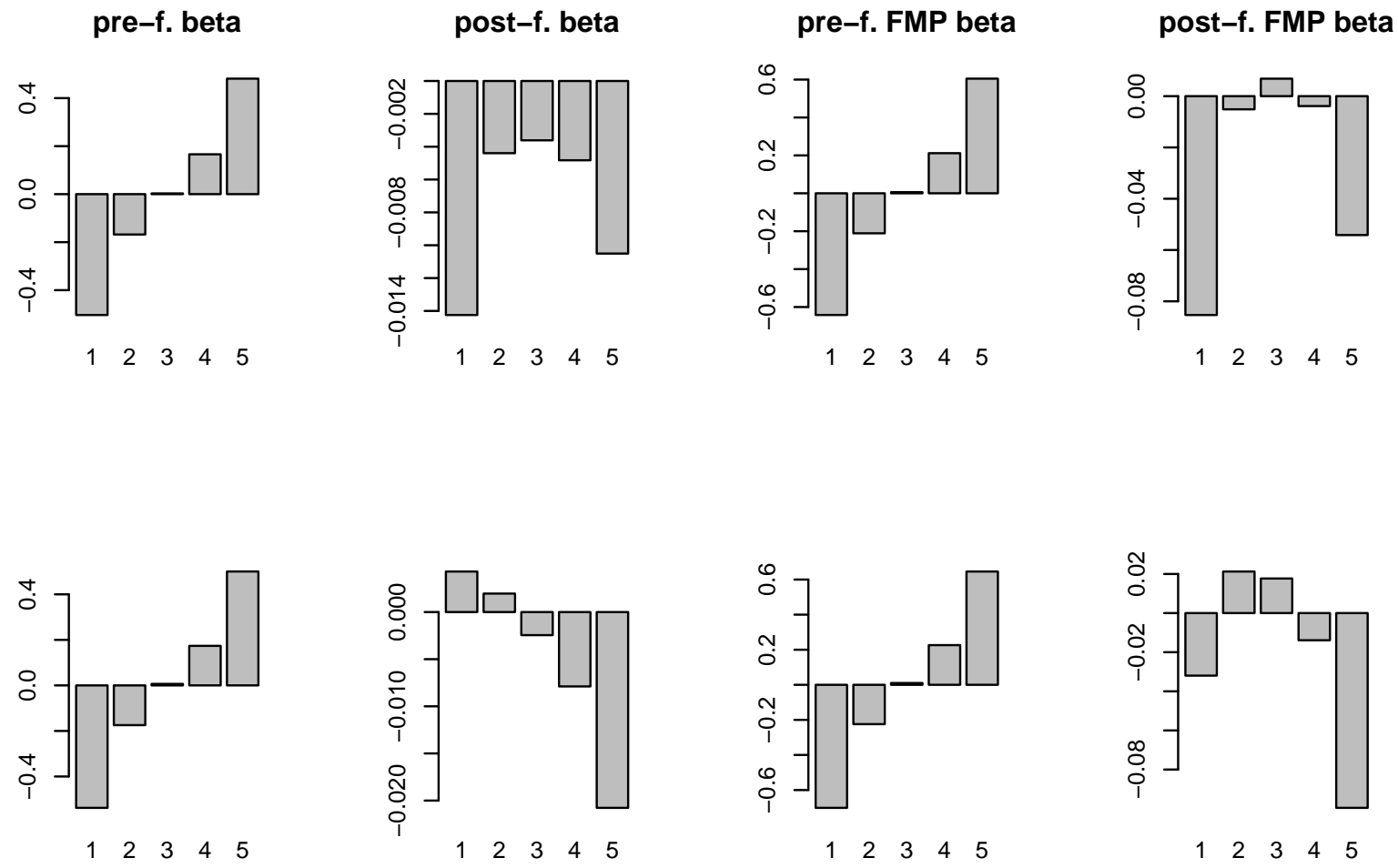

$\begin{array}{lllll}1 & 2 & 3 & 4 & 5\end{array}$
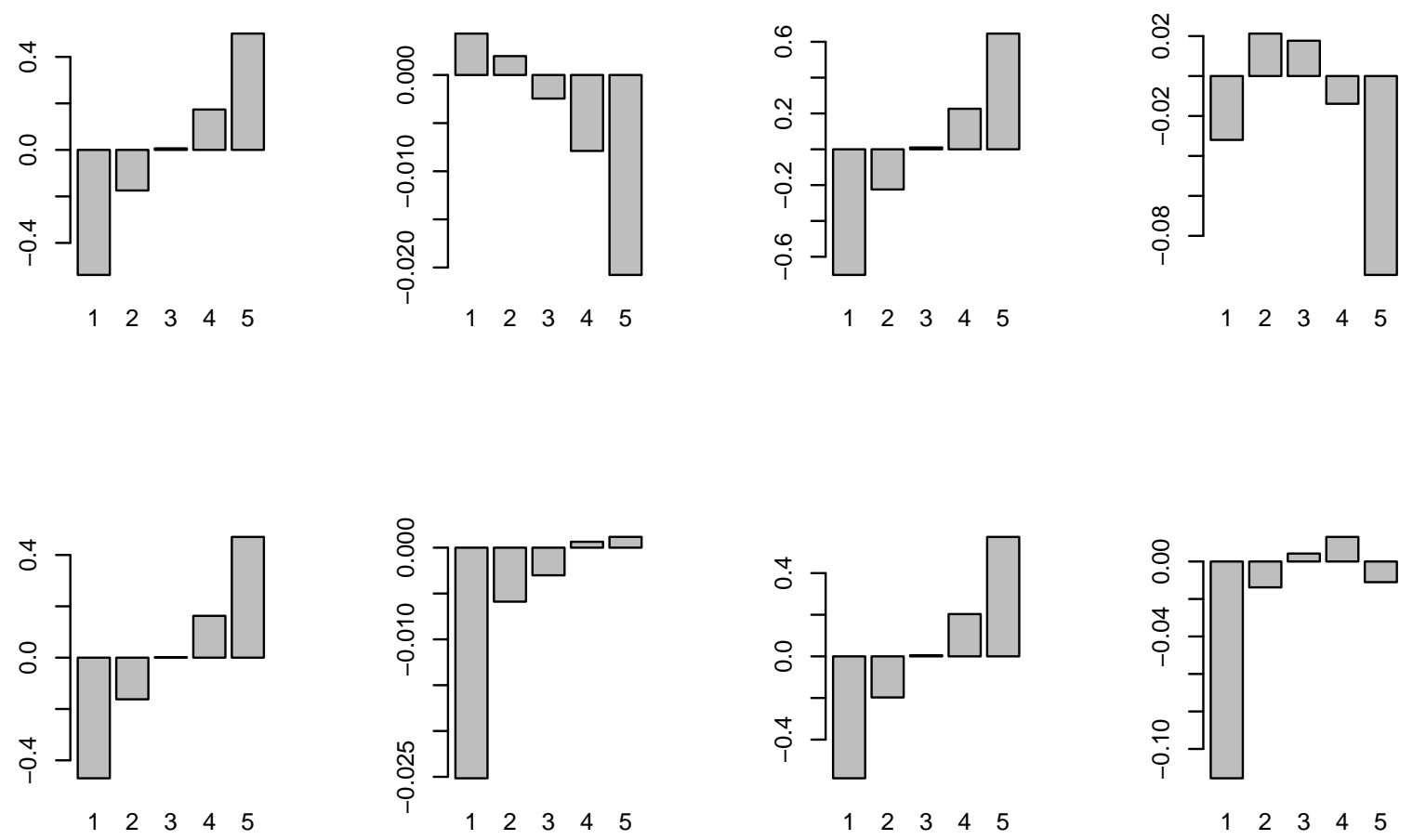

The barplots depicts the pre- and post-formation betas to investor sentiment (first and second columns) and its factor-mimicking portfolio (third and fourth columns) of value-weighted quintile portfolios sorted by prior month's beta $\left(\beta_{F E A R S}\right)$. The first row shows the pre-and post-formation betas across all months, while the second (third) row shows the post-formation betas in negative (positive) Baker-Wurgler sentiment months. 
Figure 13. Baker-Wurgler (2006) characteristics of investor attention-sorted $\left(\beta_{D J I A}\right)$ quintile portfolios through time (1:2004-09:2015) (1/2).
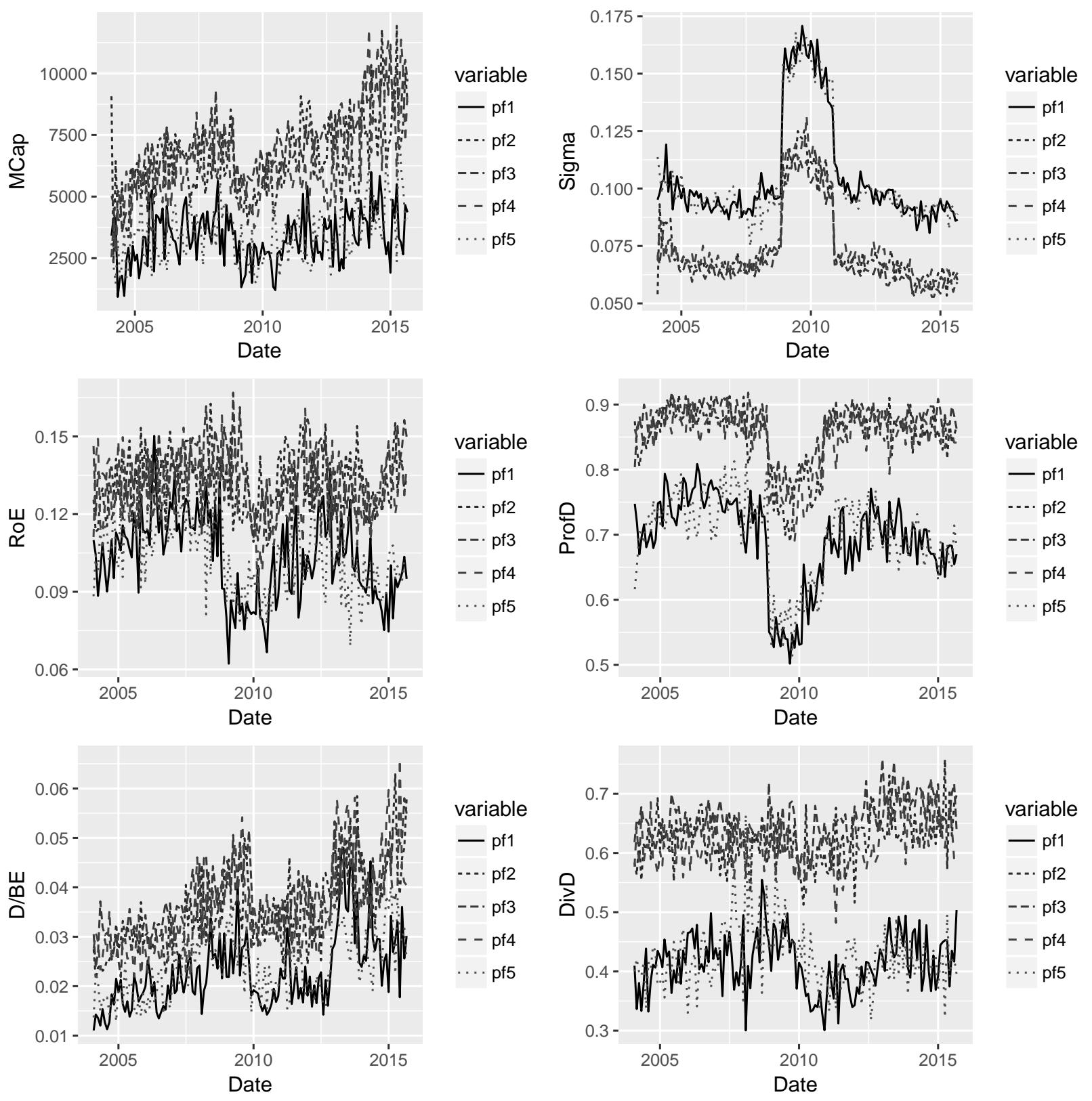

The figures depict average company characteristics relating to size, profitability, dividends, asset tangibility as well as growth opportunities of the quintile portfolios sorted by investor attention beta $\left(\beta_{D J I A}\right)$ month by month. The characteristics are all associated with difficulty to value and arbitrage stocks and are presented in Baker and Wurgler (2006). The market cap (MCap) is shown in billions of USD. Sigma $\left(\sigma_{i}\right)$ refers to the average monthly idiosyncratic volatility of quintile stocks. Further shown are quintile averages of return-on-equity $(R o E)$, the proportion of profitable companies within a quintile portfolio (Prof $D)$, the average dividends-to-book equity $(D / B E)$ as well as the average of a dividend-payer dummy (DivD). The exact definitions are discussed in the chapter on Data and are mostly as in Baker and Wurgler (2006, p.1653ff.). 
Figure 14. Baker-Wurgler (2006) characteristics of investor attention-sorted $\left(\beta_{D J I A}\right)$ quintile portfolios through time (1:2004-09:2015) (2/2).
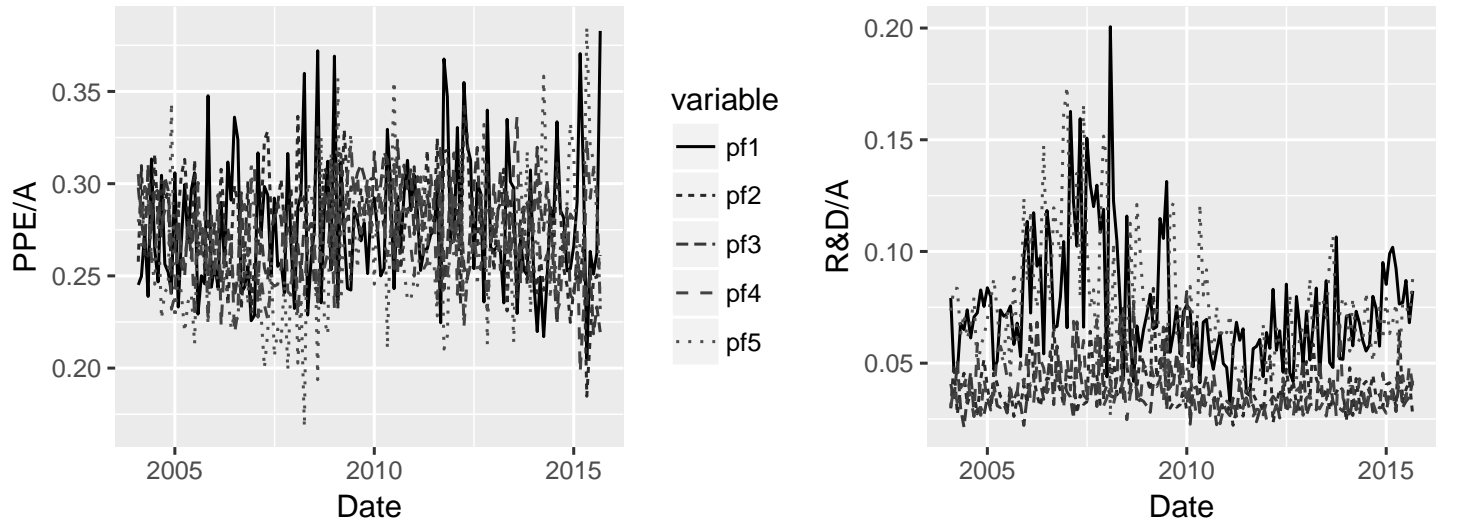

variable
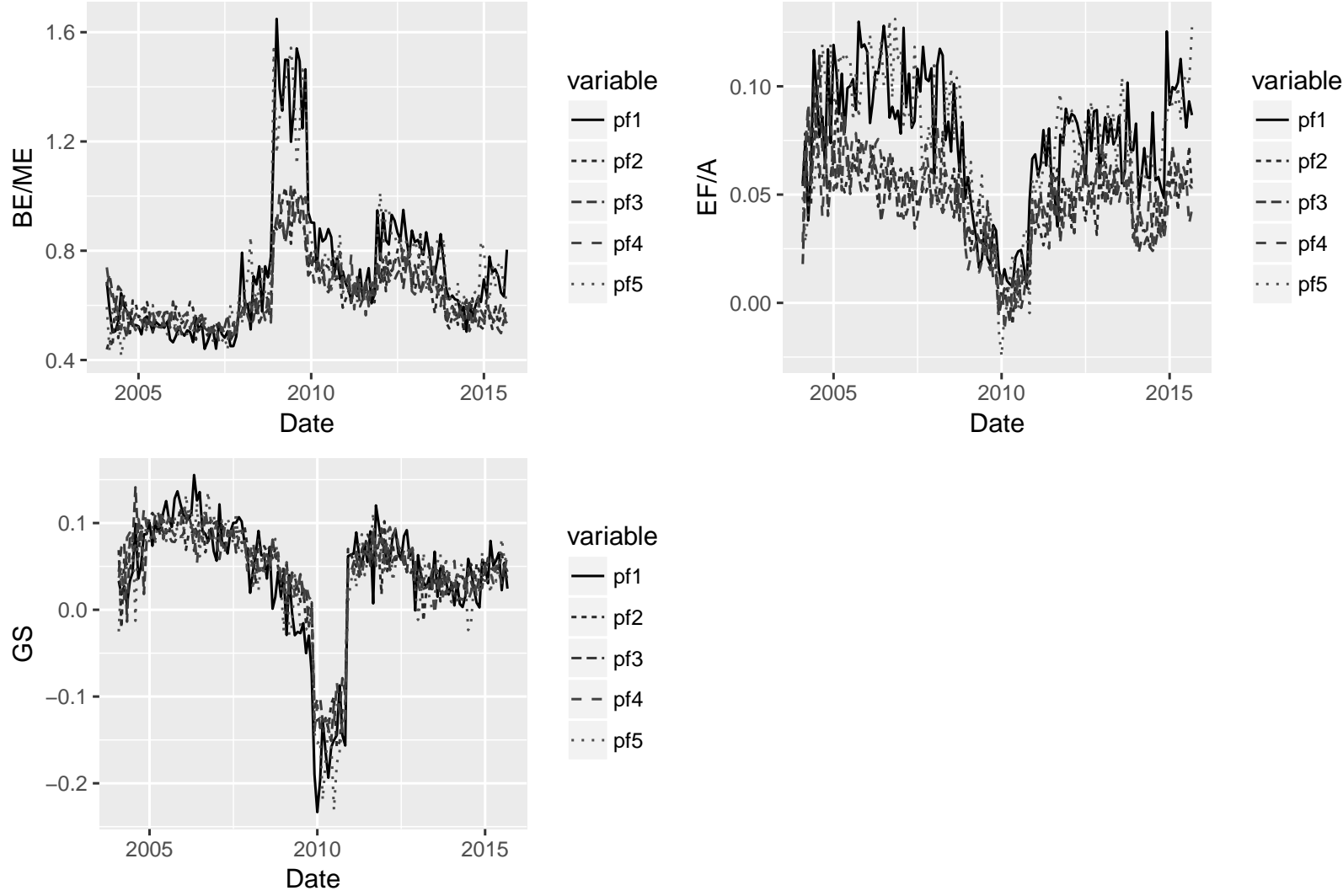

The figures depict average company characteristics relating to size, profitability, dividends, asset tangibility as well as growth opportunities of the quintile portfolios sorted by investor attention beta $\left(\beta_{D J I A}\right)$ month by month. The characteristics are all associated with difficulty to value and arbitrage stocks and are presented in Baker and Wurgler (2006). Shown are average property, plant and equipment over assets $(P P E / A)$, research and development expenses over assets $(R \& D / A)$, book-to-market equity $(B E / M E)$, external finance over assets $(E F / A)$ and lastly, sales growth in the last year relative to the year before $(G S)$. The exact definitions are discussed in the chapter on Data and are mostly as in Baker and Wurgler (2006, p.1653ff.). 
Figure 15. Double-sorted portfolio alphas: MCap/Sigma and DJIA (1:2004-09:2015).

\section{Alphas of $5 \times 5$ MCap/DJIA portfolios}

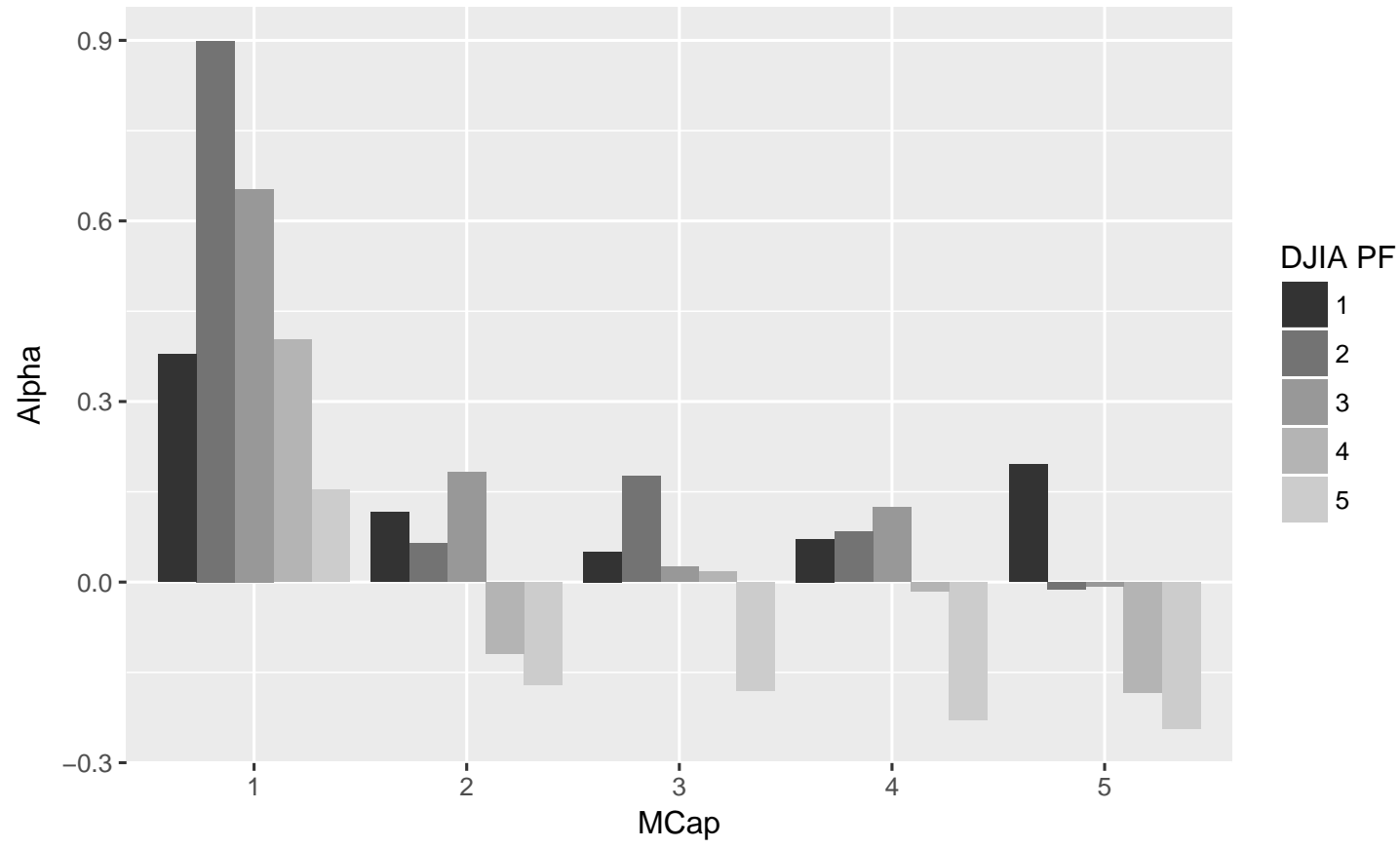

Alphas of $5 \times 5$ Sigma/DJIA portfolios

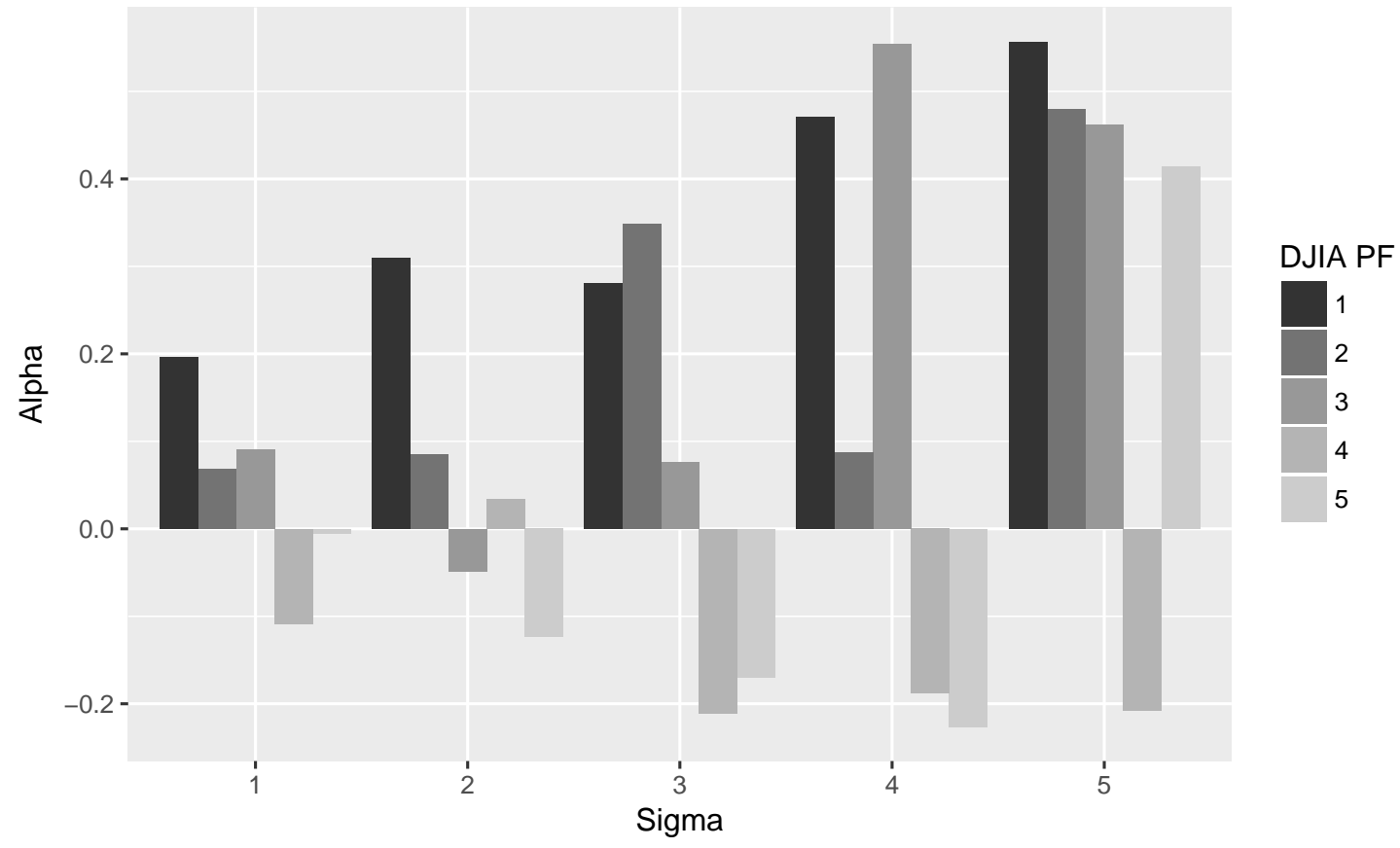

This figure shows monthly Jensen's alphas of (equally-weighted) double-sorted portfolios. In the upper bar chart I first sort companies into five portfolios by their previous month's market capitalization (MCap). Within each MCap portfolio, I then allocate them into five portfolios based on investor attention beta $\left(\beta_{D J I A}\right)$. In the lower bar chart, the first sort is by previous month's idiosyncratic volatility $\left(\sigma_{i}\right)$. The Jensen's alpha are based on daily data controlling for the Fama-French (2015) five-factor model, momentum, liquidity (Pastor-Stambaugh) and in the upper bar chart idiosyncratic volatility. 


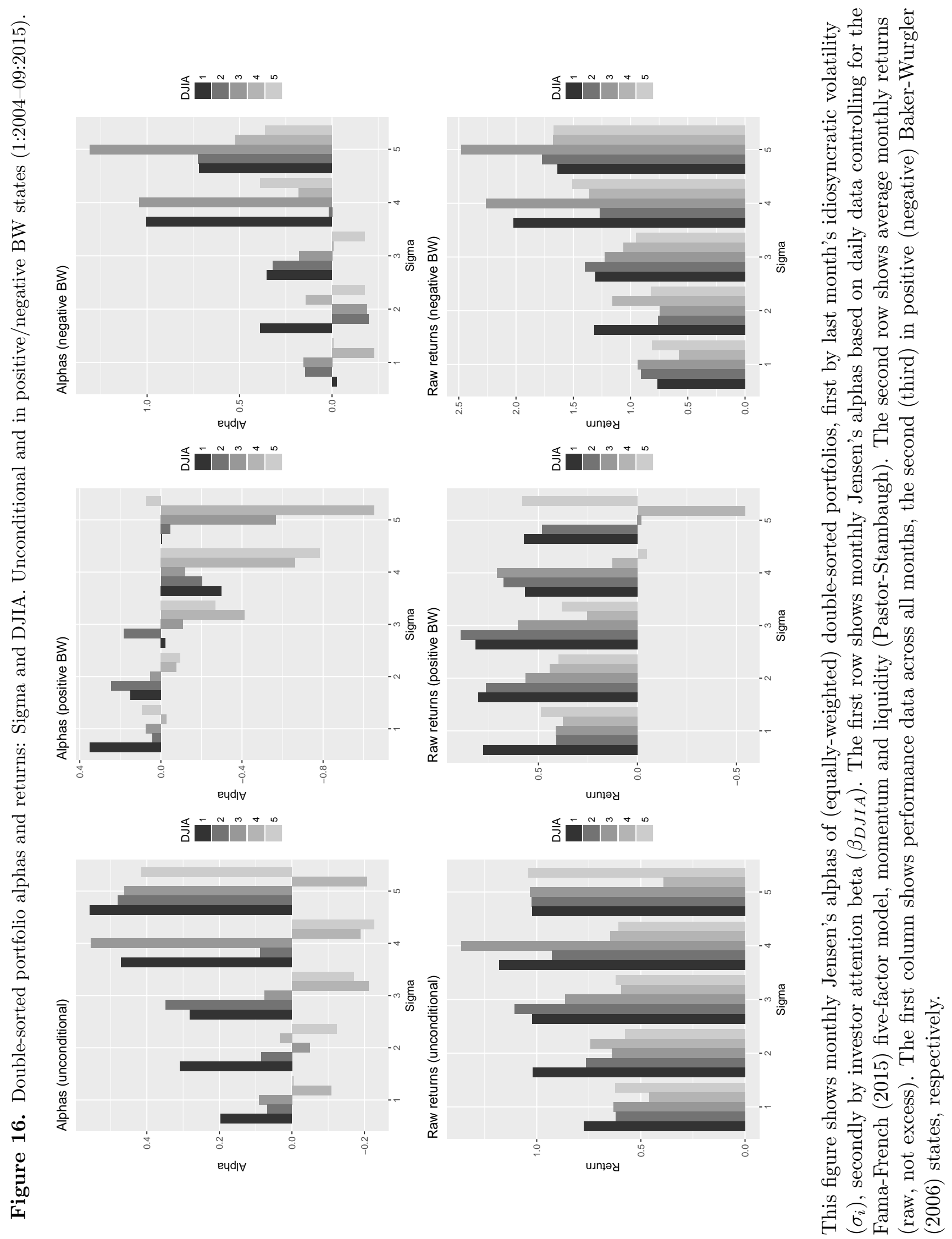




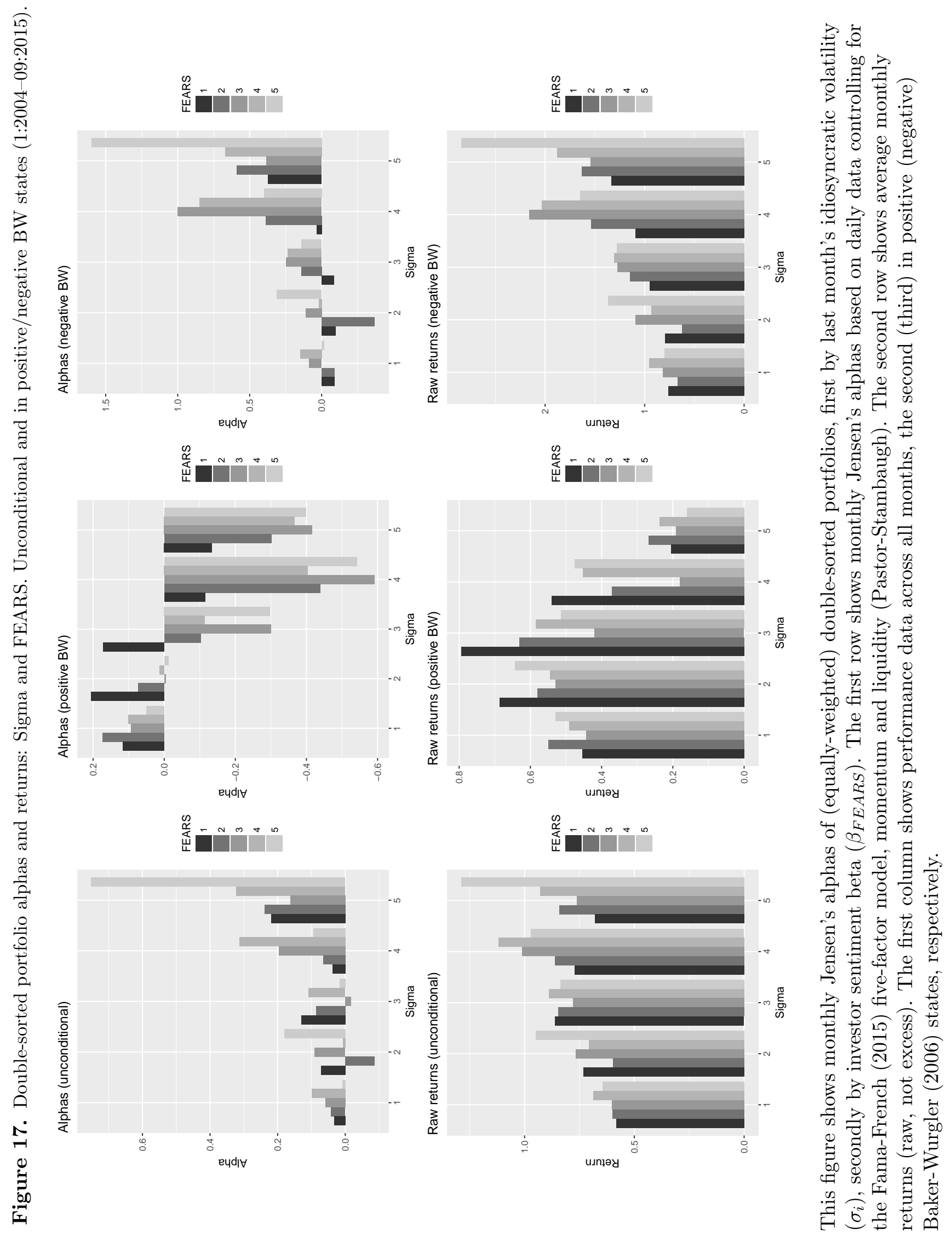



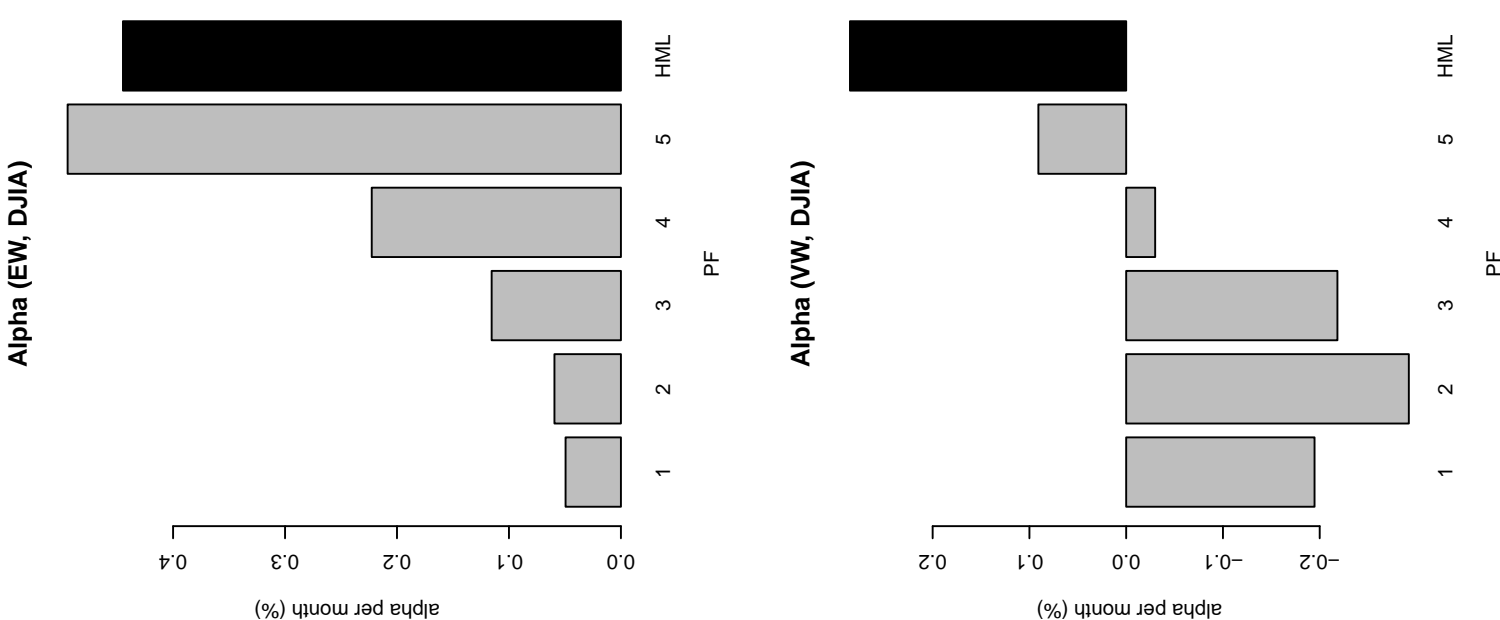

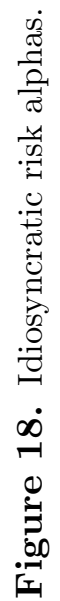
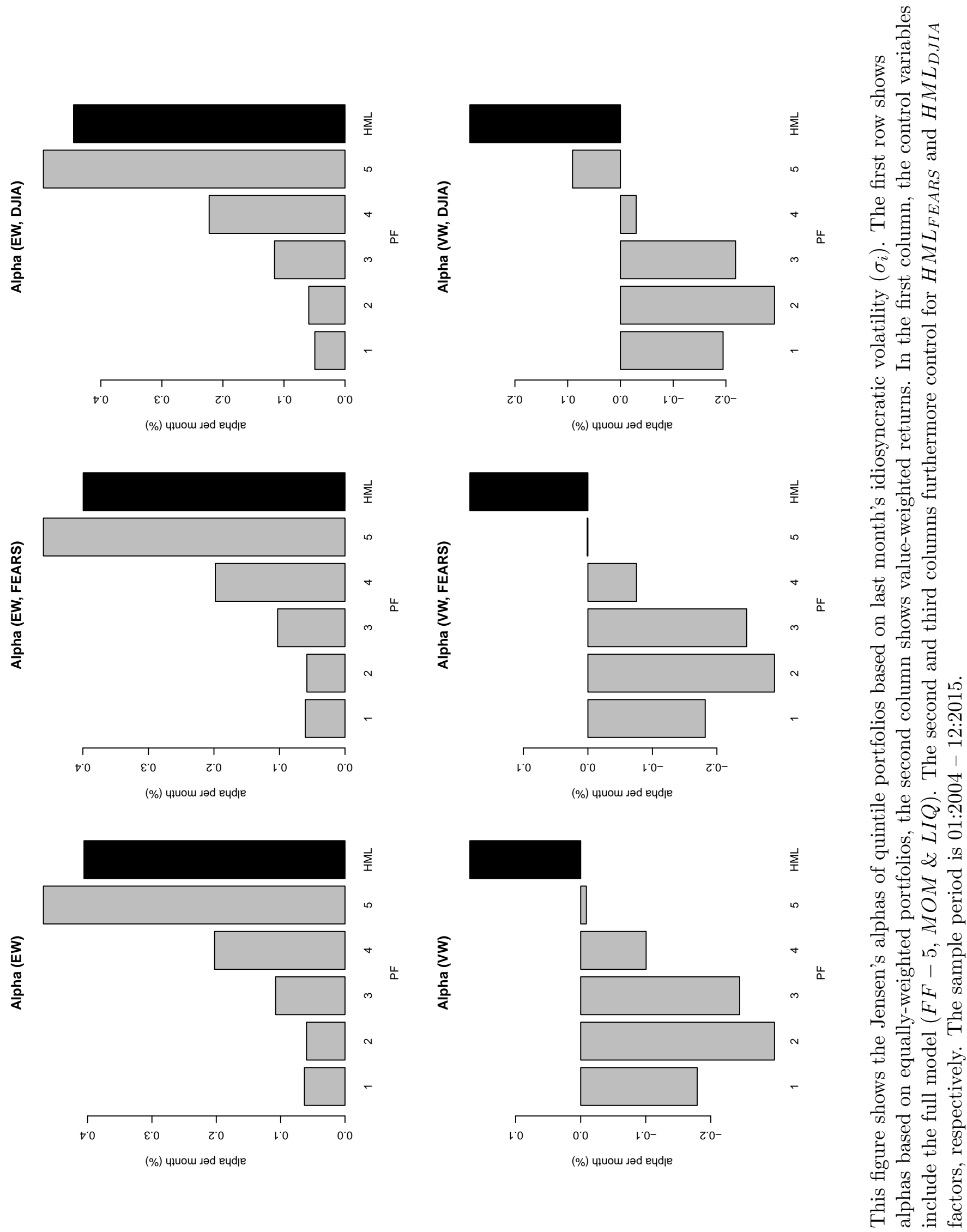
Figure 19. Idiosyncratic risk Sigma: cumulative returns through time.
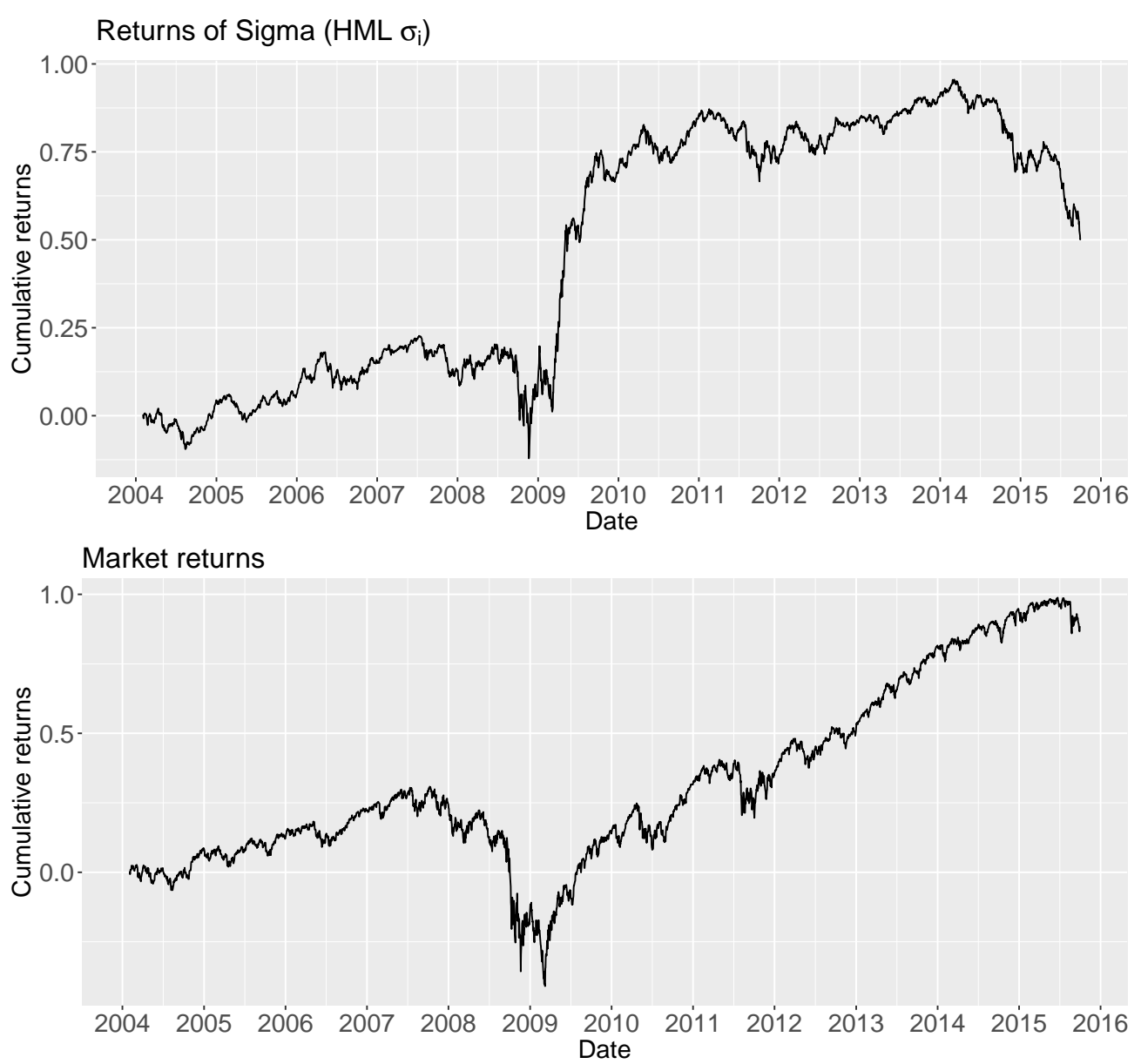

Baker-Wurgler sentiment index

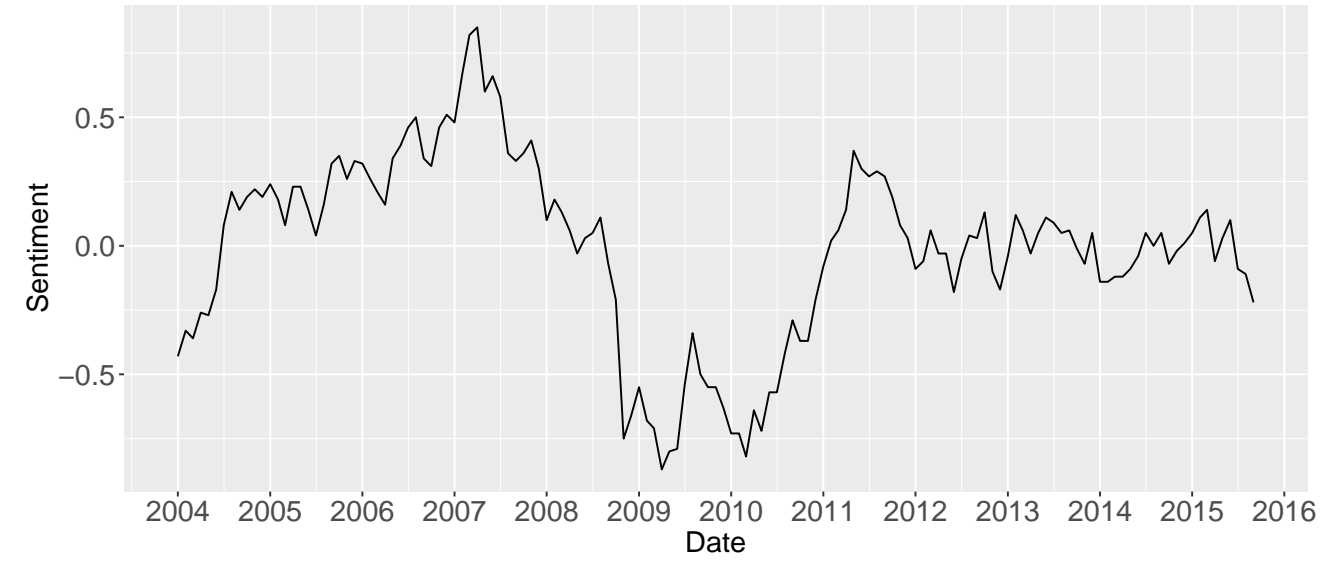

This figure shows the cumulative excess return of the HML portfolio Sigma based on stocks' last month's idiosyncratic volatility $\left(\sigma_{i}\right)$ (top row). Furthermore, it shows the cumulative market excess returns (Fama-French Mkt.RF factor) (second row) as well as the Baker-Wurgler sentiment index (Baker and Wurgler (2006)). 
Figure 20. Different investor attention proxies / Google search queries through time.
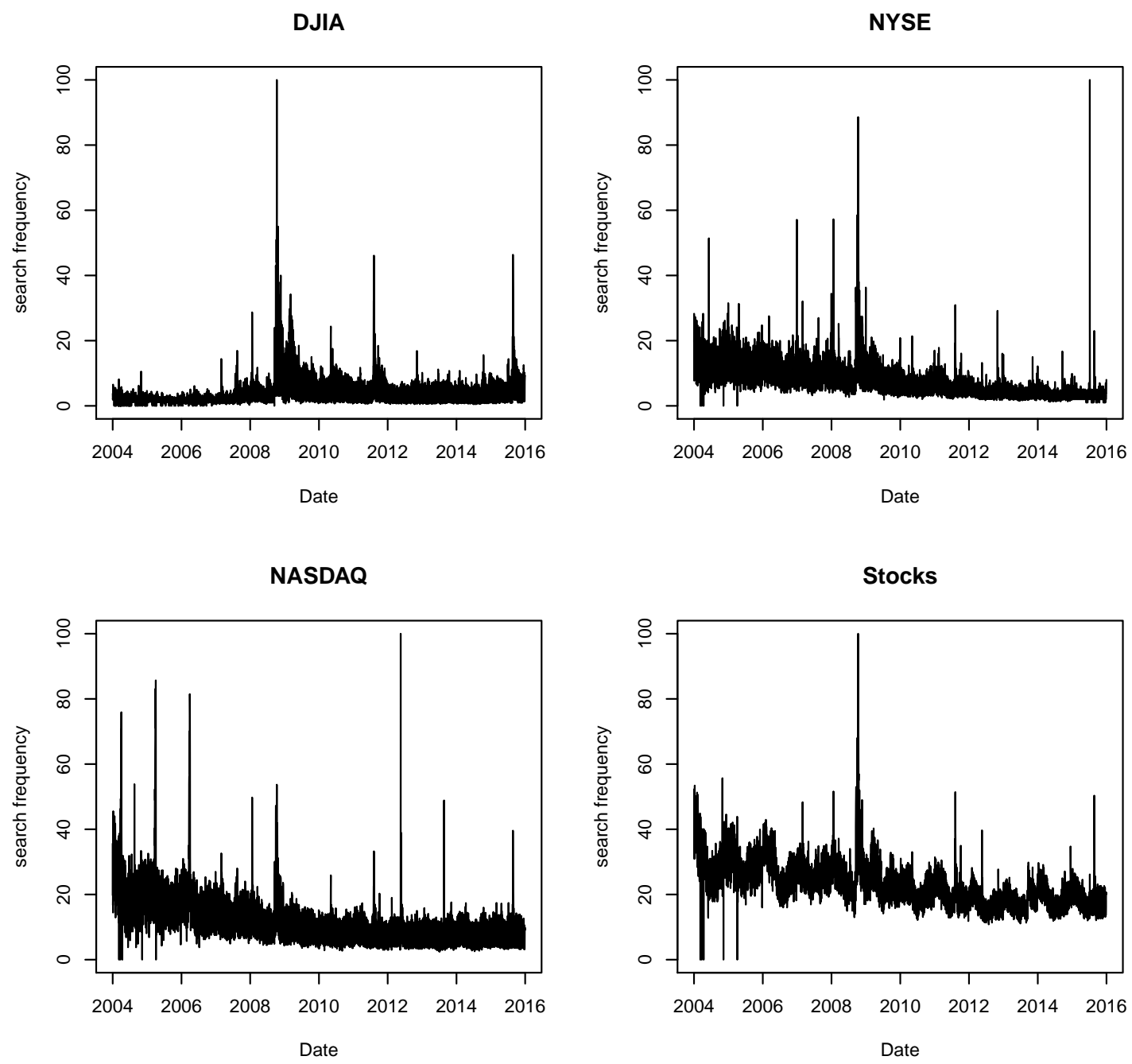

FTSE

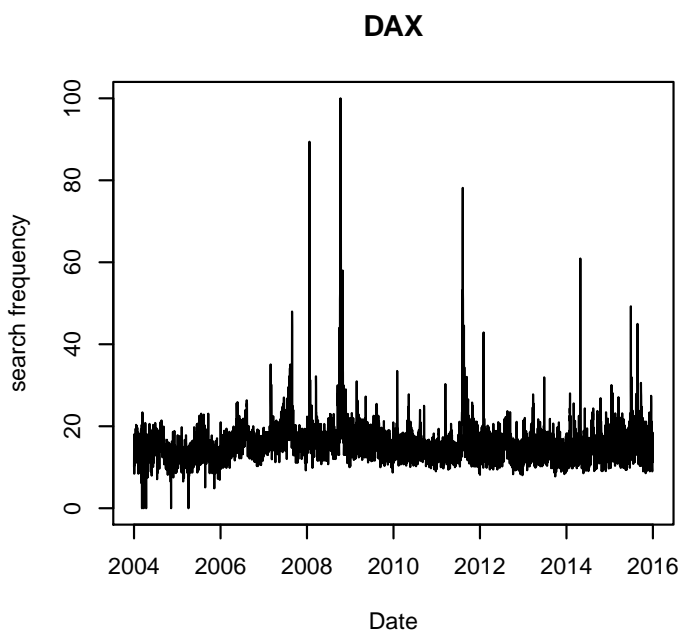

This figure shows the daily search queries in different stock investment-related search queries in Google. The sample period is 01:2004 - 12:2015. 


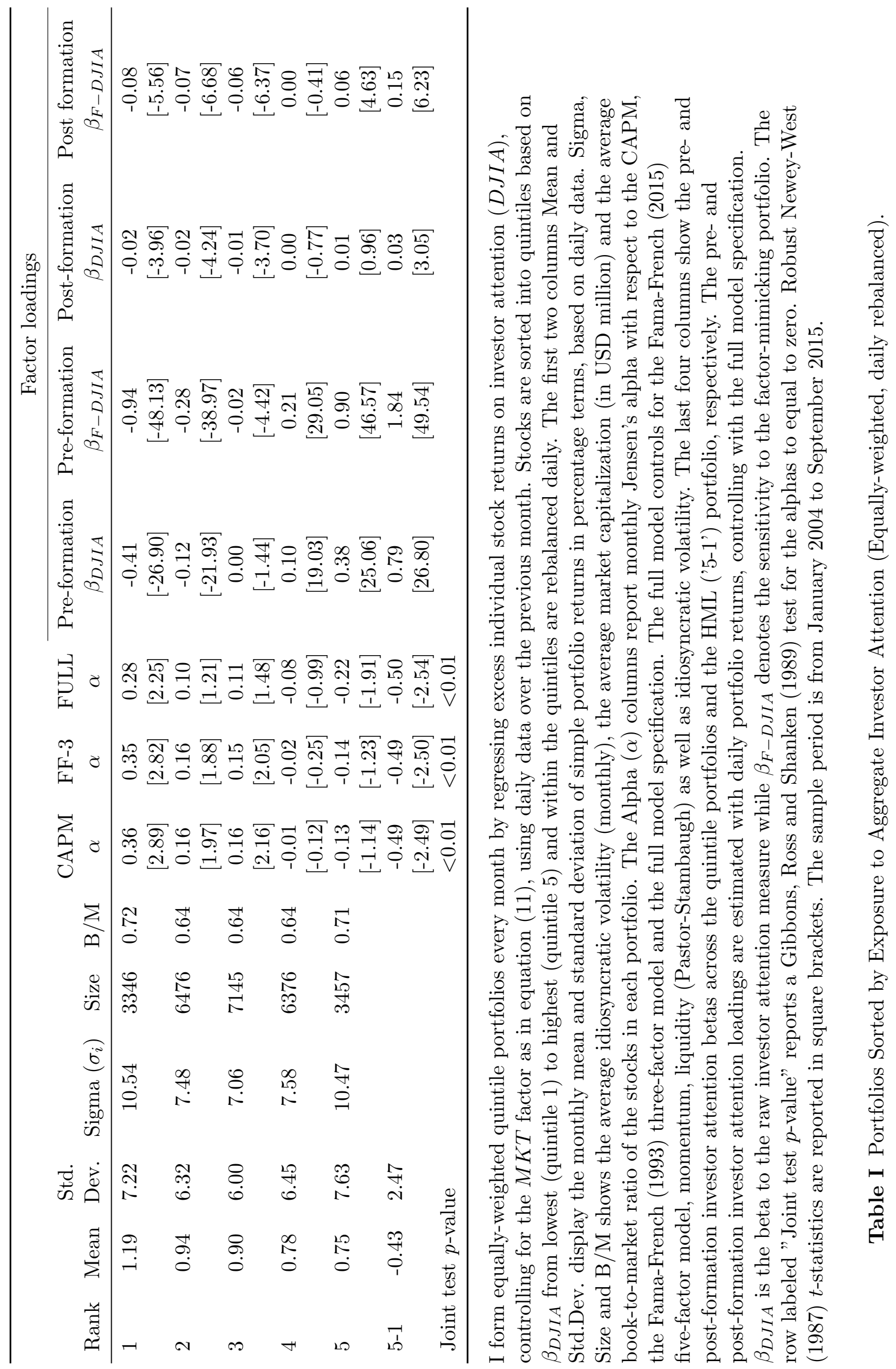




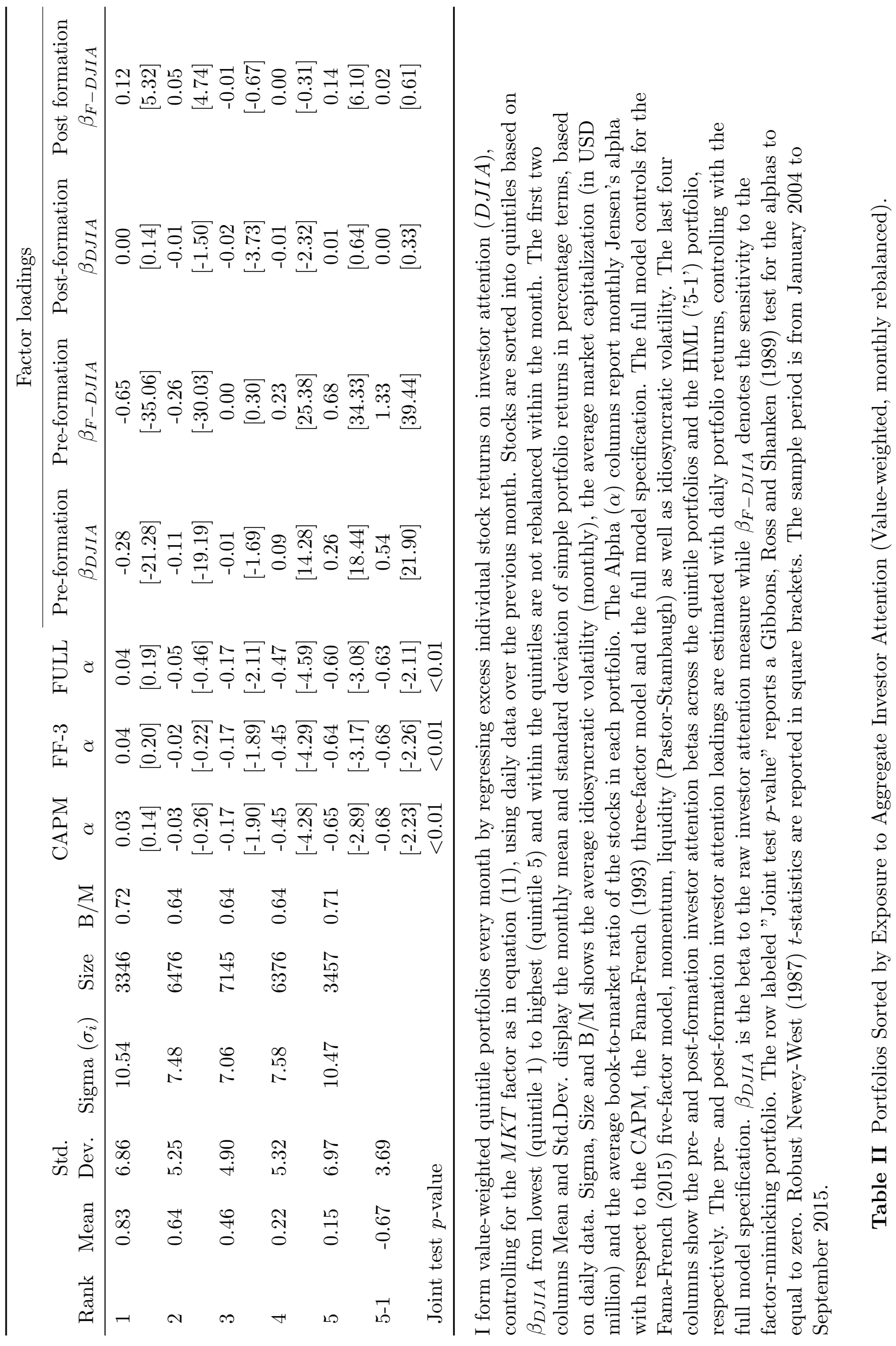




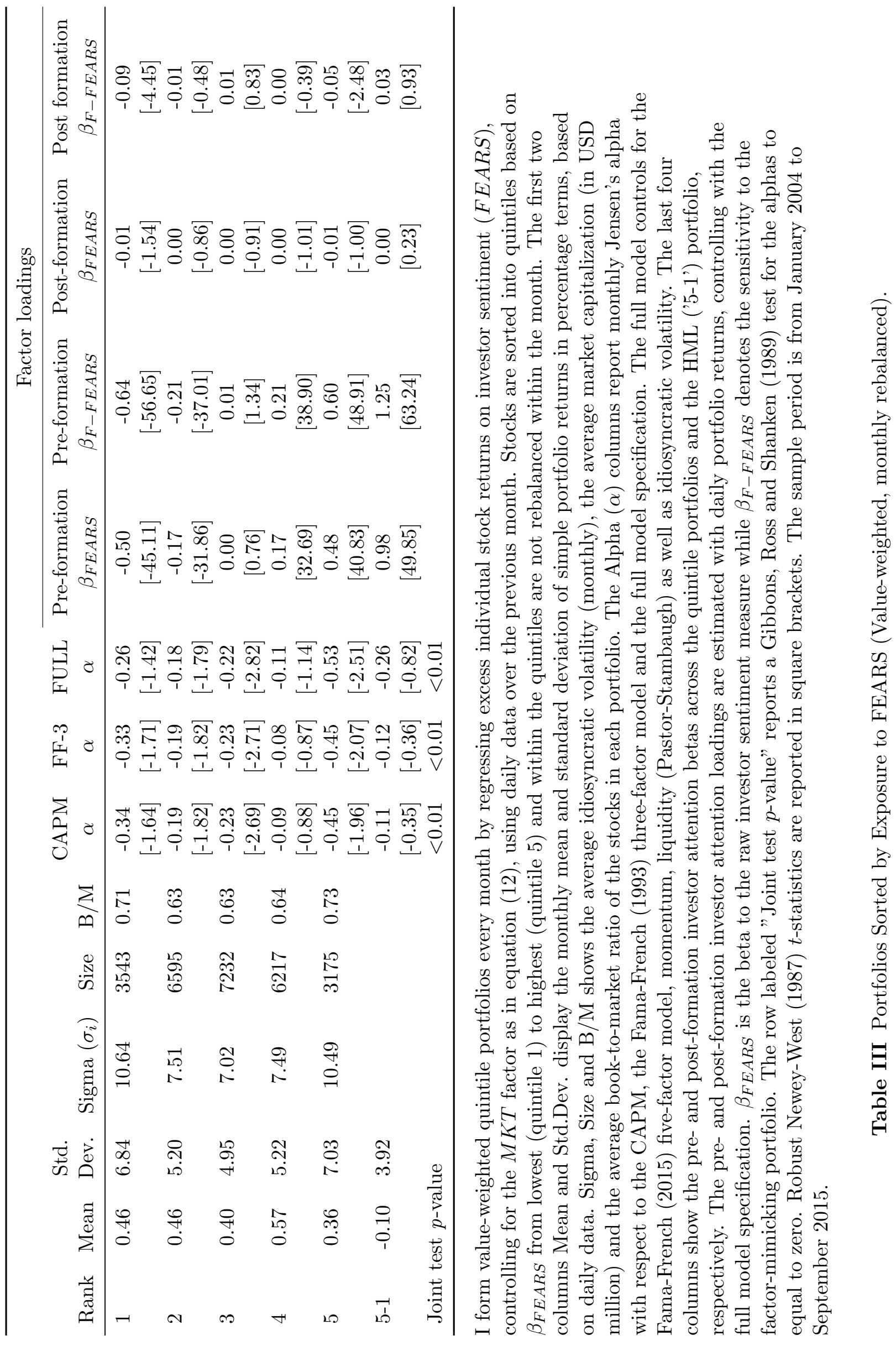




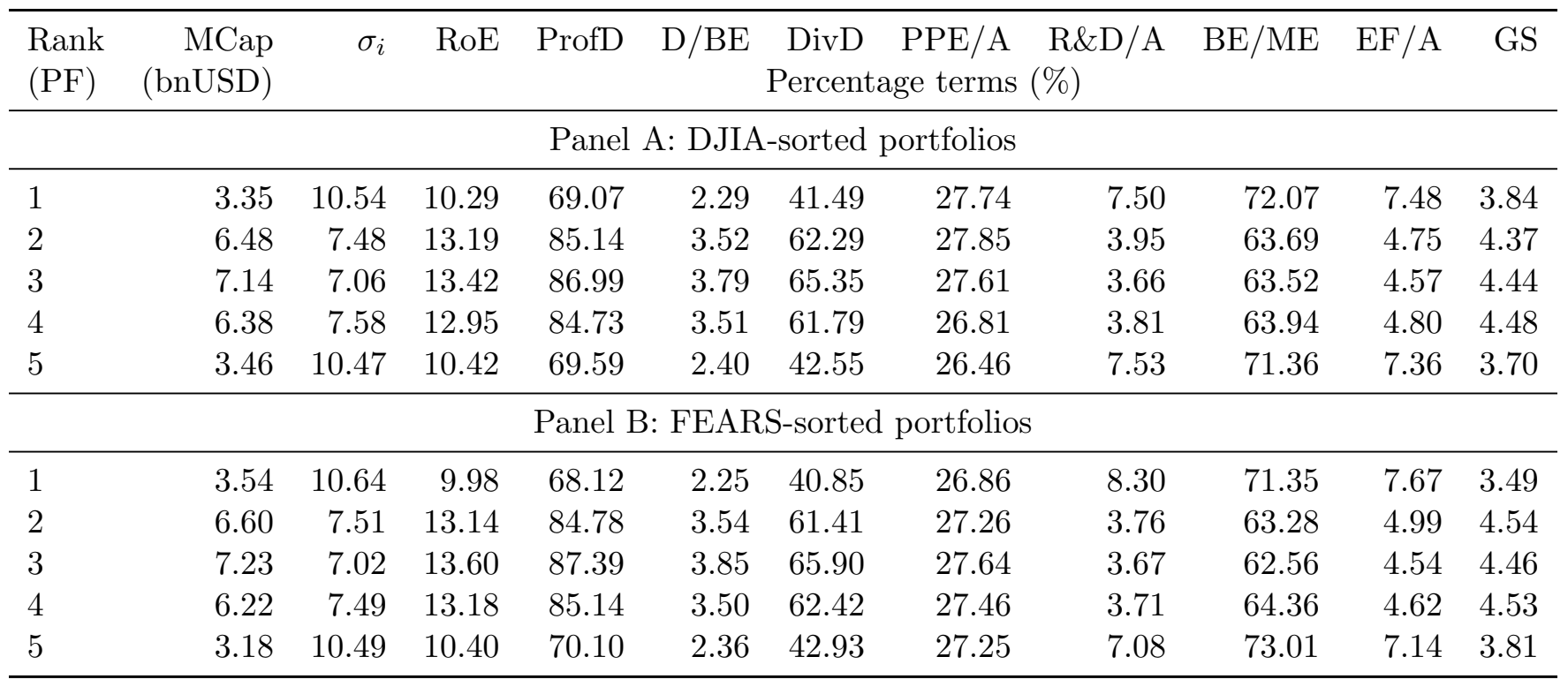

The table shows average company characteristics relating to size, profitability, dividends, asset tangibility as well as growth opportunities within the formed quintile portfolios sorted by Investor Sentiment- and Investor Attention-betas. The characteristics are all associated with difficulty to value and arbitrage stocks and are presented in Baker and Wurgler (2006). To arrive at a given quintile characteristc value, I first take the cross-sectional average across portfolio companies in a given month and subsequently take the time-series average. The market cap (MCap) is shown in billions of USD and is taken from the previous month. $\sigma_{i}$ refers to the average (monthly) idiosyncratic volatility of quintile stocks across the last 12 months. Further shown are quintile averages of return-on-equity $(R o E)$; a profitability dummy (Prof $D)$; dividends-to-book equity $(D B E)$; a dividend-payer dummy $(D i v D)$; property, plant and equipment over assets $(P P E / A)$; research and development expenses over assets $(R \& D / A)$; book-to-market equity $(B E / M E)$; external finance over assets $(E F / A)$; and lastly, sales growth in the last year relative to the year before $(G S)$. The exact definitions are discussed in the chapter on Data and are mostly as in Baker and Wurgler (2006, p.1653ff.). The sample period is from January 2004 to September 2015.

Table IV FEARS- \& DJIA- sorted portfolios: Average company characteristics as in Baker and Wurgler (2006). 


\begin{tabular}{|c|c|c|c|c|c|c|c|c|c|c|}
\hline & $F E A R S$ & $D J I A$ & Mkt.RF & SMB & HML & RMW & CMA & MOM & PS & Sigma \\
\hline$F E A R S$ & & -0.03 & -0.04 & -0.02 & -0.02 & 0.10 & 0.02 & 0.05 & 0.01 & -0.09 \\
\hline$D J I A$ & & & -0.08 & 0.00 & -0.04 & 0.04 & 0.00 & -0.01 & -0.17 & 0.01 \\
\hline Mkt.RF & & & & 0.30 & 0.37 & -0.38 & -0.11 & -0.35 & 0.06 & 0.54 \\
\hline SMB & & & & & 0.08 & -0.34 & 0.03 & -0.05 & -0.04 & 0.48 \\
\hline HML & & & & & & -0.34 & 0.17 & -0.52 & -0.28 & 0.42 \\
\hline RMW & & & & & & & -0.14 & 0.23 & 0.02 & -0.46 \\
\hline CMA & & & & & & & & 0.11 & -0.24 & -0.19 \\
\hline MOM & & & & & & & & & 0.35 & -0.49 \\
\hline PS & & & & & & & & & & -0.10 \\
\hline Sigma & & & & & & & & & & \\
\hline
\end{tabular}

The table shows the Pearson correlation coefficents between our investor sentiment (FEARS) and investor attention $(D J I A)$ proxies as well as all employed control factors based on daily data. Mkt.RF, SMB, HML, RMW, CMA and MOM denote the five Fama-French factors (2015) as well as momentum. They are all obtained from Kenneth French's website. $L I Q$ is the daily factor-mimicking portfolio on the Pastor-Stambaugh excess returns, as explained in section II.A. It is a proxy for a daily liquidity factor. Lastly, Sigma is a proxy for the daily excess returns on stocks with high idiosyncratic volatility less the returns on stocks with low idiosyncratic volatility. Idiosyncratic volatility is defined as in Ang et al. (2006) as the standard deviation of the remainder when regressing a stock's excess returns on the three Fama-French factors (equation (10)). Each month, I form a portfolio of the $30 \%$ most/least idiosyncratically volatile stocks in the past month to calculate daily high-minus-low excess returns based on these portfolios. The correlation coefficients are computed over the sample period January 2004 to September 2015.

Table V Factor correlations (daily). 


\begin{tabular}{lllllll}
\hline & \multicolumn{5}{c}{ Ranking on $\beta_{D J I A}$} \\
\cline { 2 - 5 } & 1 Low & 2 & 3 & 4 & 5 High & $5-1$ \\
\hline Controlling for MCap & 0.16 & 0.24 & 0.20 & 0.02 & -0.13 & -0.30 \\
& {$[1.26]$} & {$[2.71$} & {$[2.33]$} & {$[0.24]$} & {$[-1.14]$} & {$[-1.50]$} \\
Controlling for $\sigma_{i}$ & 0.36 & 0.21 & 0.23 & -0.14 & -0.02 & -0.39 \\
& {$[2.63]$} & {$[2.08]$} & {$[2.21]$} & {$[-1.33]$} & {$[-0.18]$} & {$[-2.10]$} \\
Controlling for RoE & 0.27 & 0.14 & 0.16 & -0.04 & -0.06 & -0.34 \\
& {$[2.03]$} & {$[1.48]$} & {$[1.88]$} & {$[-0.48]$} & {$[-0.50]$} & {$[-1.66]$} \\
Controlling for D/BE & 0.29 & 0.20 & 0.13 & -0.01 & -0.11 & -0.40 \\
& {$[2.17]$} & {$[2.03]$} & {$[1.49]$} & {$[-0.13]$} & {$[-0.89]$} & {$[-1.98]$} \\
Controlling for PPE/A & 0.24 & 0.12 & 0.14 & 0.01 & -0.06 & -0.30 \\
& {$[1.94]$} & {$[1.43]$} & {$[1.80]$} & {$[0.19]$} & {$[-0.47]$} & {$[-1.52]$} \\
Controlling for R\&D/A & 0.53 & 0.26 & 0.27 & 0.22 & 0.17 & -0.36 \\
Controlling for BE/ME & {$[3.44]$} & {$[2.33]$} & {$[2.48]$} & {$[1.95]$} & {$[1.08]$} & {$[-1.69]$} \\
& 0.23 & 0.19 & 0.15 & 0.02 & -0.12 & -0.35 \\
Controlling for EF/A & {$[1.77]$} & {$[1.97]$} & {$[1.75]$} & {$[0.21]$} & {$[-0.95]$} & {$[-1.77]$} \\
Controlling for GS & 0.29 & 0.20 & 0.10 & -0.01 & -0.07 & -0.35 \\
& {$[2.18]$} & {$[2.29]$} & {$[1.29]$} & {$[-0.15]$} & {$[-0.54]$} & {$[-1.71]$} \\
& 0.28 & 0.19 & 0.13 & -0.03 & -0.07 & -0.34 \\
& {$[2.16]$} & {$[2.14]$} & {$[1.71]$} & {$[-0.32]$} & {$[-0.54]$} & {$[-1.70]$} \\
\hline
\end{tabular}

Shown are the alphas of quintile portfolios ranked by sensitivity to investor attention $\left(\beta_{D J I A}\right)$, controllling for company characteristics that are associated with difficulty of arbitrage. The alphas are calculated with respect to the five Fama and French factors (2015), momentum, as well as the factor-mimicking returns of liquidity (Pastor Stambaugh) and idiosyncratic volatility. Robust Newey-West (1987) t-statistics are in square brackets. The column '5-1' refers to the difference in alphas between portfolio 5 and portfolio 1. Each month, I perform a double sort, first sorting into five quintiles based on company characteristics and then, within each quintile, based on sensitivity to investor attention $\left(\beta_{D J I A}\right)$. The five investor attention portfolios are then averaged over each of the five characteristic portfolios. Hence, they represent investor attention quintile portfolios controlling for the given characteristic. The company characteristics (first sorting) are as of last month $\left(\sigma_{i}\right)$ or of the last financial reporting date (annual). The market cap ( $M C a p)$ is shown in billions of USD and is taken from the previous month. $\sigma_{i}$ refers to the average (monthly) idiosyncratic volatility of quintile stocks across the last 12 months. Further shown are quintile averages of return-on-equity $(R o E)$; dividends-to-book equity $(D B E)$; property, plant and equipment over assets $(P P E / A)$; research and development expenses over assets $(R \& D / A)$; book-to-market equity $(B E / M E)$; external finance over assets $(E F / A)$; and lastly, sales growth in the last year relative to the year before $(G S)$. The exact definitions are discussed in Baker and Wurgler (2006, p.1653ff.) The sample period is January 2004 to September 2015. All portfolios are equally weighted.

Table VI Alphas of Portfolios Sorted on Investor Attention $\left(\beta_{D J I A}\right)$, controlling for Baker-Wurgler characteristics. 


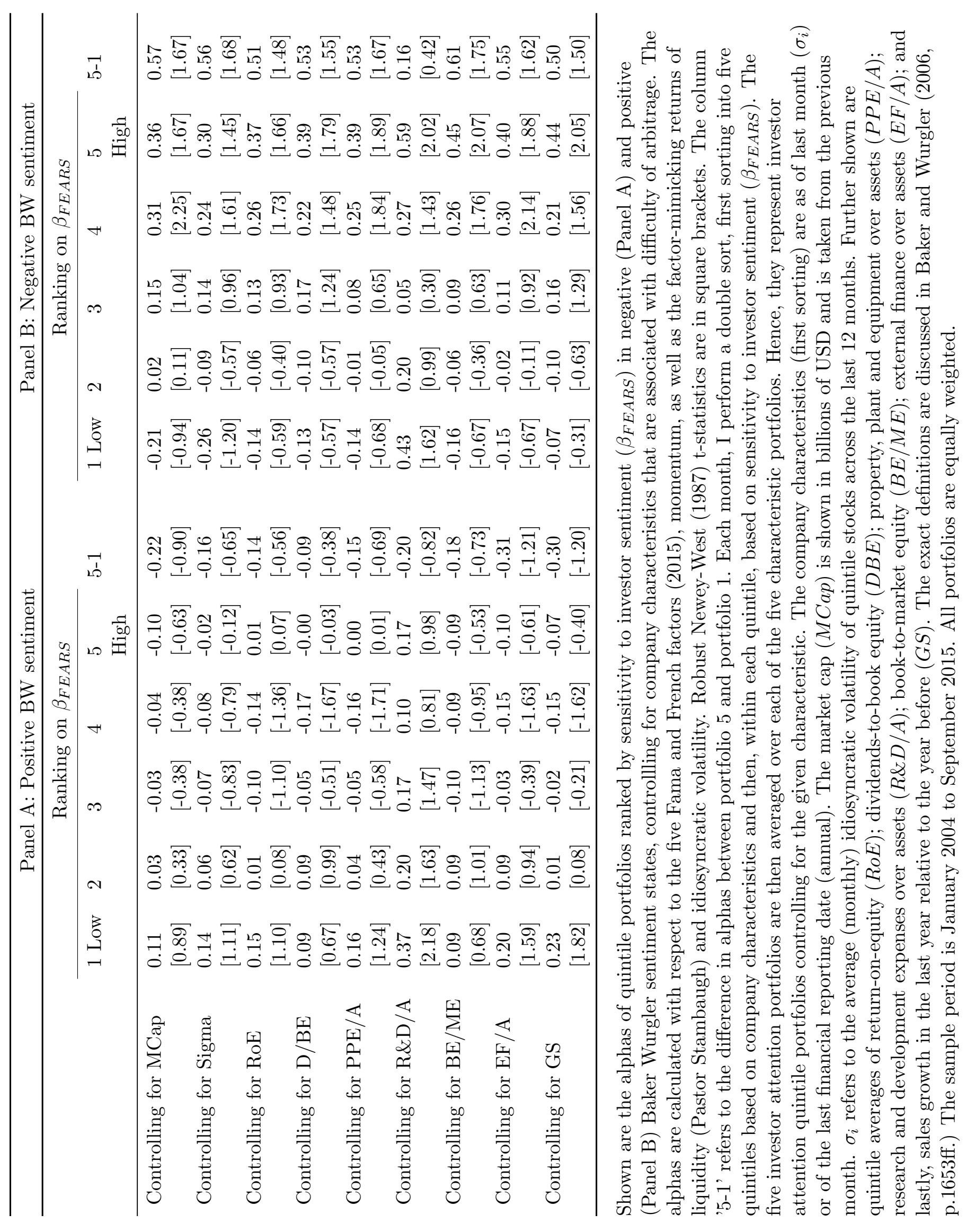




\begin{tabular}{|c|c|c|c|c|c|}
\hline & \multicolumn{5}{|c|}{ Fama-MacBeth (1973) Factor Premia } \\
\hline & $\mathrm{I}$ & II & III & IV & $\mathrm{V}$ \\
\hline \multirow[t]{2}{*}{$M K T$} & 0.41 & 0.50 & 0.69 & 0.47 & 0.69 \\
\hline & {$[1.23]$} & {$[1.47]$} & {$[1.94]$} & {$[0.42]$} & {$[2.23]$} \\
\hline \multirow[t]{2}{*}{$S M B$} & -0.15 & -0.21 & 0.02 & 1.47 & 0.11 \\
\hline & {$[-0.85]$} & {$[-0.76]$} & {$[0.09]$} & {$[1.74]$} & {$[0.62]$} \\
\hline \multirow[t]{2}{*}{$H M L$} & -0.18 & -0.29 & 0.00 & -3.42 & 0.07 \\
\hline & {$[-1.11]$} & {$[-1.48]$} & {$[0.01]$} & {$[-2.60]$} & {$[0.39]$} \\
\hline \multirow[t]{2}{*}{$R M W$} & & 0.36 & 0.30 & 1.04 & 0.25 \\
\hline & & {$[2.38]$} & {$[2.14]$} & {$[1.34]$} & {$[2.14]$} \\
\hline \multirow[t]{2}{*}{$C M A$} & & 0.14 & -0.07 & 0.18 & -0.09 \\
\hline & & {$[1.17]$} & {$[-0.53]$} & {$[0.28]$} & {$[-0.87]$} \\
\hline \multirow[t]{2}{*}{$M O M$} & & & 0.10 & 1.07 & 0.08 \\
\hline & & & {$[0.25]$} & {$[0.53]$} & {$[0.20]$} \\
\hline \multirow[t]{2}{*}{$L I Q$} & & & 0.70 & -0.18 & 0.60 \\
\hline & & & {$[0.95]$} & {$[-0.10]$} & {$[0.85]$} \\
\hline \multirow[t]{2}{*}{ Sigma } & & 0.10 & 0.34 & 0.28 & 0.47 \\
\hline & & {$[0.28]$} & {$[0.81]$} & {$[0.68]$} & {$[1.18]$} \\
\hline \multirow[t]{2}{*}{$H M L_{D J I A}$} & -0.49 & -0.72 & -0.64 & -1.93 & -0.54 \\
\hline & {$[-2.03]$} & {$[-2.68]$} & {$[-2.24]$} & {$[-2.79]$} & {$[-2.26]$} \\
\hline $\operatorname{Adj} . R^{2}$ & 0.13 & 0.49 & 0.83 & 0.47 & 0.67 \\
\hline Estimation: & $1 \mathrm{~m}$ rolling & $1 \mathrm{~m}$ rolling & $1 \mathrm{~m}$ rolling & 1 time series & $1 \mathrm{~m}$ rolling \\
\hline Assets: & 25 Portfolios & 25 Portfolios & 25 Portfolios & 25 Portfolios & $\begin{array}{l}\text { NYSE/AMEX } \\
\text { Stocks }\end{array}$ \\
\hline
\end{tabular}

This table reports the Fama-MacBeth (1973) factor premia on 25 portfolios (columns I-IV) as well as on all NYSE/AMEX stocks individually (column V, N:3,096). Estimation is based on daily data. The 25 portfolios are first sorted on last month's idiosyncratic volatility $\left(\sigma_{i}\right)$ and then on the exposure to investor attention $\left(\beta_{D J I A}\right)$. MKT is the excess return on the market portfolio, $S M B, H M L, R M W, C M A$ are the Fama-French (2015) size, value, operating profitability and investment factors. $M O M$ is the momentum factor constructed by Kenneth French, and $L I Q$ is the daily factor-mimicking portfolio on the aggregate liquidity measure from Pastor and Stambaugh (2003). Sigma is a proxy for the daily excess returns on stocks with high idiosyncratic volatility less the returns on stocks with low idiosyncratic volatility. Idiosyncratic volatility is defined as in Ang et al. (2006). $H M L_{D J I A}$ are the returns of a high-minus-low portfolio ('5-1') portfolio based on previous month's investor attention betas $\left(\beta_{D J I A}\right)$. Columns I-III show the factor premia with increasing numbers of factors whereby the factor betas are estimated on a monthly-rolling basis. In column IV the factor betas are estimated in one time-series regression covering the whole sample. The sample period is from January 2004 to September 2015.

Table VIII Estimating the price of investor attention risk $(D J I A)$. 


\begin{tabular}{|c|c|c|c|c|c|c|}
\hline & \multicolumn{6}{|c|}{ Fama-MacBeth (1973) Factor Premia } \\
\hline & $\mathrm{I}$ & II & III & IV & $\mathrm{V}$ & VI \\
\hline \multirow[t]{2}{*}{$M K T$} & 0.32 & 0.48 & 0.31 & 0.44 & 0.54 & 0.69 \\
\hline & {$[0.91]$} & {$[1.33]$} & {$[0.86]$} & {$[1.25]$} & {$[1.47]$} & {$[1.77]$} \\
\hline \multirow[t]{2}{*}{$S M B$} & 0.11 & 0.18 & 0.18 & 0.10 & 0.10 & 0.17 \\
\hline & {$[0.60]$} & {$[0.85]$} & {$[0.88]$} & {$[0.52]$} & {$[0.55]$} & {$[0.79]$} \\
\hline \multirow[t]{2}{*}{$H M L$} & 0.03 & 0.03 & 0.04 & 0.05 & 0.09 & 0.02 \\
\hline & {$[0.13]$} & {$[0.14]$} & {$[0.21]$} & {$[0.22]$} & {$[0.43]$} & {$[0.09]$} \\
\hline \multirow[t]{2}{*}{$R M W$} & 0.39 & 0.25 & 0.22 & 0.34 & 0.22 & 0.22 \\
\hline & {$[2.85]$} & {$[1.94]$} & {$[1.73]$} & {$[2.41]$} & {$[1.70]$} & {$[1.75]$} \\
\hline \multirow[t]{2}{*}{$C M A$} & -0.04 & -0.06 & -0.06 & -0.04 & -0.04 & 0.00 \\
\hline & {$[-0.39]$} & {$[-0.54$} & {$[-0.49]$} & {$[-0.38]$} & {$[-0.34]$} & {$[0.02]$} \\
\hline \multirow[t]{2}{*}{$M O M$} & 0.00 & 0.06 & 0.15 & 0.12 & 0.24 & 0.04 \\
\hline & {$[0.00]$} & {$[0.15]$} & {$[0.42]$} & {$[0.29]$} & {$[0.60]$} & {$[0.11]$} \\
\hline \multirow[t]{2}{*}{$L I Q$} & 0.29 & 0.52 & 0.48 & 0.70 & 0.36 & 0.51 \\
\hline & {$[0.41]$} & {$[0.70]$} & {$[0.66]$} & {$[0.96]$} & {$[0.49]$} & {$[0.68]$} \\
\hline \multirow[t]{2}{*}{ Sigma } & 0.26 & 0.34 & 0.32 & 0.24 & 0.36 & 0.23 \\
\hline & {$[0.64]$} & {$[0.83]$} & {$[0.81]$} & {$[0.55]$} & {$[0.84]$} & {$[0.57]$} \\
\hline \multirow[t]{2}{*}{$H M L_{D J I A}$} & -0.45 & -0.69 & -0.72 & -0.59 & -0.85 & -0.58 \\
\hline & {$[-1.63]$} & {$[-2.46]$} & {$[-2.54]$} & {$[-2.07]$} & {$[-3.05]$} & {$[-2.05]$} \\
\hline$A d j . R^{2}$ & 0.83 & 0.79 & 0.83 & 0.82 & 0.84 & 0.79 \\
\hline \multirow{3}{*}{$\begin{array}{l}\text { Estimation: } \\
\text { Assets: }\end{array}$} & \multicolumn{6}{|c|}{$1 \mathrm{~m}$ rolling } \\
\hline & Size \& & $\mathrm{BE} / \mathrm{ME} \&$ & $\mathrm{BE} / \mathrm{ME} \&$ & Size \& & Size \& & Op.Prof. \\
\hline & $\mathrm{BE} / \mathrm{ME}$ & Investment & Op.Prof. & Investment & Op.Prof. & Investment \\
\hline
\end{tabular}

This table reports the Fama-MacBeth (1973) factor premia on six different types of Fama-French Portfolios as test assets. They are ordered by different criteria and each contain 25 portfolios. They are sorted by size and book-to-market (column I), book-to-market and investment (column II), book-to-market and operating profitability (column III), size and investment (column IV), size and operating profitability (column V) as well as operating profitability and investment (column VI), respectively. The data for the Fama-French portfolios is as of Kenneth French's website http://mba.tuck.dartmouth.edu/pages/faculty/ken.french/data_library.html. Estimation is based on daily data. $M K T$ is the excess return on the market portfolio, $S M B$, $H M L, R M W, C M A$ are the Fama-French (2015) size, value, operating profitability and investment factors. MOM is the momentum factor constructed by Kenneth French, and $L I Q$ is the daily factor-mimicking portfolio on the aggregate liquidity measure from Pastor and Stambaugh (2003). Sigma is a proxy for the daily excess returns on stocks with high idiosyncratic volatility less the returns on stocks with low idiosyncratic volatility. Idiosyncratic volatility is defined as in Ang et al. (2006). $H M L_{D J I A}$ are the returns of a high-minus-low portfolio ('5-1') portfolio based on previous month's investor attention betas $\left(\beta_{D J I A}\right)$. Columns I-III show the factor premia with increasing numbers of factors whereby the factor betas are estimated on a monthly-rolling basis. In column IV the factor betas are estimated in one time-series regression covering the whole sample. The sample period is from January 2004 to September 2015.

Table IX Estimating the price of investor attention risk $(D J I A)$. 


\begin{tabular}{|c|c|c|c|c|c|c|}
\hline & \multicolumn{2}{|c|}{ Panel A: UC BW } & \multicolumn{2}{|c|}{ Panel B: Positive BW } & \multicolumn{2}{|c|}{ Panel C: Negative BW } \\
\hline & I & II & III & IV & $\mathrm{V}$ & VI \\
\hline \multirow[t]{2}{*}{$M K T$} & 0.76 & 1.01 & 0.45 & -0.26 & 1.18 & 2.75 \\
\hline & {$[2.30]$} & {$[0.83]$} & {$[1.14]$} & {$[-0.18]$} & {$[2.11]$} & {$[1.33]$} \\
\hline \multirow[t]{2}{*}{$S M B$} & 0.11 & -0.91 & 0.26 & 1.15 & -0.10 & -3.74 \\
\hline & {$[0.47]$} & {$[-0.86]$} & {$[0.99]$} & {$[0.90]$} & {$[-0.26]$} & {$[-2.12]$} \\
\hline \multirow[t]{2}{*}{$H M L$} & 0.08 & -0.07 & 0.12 & -3.21 & 0.17 & 4.25 \\
\hline & {$[0.38]$} & {$[-0.04]$} & {$[0.26]$} & {$[-1.53]$} & {$[0.38]$} & {$[1.39]$} \\
\hline \multirow[t]{2}{*}{$R M W$} & 0.32 & 0.90 & 0.31 & 0.21 & 0.33 & 1.84 \\
\hline & {$[2.27]$} & {$[0.82]$} & {$[2.10]$} & {$[0.16]$} & {$[1.25]$} & {$[0.96]$} \\
\hline \multirow[t]{2}{*}{$C M A$} & 0.04 & -0.29 & -0.13 & -1.30 & 0.27 & 1.09 \\
\hline & {$[0.34]$} & {$[-0.32]$} & {$[-0.91]$} & {$[-1.19]$} & {$[1.48]$} & {$[0.70]$} \\
\hline \multirow[t]{2}{*}{$M O M$} & 0.06 & -2.23 & 0.76 & 0.16 & -0.91 & -5.51 \\
\hline & {$[0.15]$} & {$[-1.18]$} & {$[2.17]$} & {$[0.07]$} & {$[-1.18]$} & {$[-1.70]$} \\
\hline \multirow[t]{2}{*}{$L I Q$} & 0.68 & 1.00 & 1.50 & -1.42 & -0.46 & 4.33 \\
\hline & {$[0.95]$} & {$[0.69]$} & {$[1.89]$} & {$[-0.89]$} & {$[-0.36]$} & {$[1.63]$} \\
\hline \multirow[t]{2}{*}{ Sigma } & 0.34 & 0.27 & -0.20 & -0.25 & 1.07 & 0.98 \\
\hline & {$[0.82]$} & {$[0.65]$} & {$[-0.60]$} & {$[-0.73]$} & {$[1.26]$} & {$[1.17]$} \\
\hline \multirow[t]{2}{*}{$H M L_{F E A R S}$} & 0.01 & 0.65 & -0.40 & -0.28 & 0.58 & 1.92 \\
\hline & {$[0.04]$} & {$[1.30]$} & {$[-1.15]$} & {$[-0.44]$} & {$[1.18]$} & {$[2.42]$} \\
\hline$A d j . R^{2}$ & 0.83 & 0.51 & 0.81 & 0.49 & 0.87 & 0.55 \\
\hline \multirow{2}{*}{$\begin{array}{l}\text { Estimation: } \\
\text { Assets: }\end{array}$} & $1 \mathrm{~m}$ rolling & $1 \mathrm{TS}$ & $1 \mathrm{~m}$ rolling & $1 \mathrm{TS}$ & $1 \mathrm{~m}$ rolling & $1 \mathrm{TS}$ \\
\hline & \multicolumn{6}{|c|}{$25 \mathrm{PFs}$} \\
\hline
\end{tabular}

This table reports the Fama-MacBeth (1973) factor premia on 25 portfolios based on daily data. The 25 portfolios are first sorted on last month's idiosyncratic volatility $\left(\sigma_{i}\right)$ and then on the exposure to investor sentiment $\left(\beta_{F E A R S}\right)$. $M K T$ is the excess return on the market portfolio, $S M B, H M L, R M W, C M A$ are the Fama-French (2015) size, value, operating profitability and investment factors. MOM is the momentum factor constructed by Kenneth French, and $L I Q$ is the daily factor-mimicking portfolio on the aggregate liquidity measure from Pastor and Stambaugh (2003). Sigma is a proxy for the daily excess returns on stocks with high idiosyncratic volatility less the returns on stocks with low idiosyncratic volatility. Idiosyncratic volatility is defined as in Ang et al. (2006). $H M L_{F E A R S}$ are the returns of a high-minus-low portfolio ('5-1') portfolio based on previous month's investor sentiment betas $\left(\beta_{F E A R S}\right)$. Columns I and II show the factor premia across the whole sample while columns III and IV (V and VI) show the factor premia in positive (negative) sentiment states, using the sentiment index of Baker and Wurgler (2006). Columns I, III and V estimate factor betas on a monthly-rolling basis, while columns I, IV and VI estimate them in a single time-series regression covering the whole sample. The sample period is from January 2004 to September 2015.

Table $\mathbf{X}$ Estimating the price of investor sentiment risk $(F E A R S)$. 


\begin{tabular}{lllllll}
\hline & DJIA & NYSE & NASDAQ & Stocks & FTSE & DAX \\
\hline DJIA & 1.00 & 0.38 & 0.19 & 0.39 & 0.69 & 0.70 \\
NYSE & & 1.00 & 0.70 & 0.81 & 0.70 & 0.42 \\
NASDAQ & & & 1.00 & 0.74 & 0.55 & 0.30 \\
Stocks & & & 1.00 & 0.68 & 0.41 \\
FTSE & & & & 1.00 & 0.76 \\
DAX & & & & & & 1.00 \\
\hline
\end{tabular}

This table reports the correlation between the daily search volume in different stock investment-related search queries in Google. The sample period is 01:2004 - 12:2015.

Table XI Correlation matrix of different investor attention proxies. 


\begin{tabular}{|c|c|c|c|c|c|c|c|c|c|}
\hline \multirow[b]{2}{*}{$\begin{array}{r}\text { MCap } \\
\text { quintile }\end{array}$} & \multirow[b]{2}{*}{ Mean } & \multirow[b]{2}{*}{$\begin{array}{l}\text { Std. } \\
\text { Dev. }\end{array}$} & \multirow[b]{2}{*}{$\begin{array}{r}\mathrm{CAPM} \\
\alpha\end{array}$} & \multirow[b]{2}{*}{$\begin{array}{r}\mathrm{FF}-3 \\
\alpha\end{array}$} & \multirow[b]{2}{*}{$\begin{array}{r}\text { FULL } \\
\alpha\end{array}$} & \multicolumn{4}{|c|}{ Factor loadings } \\
\hline & & & & & & $\begin{array}{l}\text { Pre-f. } \\
\beta_{D J I A}\end{array}$ & $\begin{array}{l}\text { Post-f. } \\
\beta_{D J I A}\end{array}$ & $\begin{array}{r}\text { Pre-f. } \\
\beta_{F-D J I A}\end{array}$ & $\begin{array}{r}\text { Post-f. } \\
\beta_{F-D J I A}\end{array}$ \\
\hline \multicolumn{10}{|c|}{ Panel A: Value-weighted PF returns } \\
\hline \multirow[t]{2}{*}{1} & -0.15 & 6.22 & -0.23 & -0.24 & -0.28 & 1.12 & 0.05 & 2.83 & 0.22 \\
\hline & & & {$[-0.46]$} & {$[-0.46]$} & {$[-0.54]$} & {$[20.60]$} & {$[1.93]$} & {$[37.19]$} & {$[4.35]$} \\
\hline \multirow[t]{2}{*}{2} & -0.40 & 3.21 & -0.42 & -0.43 & -0.45 & 0.79 & 0.02 & 1.69 & 0.07 \\
\hline & & & {$[-1.59]$} & {$[-1.61]$} & {$[-1.70]$} & {$[24.02]$} & {$[1.35]$} & {$[40.30]$} & {$[2.85]$} \\
\hline \multirow[t]{2}{*}{3} & -0.26 & 2.97 & -0.27 & -0.27 & -0.24 & 0.61 & 0.04 & 1.34 & 0.16 \\
\hline & & & $-[1.10]$ & {$[-1.09]$} & {$[-1.01]$} & {$[23.96]$} & {$[3.61]$} & {$[40.13]$} & {$[6.80]$} \\
\hline \multirow[t]{2}{*}{4} & -0.22 & 2.75 & -0.23 & -0.23 & -0.19 & 0.48 & -0.00 & 1.23 & -0.00 \\
\hline & & & {$[-1.01]$} & {$[-1.02]$} & {$[-0.87]$} & {$[22.35]$} & {$[-0.21]$} & {$[41.73]$} & {$[-0.17]$} \\
\hline \multirow[t]{2}{*}{5} & -0.74 & 3.58 & -0.75 & -0.75 & -0.64 & 0.42 & -0.00 & 1.13 & 0.00 \\
\hline & & & {$[-2.54]$} & {$[-2.57]$} & {$[-2.24]$} & {$[21.00]$} & {$[-0.32]$} & {$[39.91]$} & {$[0.04]$} \\
\hline \multicolumn{10}{|c|}{ Panel B: Equally-weighted PF returns } \\
\hline \multirow[t]{2}{*}{1} & -0.29 & 6.30 & -0.37 & -0.37 & -0.41 & 1.27 & 0.05 & 2.94 & 0.20 \\
\hline & & & {$[-0.71]$} & {$[-0.72]$} & {$[-0.79]$} & [22.10] & {$[1.74]$} & {$[37.78]$} & {$[3.61]$} \\
\hline \multirow[t]{2}{*}{2} & -0.24 & 3.41 & -0.29 & -0.29 & -0.33 & 0.92 & 0.04 & 2.19 & 0.13 \\
\hline & & & {$[-1.04]$} & {$[-1.06]$} & {$[-1.17]$} & {$[26.55]$} & {$[2.63]$} & {$[50.27]$} & {$[5.11]$} \\
\hline \multirow[t]{2}{*}{3} & -0.28 & 2.96 & -0.29 & -0.29 & -0.26 & 0.69 & 0.05 & 1.68 & 0.15 \\
\hline & & & {$[-1.17]$} & {$[-1.17]$} & {$[-1.09]$} & {$[25.92]$} & {$[4.05]$} & [49.33] & [6.93] \\
\hline \multirow[t]{2}{*}{4} & -0.29 & 2.75 & -0.30 & -0.30 & -0.26 & 0.53 & -0.01 & 1.36 & -0.03 \\
\hline & & & {$[-1.31]$} & {$[-1.32]$} & {$[-1.16]$} & {$[23.75]$} & {$[-0.58]$} & {$[45.57]$} & {$[-1.13]$} \\
\hline \multirow[t]{2}{*}{5} & -0.58 & 3.20 & -0.61 & -0.62 & -0.57 & 0.47 & -0.00 & 1.19 & 0.02 \\
\hline & & & {$[-2.33]$} & {$[-2.36]$} & {$[-2.21]$} & [22.85] & {$[-0.03]$} & {$[42.36]$} & {$[0.59]$} \\
\hline
\end{tabular}

This table reports the portfolio performance characteristics of the '5-1' (HML) $\beta_{D J I A}$ portfolio across different market capitalization (MCap) quintiles. Every beginning of month, I sort stocks into five quintiles based on current MCap. Within a quintile I sort the stocks according to the past month's $\beta_{D J I A}$ loading from lowest (1) to highest (5) as in equation (11) and form the '5-1' portfolio as the difference between the two extreme portfolios. Panel A shows value-weighted portfolio returns, while Panel B shows equally-weighted returns. For each '5-1' portfolio, I then analyze the following characteristics: Monthly mean and standard deviation of simple returns (in percentage terms). The Alpha $(\alpha)$ columns report monthly Jensen's alpha with respect to the CAPM, the Fama-French (1993) three-factor model and the full model specification $(F F-5$, $M O M, L I Q$ as well as Sigma). The pre- and post-formation investor attention loadings are estimated with daily portfolio returns, controlling with the full model specification. $\beta_{D J I A}$ is the beta to the raw investor attention measure while $\beta_{F-D J I A}$ denotes the sensitivity to the factor-mimicking portfolio. Robust Newey-West (1987) $t$-statistics are reported in square brackets. The sample period is from January 2004 to September 2015.

Table XII '5-1' $\beta_{D J I A}$ PF characteristics across $M C a p$ quintiles. 


\begin{tabular}{|c|c|c|c|c|c|c|c|c|c|}
\hline \multirow[b]{2}{*}{$\begin{array}{l}\text { MCap } \\
\text { quintile }\end{array}$} & \multirow[b]{2}{*}{ Mean } & \multirow[b]{2}{*}{$\begin{array}{l}\text { Std. } \\
\text { Dev. }\end{array}$} & \multirow[b]{2}{*}{$\begin{array}{r}\mathrm{CAPM} \\
\alpha\end{array}$} & \multirow[b]{2}{*}{$\begin{array}{r}\mathrm{FF}-3 \\
\alpha\end{array}$} & \multirow[b]{2}{*}{$\begin{array}{r}\text { FULL } \\
\alpha\end{array}$} & \multicolumn{4}{|c|}{ Factor loadings } \\
\hline & & & & & & $\begin{array}{l}\text { Pre-f. } \\
\beta_{D J I A}\end{array}$ & $\begin{array}{l}\text { Post-f. } \\
\beta_{D J I A} \\
\end{array}$ & $\begin{array}{r}\text { Pre-f. } \\
\beta_{F-D J I A}\end{array}$ & $\begin{array}{r}\text { Post-f. } \\
\beta_{F-D J I A}\end{array}$ \\
\hline \multicolumn{10}{|c|}{ Panel A: Value-weighted PF returns } \\
\hline \multirow[t]{2}{*}{1} & -0.37 & 5.43 & -0.41 & -0.41 & -0.44 & 1.23 & 0.03 & 2.81 & 0.12 \\
\hline & & & {$[-0.92]$} & {$[-0.93]$} & {$[-0.98]$} & {$[21.27]$} & {$[1.12]$} & {$[35.84]$} & {$[2.52]$} \\
\hline \multirow[t]{2}{*}{2} & -0.42 & 3.23 & -0.50 & -0.51 & -0.54 & 0.93 & 0.04 & 2.09 & 0.14 \\
\hline & & & {$[-1.94]$} & {$[-1.96]$} & {$[-2.10]$} & {$[24.12]$} & {$[3.00]$} & {$[42.06]$} & {$[5.82]$} \\
\hline \multirow[t]{2}{*}{3} & -0.34 & 2.18 & -0.35 & -0.35 & -0.36 & 0.77 & 0.01 & 1.68 & 0.07 \\
\hline & & & {$[-1.94]$} & {$[-1.95]$} & {$[-2.01]$} & {$[25.26]$} & {$[1.63]$} & {$[43.42]$} & {$[3.64]$} \\
\hline \multirow[t]{2}{*}{4} & -0.30 & 2.31 & -0.30 & -0.30 & -0.30 & 0.63 & 0.02 & 1.28 & 0.07 \\
\hline & & & {$[-1.59]$} & {$[-1.60]$} & {$[-1.60]$} & {$[25.21]$} & {$[2.23]$} & [40.88] & {$[4.01]$} \\
\hline \multirow[t]{2}{*}{5} & -0.65 & 3.14 & -0.66 & -0.66 & -0.60 & 0.44 & 0.00 & 1.15 & 0.00 \\
\hline & & & {$[-2.54]$} & {$[-2.57]$} & {$[-2.36]$} & {$[21.88]$} & {$[-0.31]$} & {$[41.05]$} & {$[0.11]$} \\
\hline \multicolumn{10}{|c|}{ Panel B: Equally-weighted PF returns } \\
\hline \multirow[t]{2}{*}{1} & -0.13 & 5.69 & -0.17 & -0.17 & -0.19 & 1.32 & 0.04 & 3.13 & 0.16 \\
\hline & & & {$[-0.37]$} & {$[-0.37]$} & {$[-0.40]$} & {$[20.80]$} & {$[1.56]$} & {$[35.68]$} & {$[3.37]$} \\
\hline \multirow[t]{2}{*}{2} & -0.34 & 3.24 & -0.42 & -0.42 & -0.45 & 0.94 & 0.04 & 2.22 & 0.14 \\
\hline & & & {$[-1.60]$} & {$[-1.62]$} & {$[-1.74]$} & [23.99] & {$[2.87]$} & [43.43] & {$[5.71]$} \\
\hline \multirow[t]{2}{*}{3} & -0.28 & 2.15 & -0.30 & -0.30 & -0.31 & 0.78 & 0.02 & 1.64 & 0.09 \\
\hline & & & {$[-1.68]$} & {$[-1.69]$} & {$[-1.75]$} & {$[25.47]$} & {$[2.02]$} & {$[42.59]$} & {$[4.73]$} \\
\hline \multirow[t]{2}{*}{4} & -0.26 & 2.25 & -0.27 & -0.27 & -0.27 & 0.64 & 0.02 & 1.29 & 0.06 \\
\hline & & & {$[-1.45]$} & {$[-1.46]$} & {$[-1.44]$} & {$[25.43]$} & {$[1.92]$} & {$[41.02]$} & {$[3.71]$} \\
\hline \multirow[t]{2}{*}{5} & -0.38 & 2.42 & -0.39 & -0.39 & -0.37 & 0.47 & 0.01 & 1.04 & 0.04 \\
\hline & & & {$[-1.96]$} & {$[-1.98]$} & {$[-1.89]$} & {$[23.55]$} & {$[0.63]$} & {$[39.74]$} & {$[1.75]$} \\
\hline
\end{tabular}

This table reports the portfolio performance characteristics of the '5-1' (HML) $\beta_{D J I A}$ portfolio across different market capitalization (MCap) quintiles in an enlarged sample including all NYSE/AMEX as well as NASDAQ stocks. Every beginning of month, I sort stocks into five quintiles based on current MCap. Within a quintile I sort the stocks according to the past month's $\beta_{D J I A}$ loading from lowest (1) to highest (5) as in equation (11) and form the '5-1' portfolio as the difference between the two extreme portfolios. Panel A shows value-weighted portfolio returns, while Panel B shows equally-weighted returns. For each '5-1' portfolio, I then analyze the following characteristics: Monthly mean and standard deviation of simple returns (in percentage terms). The Alpha $(\alpha)$ columns report monthly Jensen's alpha with respect to the CAPM, the Fama-French (1993) three-factor model and the full model specification $(F F-5$, $M O M, L I Q$ as well as Sigma). The pre- and post-formation investor attention loadings are estimated with daily portfolio returns, controlling with the full model specification. $\beta_{D J I A}$ is the beta to the raw investor attention measure while $\beta_{F-D J I A}$ denotes the sensitivity to the factor-mimicking portfolio. Robust Newey-West (1987) $t$-statistics are reported in square brackets. The sample period is from January 2004 to September 2015.

Table XIII '5-1' $\beta_{D J I A}$ PF characteristics across MCap quintiles in a bigger sample - including NASDAQ stocks. 


\begin{tabular}{|c|c|c|c|c|c|c|c|c|c|}
\hline \multirow[b]{2}{*}{$\begin{array}{l}\text { Time } \\
\text { period }\end{array}$} & \multirow[b]{2}{*}{ Mean } & \multirow[b]{2}{*}{$\begin{array}{l}\text { Std. } \\
\text { Dev. }\end{array}$} & \multirow[b]{2}{*}{$\begin{array}{r}\mathrm{CAPM} \\
\alpha\end{array}$} & \multirow[b]{2}{*}{$\begin{array}{r}\mathrm{FF}-3 \\
\alpha\end{array}$} & \multirow[b]{2}{*}{$\begin{array}{r}\text { FULL } \\
\alpha\end{array}$} & \multicolumn{4}{|c|}{ Factor loadings } \\
\hline & & & & & & $\begin{array}{l}\text { Pre-f. } \\
\beta_{D J I A}\end{array}$ & $\begin{array}{l}\text { Post-f. } \\
\beta_{D J I A}\end{array}$ & $\begin{array}{r}\text { Pre-f. } \\
\beta_{F-D J I A}\end{array}$ & $\begin{array}{r}\text { Post-f. } \\
\beta_{F-D J I A}\end{array}$ \\
\hline \multicolumn{10}{|c|}{ Panel A: Value-weighted PF returns } \\
\hline $\begin{array}{l}(2004: 01- \\
2007: 11) \\
(2007: 12- \\
2011: 10) \\
(2011: 11- \\
2015: 09)\end{array}$ & -0.80 & 2.36 & $\begin{array}{r}-0.80 \\
{[-2.32]} \\
-0.92 \\
{[-1.15]} \\
-0.16 \\
{[-0.55]}\end{array}$ & $\begin{array}{r}-0.76 \\
{[-2.20]} \\
-1.00 \\
{[-1.26]} \\
-0.15 \\
{[-0.51]}\end{array}$ & $\begin{array}{r}-0.45 \\
{[-1.29]} \\
-1.40 \\
{[-1.76]} \\
-0.07 \\
{[-0.25]}\end{array}$ & $\begin{array}{r}1.64 \\
{[23.73]} \\
0.44 \\
{[11.67]} \\
0.83 \\
{[16.33]}\end{array}$ & $\begin{array}{r}0.00 \\
{[0.09]} \\
-0.01 \\
{[-0.23]} \\
0.01 \\
{[0.34]}\end{array}$ & $\begin{array}{r}2.55 \\
{[36.22]} \\
1.18 \\
{[21.78]} \\
1.26 \\
{[21.64]}\end{array}$ & $\begin{array}{r}0.27 \\
{[3.40]} \\
-0.05 \\
{[-0.77]} \\
0.01 \\
{[0.17]}\end{array}$ \\
\hline \multicolumn{10}{|c|}{ Panel B: Equally-weighted PF returns } \\
\hline $\begin{array}{l}(2004: 01- \\
2007: 11) \\
(2007: 12- \\
2011: 10) \\
(2011: 11- \\
2015: 09)\end{array}$ & -0.74 & 1.74 & $\begin{array}{r}-0.77 \\
{[-3.04]} \\
-0.50 \\
{[-1.02]} \\
-0.06 \\
{[-0.27]}\end{array}$ & $\begin{array}{r}-0.72 \\
{[-2.84]} \\
-0.54 \\
{[-1.12]} \\
-0.05 \\
{[-0.24]}\end{array}$ & $\begin{array}{r}-0.40 \\
{[-1.62]} \\
-0.71 \\
{[-1.47]} \\
-0.02 \\
{[-0.11]}\end{array}$ & $\begin{array}{r}2.31 \\
{[28.90]} \\
0.66 \\
{[14.83]} \\
1.17 \\
{[17.92]}\end{array}$ & $\begin{array}{r}0.04 \\
{[1.36]} \\
0.03 \\
{[1.61]} \\
0.02 \\
{[1.29]}\end{array}$ & $\begin{array}{r}3.41 \\
{[45.63]} \\
1.64 \\
{[28.81]} \\
1.77 \\
{[24.11]}\end{array}$ & $\begin{array}{r}0.35 \\
{[7.21]} \\
0.11 \\
{[2.86]} \\
0.09 \\
{[2.29]}\end{array}$ \\
\hline \multicolumn{10}{|c|}{ Panel C: Value-weighted PF returns, controlling for MCap } \\
\hline $\begin{array}{l}(2004: 01- \\
2007: 11) \\
(2007: 12- \\
2011: 10) \\
(2011: 11- \\
2015: 09)\end{array}$ & -0.25 & 1.58 & $\begin{array}{r}-0.51 \\
{[-1.74]} \\
-1.02 \\
{[-1.41]} \\
-0.26 \\
{[-1.15]}\end{array}$ & $\begin{array}{r}-0.47 \\
{[-1.61]} \\
-1.09 \\
{[-1.53]} \\
-0.25 \\
{[-1.10]}\end{array}$ & $\begin{array}{r}-0.11 \\
{[-0.37]} \\
-1.44 \\
{[-2.03]} \\
-0.23 \\
{[-0.99]}\end{array}$ & $\begin{array}{r}1.34 \\
{[24.09]} \\
0.36 \\
{[11.88]} \\
0.65 \\
{[16.74]}\end{array}$ & $\begin{array}{r}0.01 \\
{[0.24]} \\
-0.01 \\
{[-0.47]} \\
0.03 \\
{[1.64]}\end{array}$ & $\begin{array}{r}2.15 \\
{[38.30]} \\
1.01 \\
{[22.80]} \\
1.02 \\
{[23.09]}\end{array}$ & $\begin{array}{r}0.19 \\
{[3.05]} \\
-0.04 \\
{[-0.75]} \\
0.09 \\
{[2.71]}\end{array}$ \\
\hline
\end{tabular}

This table reports the portfolio performance characteristics of the ' 5 -1' (HML) $\beta_{D J I A}$ portfolio across three same-size subsamples in time: (i) 2004-2007, (ii) 2007-2011, (iii) 2011-2015. Every month, I sort the stocks according to $\beta_{D J I A}$ loading from lowest (1) to highest (5) as in equation (11) and form the '5-1' portfolio as the difference between the two extreme portfolios. Panel A shows value-weighted portfolio returns, while Panel B shows equally-weighted returns. Panel C shows value-weighted returns controlling for market capitalization: I first sort stocks by market capitalization (MCap) and only in the second step by $\beta_{D J I A}$ loading. I then average across the five MCap quintiles per $\beta_{D J I A}$ quintile. For each '5-1' portfolio, I then analyze the following characteristics: Monthly mean and standard deviation of simple returns next month (in percentage terms). The Alpha $(\alpha)$ columns report monthly Jensen's alpha with respect to the CAPM, the Fama-French (1993) three-factor model and the full model specification $(F F-5$, $M O M, L I Q$ as well as Sigma). The pre- and post-formation investor attention loadings are estimated with daily portfolio returns, controlling with the full model specification. $\beta_{D J I A}$ is the beta to the raw investor attention measure while $\beta_{F-D J I A}$ denotes the sensitivity to the factor-mimicking portfolio. Robust Newey-West (1987) $t$-statistics are reported in square brackets. The sample period is from January 2004 to September 2015.

Table XIV '5-1' $\beta_{D J I A}$ PF characteristics across time-subsamples. 


\begin{tabular}{|c|c|c|c|c|c|c|c|c|c|}
\hline \multirow[b]{2}{*}{$\begin{array}{l}\text { Time } \\
\text { period }\end{array}$} & \multirow[b]{2}{*}{ Mean } & \multirow[b]{2}{*}{$\begin{array}{l}\text { Std. } \\
\text { Dev. }\end{array}$} & \multirow[b]{2}{*}{$\begin{array}{r}\mathrm{CAPM} \\
\alpha\end{array}$} & \multirow[b]{2}{*}{$\begin{array}{r}\mathrm{FF}-3 \\
\alpha \\
\end{array}$} & \multirow[b]{2}{*}{$\begin{array}{r}\text { FULL } \\
\alpha\end{array}$} & \multicolumn{4}{|c|}{ Factor loadings } \\
\hline & & & & & & $\begin{array}{l}\text { Pre-f. } \\
\beta_{D J I A} \\
\end{array}$ & $\begin{array}{l}\text { Post-f. } \\
\beta_{D J I A} \\
\end{array}$ & $\begin{array}{r}\text { Pre-f. } \\
\beta_{F-D J I A}\end{array}$ & $\begin{array}{r}\text { Post-f. } \\
\beta_{F-D J I A}\end{array}$ \\
\hline \multicolumn{10}{|c|}{ Panel A: Value-weighted PF returns } \\
\hline $\begin{array}{l}(2004: 01- \\
2007: 11) \\
(2007: 12- \\
2011: 10) \\
(2011: 11- \\
2015: 09)\end{array}$ & -0.60 & 4.78 & $\begin{array}{r}-0.60 \\
{[-1.96]} \\
-1.03 \\
{[-1.49]} \\
-0.23 \\
{[-0.90]}\end{array}$ & $\begin{array}{r}-0.55 \\
{[-1.82]} \\
-1.12 \\
{[-1.63]} \\
-0.22 \\
{[-0.84]}\end{array}$ & $\begin{array}{r}-0.22 \\
{[-0.72]} \\
-1.25 \\
{[-1.80]} \\
-0.14 \\
{[-0.56]}\end{array}$ & $\begin{array}{r}1.52 \\
{[25.11]} \\
0.39 \\
{[11.86]} \\
0.75 \\
{[17.47]}\end{array}$ & $\begin{array}{r}0.01 \\
{[0.43]} \\
-0.00 \\
{[-0.03]} \\
-0.00 \\
{[-0.02]}\end{array}$ & $\begin{array}{r}2.47 \\
{[43.11]} \\
1.18 \\
{[24.16]} \\
1.17 \\
{[23.75]}\end{array}$ & $\begin{array}{r}0.21 \\
{[3.26]} \\
-0.09 \\
{[-1.65]} \\
-0.02 \\
{[-0.40]}\end{array}$ \\
\hline \multicolumn{10}{|c|}{ Panel B: Equally-weighted PF returns } \\
\hline $\begin{array}{l}(2004: 01- \\
2007: 11) \\
(2007: 12- \\
2011: 10) \\
(2011: 11- \\
2015: 09)\end{array}$ & -0.25 & 3.13 & $\begin{array}{r}-0.71 \\
{[-2.94]} \\
-0.25 \\
{[-0.56]} \\
-0.16 \\
{[-0.69]} \\
\end{array}$ & $\begin{array}{r}-0.66 \\
{[-2.76]} \\
-0.29 \\
{[-0.65]} \\
-0.15 \\
{[-0.65]} \\
\end{array}$ & $\begin{array}{r}-0.31 \\
{[-1.31]} \\
-0.52 \\
{[-1.18]} \\
-0.14 \\
{[-0.62]} \\
\end{array}$ & $\begin{array}{r}2.26 \\
{[29.24]} \\
0.53 \\
{[13.20]} \\
1.18 \\
{[19.08]} \\
\end{array}$ & $\begin{array}{r}0.06 \\
{[2.34]} \\
0.01 \\
{[0.86]} \\
0.02 \\
{[0.88]}\end{array}$ & $\begin{array}{r}3.37 \\
{[48.71]} \\
1.42 \\
{[25.62]} \\
1.50 \\
{[22.62]}\end{array}$ & $\begin{array}{r}0.34 \\
{[7.80]} \\
0.06 \\
{[1.68]} \\
0.05 \\
{[1.32]}\end{array}$ \\
\hline
\end{tabular}

This table reports the portfolio performance characteristics of the ' 5 -1' (HML) $\beta_{D J I A}$ portfolio across three same-size subsamples in time and controlling for return reversal. Every month, I double-sort the stocks according to their monthly simple returns as well as their $\beta_{D J I A}$ loading last month (equation (11) from lowest (1) to highest (5). I then form the '5-1' portfolio in $\beta_{D J I A}$ loadings across different return quintiles. Panel A shows value-weighted portfolio returns, while Panel B shows equally-weighted returns. For each '5-1' portfolio, I then analyze the following characteristics: Monthly mean and standard deviation of simple returns (in percentage terms). The Alpha $(\alpha)$ columns report monthly Jensen's alpha with respect to the CAPM, the Fama-French (1993) three-factor model and the full model specification $(F F-5, M O M, L I Q$ as well as Sigma). The pre- and post-formation investor attention loadings are estimated with daily portfolio returns, controlling with the full model specification. $\beta_{D J I A}$ is the beta to the raw investor attention measure while $\beta_{F-D J I A}$ denotes the sensitivity to the factor-mimicking portfolio. Robust Newey-West (1987) $t$-statistics are reported in square brackets. The sample period is from January 2004 to September 2015.

Table XV '5-1' $\beta_{D J I A}$ PF characteristics across time-subsamples, controlling for return reversal. 


\begin{tabular}{|c|c|c|c|c|c|c|c|c|c|}
\hline \multirow[b]{2}{*}{$\begin{array}{l}\text { Dimson } \\
\text { lags }\end{array}$} & \multirow[b]{2}{*}{ Mean } & \multirow[b]{2}{*}{$\begin{array}{l}\text { Std. } \\
\text { Dev. }\end{array}$} & \multirow[b]{2}{*}{$\begin{array}{r}\mathrm{CAPM} \\
\alpha\end{array}$} & \multirow[b]{2}{*}{$\begin{array}{r}\mathrm{FF}-3 \\
\alpha\end{array}$} & \multirow[b]{2}{*}{$\begin{array}{r}\text { FULL } \\
\alpha\end{array}$} & \multicolumn{4}{|c|}{ Factor loadings } \\
\hline & & & & & & $\begin{array}{l}\text { Pre-f. } \\
\beta_{D J I A}\end{array}$ & $\begin{array}{l}\text { Post-f. } \\
\beta_{D J I A}\end{array}$ & $\begin{array}{r}\text { Pre-f. } \\
\beta_{F-D J I A}\end{array}$ & $\begin{array}{r}\text { Post-f. } \\
\beta_{F-D J I A}\end{array}$ \\
\hline \multicolumn{10}{|c|}{ Panel A: Value-weighted PF returns } \\
\hline \multirow[t]{2}{*}{0} & -0.68 & 3.69 & -0.68 & -0.68 & -0.64 & 0.54 & 0.00 & 1.33 & 0.02 \\
\hline & & & {$[-2.25]$} & {$[-2.27]$} & {$[-2.12]$} & [21.91] & {$[0.32]$} & {$[39.41]$} & {$[0.61]$} \\
\hline \multirow[t]{2}{*}{1} & -0.37 & 3.77 & -0.39 & -0.39 & -0.37 & 0.44 & 0.01 & 1.09 & 0.06 \\
\hline & & & {$[-1.26]$} & {$[-1.27]$} & {$[-1.20]$} & [17.98] & {$[0.82]$} & {$[30.92]$} & {$[1.58]$} \\
\hline \multirow[t]{2}{*}{2} & -0.32 & 3.61 & -0.35 & -0.34 & -0.21 & 0.35 & -0.01 & 1.10 & -0.09 \\
\hline & & & {$[-1.16]$} & {$[-1.16]$} & {$[-0.74]$} & {$[14.51]$} & {$[-0.64]$} & {$[27.75]$} & {$[-2.86]$} \\
\hline \multirow[t]{2}{*}{3} & 0.08 & 3.68 & 0.05 & 0.06 & 0.17 & 0.33 & -0.01 & 1.00 & -0.12 \\
\hline & & & {$[0.18]$} & {$[0.21]$} & {$[0.61]$} & {$[13.38]$} & {$[-0.87]$} & {$[24.72]$} & {$[-3.58]$} \\
\hline \multicolumn{10}{|c|}{ Panel B: Equally-weighted PF returns } \\
\hline \multirow[t]{2}{*}{0} & -0.45 & 2.45 & -0.49 & -0.49 & -0.49 & 0.72 & 0.02 & 1.53 & 0.10 \\
\hline & & & {$[-2.44]$} & {$[-2.46]$} & {$[-2.50]$} & {$[25.03]$} & {$[2.17]$} & {$[41.77]$} & {$[4.46]$} \\
\hline \multirow[t]{2}{*}{1} & -0.35 & 2.38 & -0.38 & -0.38 & -0.38 & 0.57 & 0.01 & 1.42 & 0.05 \\
\hline & & & {$[-1.93]$} & {$[-1.94]$} & {$[-1.99]$} & {$[19.72]$} & {$[1.42]$} & {$[34.68]$} & {$[2.59]$} \\
\hline \multirow[t]{2}{*}{2} & -0.47 & 2.26 & -0.48 & -0.48 & -0.42 & 0.46 & -0.02 & 1.27 & -0.06 \\
\hline & & & {$[-2.60]$} & {$[-2.60]$} & {$[-2.30]$} & [16.01] & {$[-1.66]$} & [28.71] & {$[-3.35]$} \\
\hline \multirow[t]{2}{*}{3} & -0.33 & 2.32 & -0.35 & -0.34 & -0.26 & 0.41 & -0.02 & 1.12 & -0.06 \\
\hline & & & {$[-1.81]$} & {$[-1.81]$} & {$[-1.44]$} & [14.01] & {$[-1.78]$} & {$[24.62]$} & {$[-3.41]$} \\
\hline
\end{tabular}

This table reports the portfolio performance characteristics of the '5-1' $\beta_{D J I A}$ portfolio varying the number of lags in estimating the $\beta_{D J I A}$ loading. $\beta_{D J I A}$ here incorporates a varying number of time-series lags, from 0 to 3 as follows: $\beta_{D J I A}^{\text {Dimson }}=\sum_{\tau=0}^{3} \beta_{D J I A, t-\tau} \cdot \tau=0$ is the normal case employed so far whereby only the contemporaneous day $t$ is used for estimation. When $\tau>=1$, the $\beta_{D J I A}^{\text {Dimson }}$ is estimated as the sum of the factor loadings with respect to the same-day's as well as past-days' investor attention. Every beginning of month, I sort stocks into five quintiles based on current MCap. Within a quintile I sort the stocks according to the past month's $\beta_{D J I A}^{\text {Dimson }}$ loading from lowest (1) to highest (5) and form the '5-1' portfolio as the difference between the two extreme portfolios. Panel A shows value-weighted portfolio returns, while Panel B shows equally-weighted returns. For each ' 5 -1' portfolio, I then analyze the following characteristics: Monthly mean and standard deviation of simple returns (in percentage terms). The Alpha $(\alpha)$ columns report monthly Jensen's alpha with respect to the CAPM, the Fama-French (1993) three-factor model and the full model specification ( FF - 5, MOM, LIQ as well as Sigma). The pre- and post-formation investor attention loadings are estimated with daily portfolio returns, controlling with the full model specification. $\beta_{D J I A}$ is the beta to the raw investor attention measure while $\beta_{F-D J I A}$ denotes the sensitivity to the factor-mimicking portfolio. Robust Newey-West (1987) $t$-statistics are reported in square brackets. The sample period is from January 2004 to September 2015.

Table XVI '5-1' $\beta_{D J I A}$ PF characteristics with different Dimson lags. 


\begin{tabular}{|c|c|c|c|c|c|c|c|c|c|}
\hline \multirow[b]{2}{*}{$\begin{array}{l}\text { MCap } \\
\text { quintile }\end{array}$} & \multirow[b]{2}{*}{ Mean } & \multirow[b]{2}{*}{$\begin{array}{l}\text { Std. } \\
\text { Dev. }\end{array}$} & \multirow[b]{2}{*}{$\begin{array}{r}\mathrm{CAPM} \\
\alpha\end{array}$} & \multirow[b]{2}{*}{$\begin{array}{r}\mathrm{FF}-3 \\
\alpha\end{array}$} & \multirow[b]{2}{*}{$\begin{array}{r}\text { FULL } \\
\alpha\end{array}$} & \multicolumn{4}{|c|}{ Factor loadings } \\
\hline & & & & & & $\begin{array}{l}\text { Pre-f. } \\
\beta_{D J I A}\end{array}$ & $\begin{array}{l}\text { Post-f. } \\
\beta_{D J I A}\end{array}$ & $\begin{array}{r}\text { Pre-f. } \\
\beta_{F-D J I A}\end{array}$ & $\begin{array}{r}\text { Post-f. } \\
\beta_{F-D J I A}\end{array}$ \\
\hline \multicolumn{10}{|c|}{ Panel A: Value-weighted PF returns } \\
\hline 1 & -1.11 & 6.10 & $\begin{array}{r}-1.27 \\
{[-2.61]}\end{array}$ & $\begin{array}{r}-1.27 \\
{[-2.62]}\end{array}$ & $\begin{array}{r}-1.34 \\
{[-2.88]}\end{array}$ & $\begin{array}{r}-0.08 \\
{[-2.47]}\end{array}$ & $\begin{array}{r}0.00 \\
{[0.05]}\end{array}$ & $\begin{array}{r}-0.09 \\
{[-1.58]}\end{array}$ & $\begin{array}{r}0.14 \\
{[3.22]}\end{array}$ \\
\hline 2 & -0.12 & 3.48 & $\begin{array}{r}-0.27 \\
{[-1.03]}\end{array}$ & $\begin{array}{r}-0.27 \\
{[-1.06]}\end{array}$ & $\begin{array}{r}-0.28 \\
{[-1.23]}\end{array}$ & $\begin{array}{r}-0.06 \\
{[-3.53]}\end{array}$ & $\begin{array}{r}-0.04 \\
{[-3.01]}\end{array}$ & $\begin{array}{r}-0.10 \\
{[-3.70]}\end{array}$ & $\begin{array}{r}-0.03 \\
{[-1.35]}\end{array}$ \\
\hline 3 & -0.21 & 2.94 & $\begin{array}{r}-0.36 \\
{[-1.71]}\end{array}$ & $\begin{array}{r}-0.36 \\
{[-1.77]}\end{array}$ & $\begin{array}{r}-0.36 \\
{[-1.90]}\end{array}$ & $\begin{array}{r}-0.02 \\
{[-1.42]}\end{array}$ & $\begin{array}{r}0.00 \\
{[0.06]}\end{array}$ & $\begin{array}{r}0.03 \\
{[1.36]}\end{array}$ & $\begin{array}{r}0.05 \\
{[3.07]}\end{array}$ \\
\hline 4 & -0.03 & 2.65 & $\begin{array}{r}-0.18 \\
{[-0.98]}\end{array}$ & $\begin{array}{r}-0.18 \\
{[-0.99]}\end{array}$ & $\begin{array}{r}-0.20 \\
{[-1.21]}\end{array}$ & $\begin{array}{r}-0.01 \\
{[-1.00]}\end{array}$ & $\begin{array}{r}0.01 \\
{[1.23]}\end{array}$ & $\begin{array}{r}0.01 \\
{[0.53]}\end{array}$ & $\begin{array}{r}0.12 \\
{[5.77]}\end{array}$ \\
\hline 5 & -0.03 & 3.92 & $\begin{array}{r}-0.25 \\
{[-0.90]} \\
\end{array}$ & $\begin{array}{r}-0.23 \\
{[-0.94]} \\
\end{array}$ & $\begin{array}{r}-0.15 \\
{[-0.64]}\end{array}$ & $\begin{array}{r}0.01 \\
{[1.08]}\end{array}$ & $\begin{array}{r}0.04 \\
{[3.45]}\end{array}$ & $\begin{array}{r}0.09 \\
{[3.95]}\end{array}$ & $\begin{array}{r}0.19 \\
{[8.07]}\end{array}$ \\
\hline & & & Panel I & : Equall & -weight & d PF re & urns & & \\
\hline 1 & -0.92 & 6.45 & $\begin{array}{r}-1.00 \\
{[-1.88]}\end{array}$ & $\begin{array}{r}-1.00 \\
{[-1.88]}\end{array}$ & $\begin{array}{r}-1.14 \\
{[-2.23]}\end{array}$ & $\begin{array}{r}-0.12 \\
{[-3.91]}\end{array}$ & $\begin{array}{r}0.00 \\
{[0.19]}\end{array}$ & $\begin{array}{r}-0.21 \\
{[-3.92]}\end{array}$ & $\begin{array}{r}0.15 \\
{[3.09]}\end{array}$ \\
\hline 2 & -0.11 & 3.45 & $\begin{array}{r}-0.26 \\
{[-0.99]}\end{array}$ & $\begin{array}{r}-0.26 \\
{[-1.01]}\end{array}$ & $\begin{array}{r}-0.27 \\
{[-1.18]}\end{array}$ & $\begin{array}{r}-0.05 \\
{[-3.39]}\end{array}$ & $\begin{array}{r}-0.03 \\
{[-2.95]}\end{array}$ & $\begin{array}{r}-0.09 \\
{[-3.35]}\end{array}$ & $\begin{array}{r}-0.03 \\
{[-1.50]}\end{array}$ \\
\hline 3 & -0.22 & 2.89 & $\begin{array}{r}-0.37 \\
{[-1.78]}\end{array}$ & $\begin{array}{r}-0.37 \\
{[-1.83]}\end{array}$ & $\begin{array}{r}-0.36 \\
{[-1.97]}\end{array}$ & $\begin{array}{r}-0.01 \\
{[-1.04]}\end{array}$ & $\begin{array}{r}0.00 \\
{[0.19]}\end{array}$ & $\begin{array}{r}0.05 \\
{[1.83]}\end{array}$ & $\begin{array}{r}0.05 \\
{[2.76]}\end{array}$ \\
\hline 4 & -0.05 & 2.62 & $\begin{array}{r}-0.21 \\
{[-1.15]}\end{array}$ & $\begin{array}{r}-0.21 \\
{[-1.16]}\end{array}$ & $\begin{array}{r}-0.23 \\
{[-1.39]}\end{array}$ & $\begin{array}{r}-0.01 \\
{[-1.60]}\end{array}$ & $\begin{array}{r}0.01 \\
{[1.00]}\end{array}$ & $\begin{array}{r}-0.01 \\
{[-0.27]}\end{array}$ & $\begin{array}{r}0.10 \\
{[5.19]}\end{array}$ \\
\hline 5 & -0.08 & 2.92 & $\begin{array}{r}-0.26 \\
{[-1.30]}\end{array}$ & $\begin{array}{r}-0.25 \\
{[-1.34]}\end{array}$ & $\begin{array}{r}-0.28 \\
{[-1.65]}\end{array}$ & $\begin{array}{r}-0.01 \\
{[-0.84]}\end{array}$ & $\begin{array}{r}0.03 \\
{[3.55]}\end{array}$ & $\begin{array}{r}0.03 \\
{[1.56]}\end{array}$ & $\begin{array}{r}0.11 \\
{[6.86]}\end{array}$ \\
\hline
\end{tabular}

This table reports the portfolio performance characteristics of the '5-1' absolute $\left|\beta_{D J I A}\right|$ portfolio across different market capitalization (MCap) quintiles. Every beginning of month, I sort the stocks according to the past month's $\left|\beta_{D J I A}\right|$ loading from lowest (1) to highest (5) (based on equation (11) ) and form the '5-1' portfolio as the difference between the two extreme portfolios. Panel A shows value-weighted portfolio returns, while Panel B shows equally-weighted returns. For each '5-1' portfolio, I then analyze the following characteristics: Monthly mean and standard deviation of simple returns (in percentage terms). The Alpha $(\alpha)$ columns report monthly Jensen's alpha with respect to the CAPM, the Fama-French (1993) three-factor model and the full model specification ( $F F-5, M O M, L I Q$ as well as Sigma). The pre- and post-formation investor attention loadings are estimated with daily portfolio returns, controlling with the full model specification. $\beta_{D J I A}$ is the beta to the raw investor attention measure while $\beta_{F-D J I A}$ denotes the sensitivity to the factor-mimicking portfolio. Robust Newey-West (1987) $t$-statistics are reported in square brackets. The sample period is from January 2004 to September 2015.

Table XVII '5-1' $\left|\beta_{D J I A}\right|$ PF characteristics across across MCap quintiles. 


\begin{tabular}{|c|c|c|c|c|c|c|c|c|c|}
\hline \multirow[b]{2}{*}{$\begin{array}{r}\text { MCap } \\
\text { quintile }\end{array}$} & \multirow[b]{2}{*}{ Mean } & \multirow[b]{2}{*}{$\begin{array}{l}\text { Std. } \\
\text { Dev. }\end{array}$} & \multirow[b]{2}{*}{$\begin{array}{r}\mathrm{CAPM} \\
\alpha\end{array}$} & \multirow[b]{2}{*}{$\begin{array}{r}\mathrm{FF}-3 \\
\alpha\end{array}$} & \multirow[b]{2}{*}{$\begin{array}{r}\text { FULL } \\
\alpha\end{array}$} & \multicolumn{4}{|c|}{ Factor loadings } \\
\hline & & & & & & $\begin{array}{r}\text { Pre-f. } \\
\beta_{F E A R S}\end{array}$ & $\begin{array}{l}\text { Post-f. } \\
\beta_{F E A R S}\end{array}$ & $\begin{array}{r}\text { Pre-f. } \\
\beta_{F-F E A R S}\end{array}$ & $\begin{array}{r}\text { Post-f. } \\
\beta_{F-F E A R S}\end{array}$ \\
\hline \multicolumn{10}{|c|}{ Panel A: Positive Baker-Wurgler sentiment } \\
\hline \multirow[t]{2}{*}{1} & 0.38 & 5.09 & 0.33 & 0.3 & 0.3 & 2.38 & 0.01 & 2.9 & 0.06 \\
\hline & & & {$[0.59]$} & {$[0.55]$} & {$[0.54]$} & {$[57.56]$} & {$[0.46]$} & [83.73] & [0.99] \\
\hline \multirow[t]{2}{*}{2} & 0.22 & 2.80 & 0.22 & 0.24 & 0.11 & 1.4 & 0.02 & 1.69 & 0.07 \\
\hline & & & {$[0.72]$} & {$[0.78]$} & {$[0.38]$} & {$[56.79]$} & {$[1.02]$} & {$[80.18]$} & {$[2.28]$} \\
\hline \multirow[t]{2}{*}{3} & -0.17 & 2.58 & -0.19 & -0.16 & -0.3 & 1.08 & 0.01 & 1.31 & 0.03 \\
\hline & & & {$[-0.67]$} & {$[-0.59]$} & {$[-1.11]$} & {$[53.37]$} & {$[0.78]$} & {$[72.93]$} & [1.13] \\
\hline \multirow[t]{2}{*}{4} & -0.48 & 2.70 & -0.49 & -0.46 & -0.67 & 0.89 & 0.03 & 1.09 & 0.12 \\
\hline & & & {$[-1.68]$} & {$[-1.61]$} & {$[-2.37]$} & {$[47.31]$} & {$[1.87]$} & {$[63.01]$} & {$[3.87]$} \\
\hline \multirow[t]{2}{*}{5} & -0.47 & 3.24 & -0.45 & -0.4 & -0.71 & 0.71 & 0.02 & 0.95 & 0.07 \\
\hline & & & {$[-1.28]$} & {$[-1.18]$} & {$[-2.16]$} & {$[34.68]$} & {$[1.17]$} & {$[45.67]$} & [2.03] \\
\hline \multicolumn{10}{|c|}{ Panel B: Negative Baker-Wurgler sentiment } \\
\hline \multirow[t]{2}{*}{1} & 2.18 & 7.89 & 2.06 & 2.1 & 1.59 & 2.65 & 0.01 & 3.28 & 0.07 \\
\hline & & & {$[2.07]$} & {$[2.12]$} & {$[1.62]$} & [36.63] & {$[0.25]$} & [47.13] & {$[0.76]$} \\
\hline \multirow[t]{2}{*}{2} & 0.62 & 3.78 & 0.6 & 0.61 & 0.53 & 1.6 & 0.04 & 1.95 & 0.17 \\
\hline & & & {$[1.25]$} & {$[1.28]$} & {$[1.11]$} & [40.89] & {$[1.76]$} & {$[53.87]$} & {$[3.61]$} \\
\hline \multirow[t]{2}{*}{3} & 0.50 & 3.18 & 0.48 & 0.51 & 0.42 & 1.12 & 0.03 & 1.41 & 0.13 \\
\hline & & & {$[1.18]$} & {$[1.28]$} & {$[1.05]$} & {$[38.53]$} & [1.58] & [51.31] & [3.34] \\
\hline \multirow[t]{2}{*}{4} & 0.51 & 3.29 & 0.52 & 0.56 & 0.47 & 0.93 & 0 & 1.22 & 0.01 \\
\hline & & & {$[1.24]$} & {$[1.37]$} & {$[1.15]$} & [33.8] & {$[0.01]$} & {$[45.1]$} & {$[0.33]$} \\
\hline \multirow[t]{2}{*}{5} & 0.19 & 4.10 & 0.17 & 0.19 & 0.15 & 0.75 & -0.02 & 1.05 & -0.05 \\
\hline & & & {$[0.32]$} & {$[0.37]$} & {$[0.29]$} & [27.09] & {$[-0.88]$} & {$[36.28]$} & {$[-1.01]$} \\
\hline
\end{tabular}

This table reports the portfolio performance characteristics of the value-weighted '5-1' (HML) $\beta_{F E A R S}$ portfolio across different market capitalization (MCap) quintiles. Every beginning of month, I sort stocks into five quintiles based on current MCap. Within a quintile I sort the stocks according to the past month's $\beta_{F E A R S}$ loading from lowest (1) to highest (5) as in equation (12) and form the ' 5 -1' portfolio as the difference between the two extreme portfolios. Panel A (B) shows portfolio returns in positive (negative) sentiment states. For each '5-1' portfolio, I then analyze the following characteristics: Monthly mean and standard deviation of simple returns (in percentage terms). The Alpha $(\alpha)$ columns report monthly Jensen's alpha with respect to the CAPM, the Fama-French (1993) three-factor model and the full model specification $(F F-5$, $M O M, L I Q$ as well as Sigma). The pre- and post-formation investor attention loadings are estimated with daily portfolio returns, controlling with the full model specification. $\beta_{F E A R S}$ is the beta to the raw investor sentiment measure while $\beta_{F-F E A R S}$ denotes the sensitivity to the factor-mimicking portfolio. Robust Newey-West (1987) $t$-statistics are reported in square brackets. The sample period is from January 2004 to September 2015.

Table XVIII '5-1' $\beta_{F E A R S}$ PF characteristics across MCap quintiles. 


\begin{tabular}{|c|c|c|c|c|c|c|c|c|c|}
\hline \multirow[b]{2}{*}{$\begin{array}{l}\text { MCap } \\
\text { quintile }\end{array}$} & \multirow[b]{2}{*}{ Mean } & \multirow[b]{2}{*}{$\begin{array}{l}\text { Std. } \\
\text { Dev. }\end{array}$} & \multirow[b]{2}{*}{$\begin{array}{r}\mathrm{CAPM} \\
\alpha \\
\end{array}$} & \multirow[b]{2}{*}{$\begin{array}{r}\mathrm{FF}-3 \\
\alpha\end{array}$} & \multirow[b]{2}{*}{$\begin{array}{r}\text { FULL } \\
\alpha \\
\end{array}$} & \multicolumn{4}{|c|}{ Factor loadings } \\
\hline & & & & & & $\begin{array}{r}\text { Pre-f. } \\
\beta_{F E A R S}\end{array}$ & $\begin{array}{r}\text { Post-f. } \\
\beta_{F E A R S}\end{array}$ & $\begin{array}{r}\text { Pre-f. } \\
\beta_{F-F E A R S}\end{array}$ & $\begin{array}{r}\text { Post-f. } \\
\beta_{F-F E A R S}\end{array}$ \\
\hline \multicolumn{10}{|c|}{ Panel A: Positive Baker-Wurgler sentiment } \\
\hline \multirow[t]{2}{*}{1} & -0.11 & 4.00 & -0.12 & -0.13 & -0.27 & 2.78 & 0.06 & 3.15 & 0.24 \\
\hline & & & {$[-0.28]$} & {$[-0.29]$} & {$[-0.63]$} & {$[75.69]$} & {$[2.46]$} & {$[107.67]$} & {$[5.12]$} \\
\hline \multirow[t]{2}{*}{2} & -0.13 & 2.45 & -0.17 & -0.17 & -0.3 & 1.83 & 0.01 & 2.04 & 0.05 \\
\hline & & & {$[-0.66]$} & {$[-0.64]$} & {$[-1.17]$} & {$[73.66]$} & {$[0.75]$} & {$[97.33]$} & {$[1.72]$} \\
\hline \multirow[t]{2}{*}{3} & -0.35 & 1.90 & -0.35 & -0.34 & -0.43 & 1.45 & 0.03 & 1.65 & 0.14 \\
\hline & & & {$[-1.68]$} & {$[-1.65]$} & {$[-2.11]$} & {$[67.15]$} & {$[2.79]$} & [89.93] & {$[6.11]$} \\
\hline \multirow[t]{2}{*}{4} & -0.19 & 1.97 & -0.2 & -0.18 & -0.29 & 1.14 & 0.01 & 1.32 & 0.03 \\
\hline & & & {$[-0.93]$} & {$[-0.87]$} & {$[-1.37]$} & {$[60.77]$} & {$[0.74]$} & [80.75] & {$[1.28]$} \\
\hline \multirow[t]{2}{*}{5} & -0.28 & 2.87 & -0.26 & -0.22 & -0.44 & 0.79 & 0.04 & 1 & 0.16 \\
\hline & & & {$[-0.85]$} & {$[-0.73]$} & {$[-1.47]$} & {$[41.28]$} & [2.35] & {$[53.58]$} & [4.98] \\
\hline \multicolumn{10}{|c|}{ Panel B: Negative Baker-Wurgler sentiment } \\
\hline \multirow[t]{2}{*}{1} & 1.25 & 6.47 & 1.19 & 1.22 & 1.12 & 3.13 & 0.06 & 3.7 & 0.24 \\
\hline & & & {$[1.45]$} & [1.48] & {$[1.36]$} & [48.37] & {$[1.53]$} & [64.48] & {$[3.08]$} \\
\hline \multirow[t]{2}{*}{2} & 0.73 & 3.78 & 0.58 & 0.6 & 0.46 & 2.01 & -0.02 & 2.31 & -0.05 \\
\hline & & & {$[1.27]$} & {$[1.32]$} & {$[1.04]$} & [46.81] & {$[-0.73]$} & [58.34] & {$[-1.27]$} \\
\hline \multirow[t]{2}{*}{3} & -0.02 & 2.41 & -0.03 & -0.03 & -0.02 & 1.53 & 0.05 & 1.79 & 0.21 \\
\hline & & & {$[-0.1]$} & {$[-0.09]$} & {$[-0.07]$} & {$[50.44]$} & {$[3.57]$} & [67.35] & {$[7.41]$} \\
\hline \multirow[t]{2}{*}{4} & 0.16 & 2.40 & 0.15 & 0.17 & 0.06 & 1.16 & 0.02 & 1.4 & 0.09 \\
\hline & & & {$[0.49]$} & {$[0.57]$} & {$[0.22]$} & [44.89] & {$[1.36]$} & [59.45] & {$[3.21]$} \\
\hline \multirow[t]{2}{*}{5} & 0.16 & 3.81 & 0.16 & 0.18 & 0.13 & 0.83 & 0 & 1.12 & 0.04 \\
\hline & & & {$[0.34]$} & {$[0.37]$} & {$[0.27]$} & [31.49] & {$[0.06]$} & [41.92] & {$[0.97]$} \\
\hline
\end{tabular}

This table reports the portfolio performance characteristics of the value-weighted ' 5 -1' (HML) $\beta_{F E A R S}$ portfolio across different market capitalization (MCap) quintiles in an enlarged sample including all NYSE/AMEX as well as NASDAQ stocks. Every beginning of month, I sort stocks into five quintiles based on current MCap. Within a MCap quintile I sort the stocks according to the past month's $\beta_{F E A R S}$ loading from lowest (1) to highest (5) as in equation (12) and form the '5-1' portfolio as the difference between the two extreme portfolios. Panel A (B) shows portfolio returns in positive (negative) sentiment states. For each '5-1' portfolio, I then analyze the following characteristics: Monthly mean and standard deviation of simple returns (in percentage terms). The Alpha $(\alpha)$ columns report monthly Jensen's alpha with respect to the CAPM, the Fama-French (1993) three-factor model and the full model specification $(F F-5, M O M, L I Q$ as well as Sigma). The pre- and post-formation investor attention loadings are estimated with daily portfolio returns, controlling with the full model specification. $\beta_{F E A R S}$ is the beta to the raw investor sentiment measure while $\beta_{F-F E A R S}$ denotes the sensitivity to the factor-mimicking portfolio. Robust Newey-West (1987) $t$-statistics are reported in square brackets. The sample period is from January 2004 to September 2015.

Table XIX '5-1' $\beta_{F E A R S}$ PF characteristics across MCap quintiles in a bigger sample - including NASDAQ stocks. 


\begin{tabular}{|c|c|c|c|c|c|c|c|c|c|}
\hline \multirow[b]{2}{*}{$\begin{array}{l}\text { BW } \\
\text { sentiment }\end{array}$} & \multirow[b]{2}{*}{ Mean } & \multirow[b]{2}{*}{$\begin{array}{l}\text { Std. } \\
\text { Dev. }\end{array}$} & \multirow[b]{2}{*}{$\begin{array}{r}\mathrm{CAPM} \\
\alpha\end{array}$} & \multirow[b]{2}{*}{$\begin{array}{r}\mathrm{FF}-3 \\
\alpha\end{array}$} & \multirow[b]{2}{*}{$\begin{array}{r}\text { FULL } \\
\alpha \\
\end{array}$} & \multicolumn{4}{|c|}{ Factor loadings } \\
\hline & & & & & & $\begin{array}{r}\text { Pre-f. } \\
\beta_{F E A R S}\end{array}$ & $\begin{array}{r}\text { Post-f. } \\
\beta_{F E A R S}\end{array}$ & $\begin{array}{r}\text { Pre-f. } \\
\beta_{F-F E A R S}\end{array}$ & $\begin{array}{r}\text { Post-f. } \\
\beta_{F-F E A R S}\end{array}$ \\
\hline \multicolumn{10}{|c|}{ Panel A: Value-weighted PF returns } \\
\hline \multirow[t]{2}{*}{$\mathrm{UC}$} & -0.02 & 3.32 & -0.03 & -0.03 & -0.16 & 0.89 & 0 & 1.13 & 0 \\
\hline & & & {$[-0.1]$} & {$[-0.11]$} & {$[-0.6]$} & {$[53.75]$} & {$[-0.28]$} & [69.99] & {$[-0.02]$} \\
\hline \multirow[t]{2}{*}{ Pos } & -0.14 & 2.67 & -0.14 & -0.11 & -0.3 & 0.86 & 0.02 & 1.06 & 0.08 \\
\hline & & & {$[-0.47]$} & {$[-0.39]$} & {$[-1.07]$} & {$[44.58]$} & {$[1.44]$} & {$[57.98]$} & [2.63] \\
\hline \multirow[t]{2}{*}{ Neg } & 0.15 & 4.05 & 0.12 & 0.15 & 0.11 & 0.93 & -0.03 & 1.2 & -0.11 \\
\hline & & & {$[0.24]$} & {$[0.3]$} & {$[0.22]$} & {$[33.12]$} & {$[-1.44]$} & {$[43.32]$} & {$[-2.22]$} \\
\hline \multicolumn{10}{|c|}{ Panel B: Equally-weighted PF returns } \\
\hline \multirow[t]{2}{*}{$\mathrm{UC}$} & 0.23 & 2.20 & 0.2 & 0.2 & 0.14 & 1.39 & 0.02 & 1.55 & 0.08 \\
\hline & & & {$[1.13]$} & {$[1.12]$} & {$[0.77]$} & {$[78.63]$} & {$[1.88]$} & {$[94.3]$} & [4.25] \\
\hline \multirow[t]{2}{*}{ Pos } & -0.03 & 1.95 & -0.06 & -0.05 & -0.18 & 1.34 & 0.03 & 1.47 & 0.11 \\
\hline & & & {$[-0.26]$} & {$[-0.23]$} & {$[-0.88]$} & {$[71.89]$} & {$[2.32]$} & {$[89.92]$} & {$[4.81]$} \\
\hline \multirow[t]{2}{*}{ Neg } & 0.59 & 2.49 & 0.56 & 0.58 & 0.49 & 1.45 & 0.01 & 1.63 & 0.04 \\
\hline & & & {$[1.76]$} & {$[1.89]$} & {$[1.65]$} & {$[45.91]$} & {$[0.37]$} & {$[54.25]$} & [1.41] \\
\hline
\end{tabular}

This table reports the portfolio performance characteristics of the value-weighted ' 5 -1' (HML) $\beta_{F E A R S}$ portfolio across the whole sample (UC) as well as positive (POS) and negative (NEG) Baker-Wurgler sentiment months, controlling for return reversal. Every month, I double-sort the stocks according to their monthly simple returns as well as their $\beta_{F E A R S}$ loading last month (equation (12)) from lowest (1) to highest (5). I then form the ' 5 - 1 ' portfolio in $\beta_{F E A R S}$ loadings across different return quintiles. Panel A shows value-weighted portfolio returns, while Panel B shows equally-weighted returns. For each '5-1' portfolio, I then analyze the following characteristics: Monthly mean and standard deviation of simple returns (in percentage terms). The Alpha $(\alpha)$ columns report monthly Jensen's alpha with respect to the CAPM, the Fama-French (1993) three-factor model and the full model specification $(F F-5, M O M, L I Q$ as well as Sigma). The pre- and post-formation investor attention loadings are estimated with daily portfolio returns, controlling with the full model specification. $\beta_{F E A R S}$ is the beta to the raw investor sentiment measure while $\beta_{F-F E A R S}$ denotes the sensitivity to the factor-mimicking portfolio. Robust Newey-West (1987) t-statistics are reported in square brackets. The sample period is from January 2004 to September 2015.

Table XX '5-1' $\beta_{F E A R S}$ PF characteristics, controlling for return reversal. 


\begin{tabular}{|c|c|c|c|c|c|c|c|c|c|}
\hline \multirow{3}{*}{$\begin{array}{l}\text { Dimson } \\
\text { lags }\end{array}$} & \multirow[b]{3}{*}{ Mean } & \multirow{3}{*}{$\begin{array}{l}\text { Std. } \\
\text { Dev. }\end{array}$} & \multirow{3}{*}{$\begin{array}{r}\mathrm{CAPM} \\
\alpha\end{array}$} & \multirow{3}{*}{$\begin{array}{r}\mathrm{FF}-3 \\
\alpha\end{array}$} & \multirow{3}{*}{$\begin{array}{r}\text { FULL } \\
\alpha\end{array}$} & \multicolumn{4}{|c|}{ Factor loadings } \\
\hline & & & & & & Pre-f. & Post-f. & Pre-f. & Post-f. \\
\hline & & & & & & $\beta_{F E A R S}$ & $\beta_{F E A R S}$ & $\beta_{F-F E A R S}$ & $\beta_{F-F E A R S}$ \\
\hline \multicolumn{10}{|c|}{ Panel A: Positive Baker-Wurgler sentiment } \\
\hline \multirow[t]{2}{*}{0} & -0.42 & 3.28 & -0.42 & -0.37 & -0.71 & 0.94 & 0.03 & 1.16 & 0.1 \\
\hline & & & {$[-1.18]$} & {$[-1.08]$} & {$[-2.13]$} & {$[39.9]$} & {$[1.48]$} & [49.95] & {$[2.88]$} \\
\hline \multirow[t]{2}{*}{1} & -0.11 & 2.85 & -0.1 & -0.14 & -0.04 & 0.54 & 0.01 & 1.35 & 0.06 \\
\hline & & & {$[-0.33]$} & {$[-0.44]$} & {$[-0.14]$} & {$[18.28]$} & {$[0.76]$} & {$[34.35]$} & {$[1.65]$} \\
\hline \multirow[t]{2}{*}{2} & -0.15 & 3.14 & -0.16 & -0.17 & -0.05 & 0.36 & 0.01 & 1.21 & 0.02 \\
\hline & & & {$[-0.48]$} & {$[-0.5]$} & {$[-0.15]$} & {$[10.96]$} & {$[0.38]$} & [21.91] & {$[0.47]$} \\
\hline \multirow[t]{2}{*}{3} & 0.35 & 3.13 & 0.31 & 0.26 & 0.46 & 0.21 & 0 & 0.87 & 0 \\
\hline & & & {$[0.93]$} & {$[0.79]$} & {$[1.45]$} & {$[6.29]$} & {$[-0.03]$} & {$[13.04]$} & {$[-0.06]$} \\
\hline \multicolumn{10}{|c|}{ Panel B: Negative Baker-Wurgler sentiment } \\
\hline \multirow[t]{2}{*}{0} & 0.32 & 4.66 & 0.3 & 0.34 & 0.21 & 1.04 & -0.02 & 1.35 & -0.06 \\
\hline & & & {$[0.5]$} & {$[0.58]$} & {$[0.37]$} & {$[31.61]$} & {$[-0.91]$} & {$[40.7]$} & {$[-1.12]$} \\
\hline \multirow[t]{2}{*}{1} & -0.68 & 4.90 & -0.71 & -0.68 & -0.96 & 0.64 & -0.03 & 1.6 & -0.13 \\
\hline & & & {$[-1.14]$} & {$[-1.11]$} & {$[-1.57]$} & {$[15.84]$} & {$[-1.19]$} & {$[29.62]$} & {$[-2.26]$} \\
\hline \multirow[t]{2}{*}{2} & -0.43 & 4.85 & -0.5 & -0.46 & -0.78 & 0.46 & -0.02 & 1.68 & -0.1 \\
\hline & & & {$[-0.82]$} & {$[-0.76]$} & {$[-1.31]$} & [11.16] & {$[-0.59]$} & {$[24.36]$} & {$[-1.68]$} \\
\hline \multirow[t]{2}{*}{3} & -0.05 & 4.12 & -0.1 & -0.08 & -0.28 & 0.29 & -0.02 & 1.23 & -0.07 \\
\hline & & & {$[-0.2]$} & {$[-0.16]$} & {$[-0.55]$} & {$[7.33]$} & {$[-0.66]$} & [16.11] & {$[-1.31]$} \\
\hline
\end{tabular}

This table reports the portfolio performance characteristics of the value-weighted '5-1' (HML) $\beta_{F E A R S}$ portfolio varying the number of lags in estimating the $\beta_{F E A R S}$ loading. $\beta_{F E A R S}$ here incorporates a varying number of time-series lags, from 0 to 3 as follows:

$\beta_{F E A R S}^{\text {Dimson }}=\sum_{\tau=0}^{3} \beta_{F E A R S, t-\tau} . \tau=0$ is the normal case employed so far whereby only the contemporaneous day $t$ is used for estimation. When $\tau>=1$, the $\beta_{F E A R S}^{\text {Dimson }}$ is estimated as the sum of the factor loadings with respect to the same-day's as well as past-days' investor attention. Every beginning of month, I sort stocks into five quintiles based on current MCap. Within a quintile I sort the stocks according to the past month's $\beta_{F E A R S}$ loading from lowest (1) to highest (5) and form the '5-1' portfolio as the difference between the two extreme portfolios. Panel A (B) shows portfolio returns in positive (negative) sentiment states. For each '5-1' portfolio, I then analyze the following characteristics: Monthly mean and standard deviation of simple returns (in percentage terms). The Alpha $(\alpha)$ columns report monthly Jensen's alpha with respect to the CAPM, the Fama-French (1993) three-factor model and the full model specification $(F F-5$, $M O M, L I Q$ as well as Sigma). The pre- and post-formation investor attention loadings are estimated with daily portfolio returns, controlling with the full model specification. $\beta_{F E A R S}$ is the beta to the raw investor sentiment measure while $\beta_{F-F E A R S}$ denotes the sensitivity to the factor-mimicking portfolio. Robust Newey-West (1987) $t$-statistics are reported in square brackets. The sample period is from January 2004 to September 2015.

Table XXI 5-1' $\beta_{F E A R S}$ PF characteristics with different Dimson lags. 


\begin{tabular}{|c|c|c|c|c|c|c|c|c|c|}
\hline \multirow[b]{2}{*}{$\begin{array}{l}\text { MCap } \\
\text { quintile }\end{array}$} & \multirow[b]{2}{*}{ Mean } & \multirow[b]{2}{*}{$\begin{array}{l}\text { Std. } \\
\text { Dev. }\end{array}$} & \multirow[b]{2}{*}{$\begin{array}{r}\mathrm{CAPM} \\
\alpha\end{array}$} & \multirow[b]{2}{*}{$\begin{array}{r}\mathrm{FF}-3 \\
\alpha\end{array}$} & \multirow[b]{2}{*}{$\begin{array}{r}\text { FULL } \\
\alpha \\
\end{array}$} & \multicolumn{4}{|c|}{ Factor loadings } \\
\hline & & & & & & $\begin{array}{r}\text { Pre-f. } \\
\beta_{F E A R S}\end{array}$ & $\begin{array}{r}\text { Post-f. } \\
\beta_{F E A R S}\end{array}$ & $\begin{array}{r}\text { Pre-f. } \\
\beta_{F-F E A R S}\end{array}$ & $\begin{array}{r}\text { Post-f. } \\
\beta_{F-F E A R S} \\
\end{array}$ \\
\hline \multicolumn{10}{|c|}{ Panel A: Positive Baker-Wurgler sentiment } \\
\hline \multirow[t]{2}{*}{1} & \multirow[t]{2}{*}{-0.97} & \multirow[t]{2}{*}{5.05} & -1.03 & -1.01 & -0.63 & 0.07 & 0.02 & 0.18 & -0.01 \\
\hline & & & {$[-1.89]$} & {$[-1.87]$} & {$[-1.22]$} & {$[2.11]$} & {$[0.78]$} & {$[2.8]$} & {$[-0.1]$} \\
\hline \multirow[t]{2}{*}{2} & \multirow[t]{2}{*}{-0.30} & \multirow[t]{2}{*}{2.87} & -0.4 & -0.42 & -0.07 & 0.08 & 0.04 & 0.2 & 0.07 \\
\hline & & & {$[-1.35]$} & {$[-1.44]$} & {$[-0.27]$} & {$[5.02]$} & {$[2.99]$} & {$[6.74]$} & {$[2.51]$} \\
\hline \multirow[t]{2}{*}{3} & \multirow[t]{2}{*}{0.13} & \multirow[t]{2}{*}{2.35} & 0.04 & 0.02 & 0.18 & 0.05 & 0 & 0.14 & -0.06 \\
\hline & & & {$[0.17]$} & {$[0.09]$} & {$[0.84]$} & {$[4.05]$} & {$[-0.24]$} & {$[5.62]$} & {$[-2.62]$} \\
\hline \multirow[t]{2}{*}{4} & \multirow[t]{2}{*}{-0.12} & \multirow[t]{2}{*}{2.25} & -0.21 & -0.21 & -0.18 & -0.02 & 0 & -0.11 & -0.03 \\
\hline & & & {$[-0.95]$} & {$[-0.98]$} & {$[-0.89]$} & {$[-1.49]$} & {$[0.05]$} & {$[-4.88]$} & {$[-1.23]$} \\
\hline \multirow[t]{2}{*}{5} & \multirow[t]{2}{*}{0.18} & \multirow[t]{2}{*}{2.50} & 0.06 & 0.05 & 0.03 & -0.02 & -0.02 & -0.1 & -0.12 \\
\hline & & & {$[0.26]$} & {$[0.19]$} & {$[0.15]$} & {$[-1.64]$} & {$[-1.58]$} & {$[-3.94]$} & {$[-4.94]$} \\
\hline \multicolumn{10}{|c|}{ Panel B: Negative Baker-Wurgler sentiment } \\
\hline \multirow[t]{2}{*}{1} & \multirow[t]{2}{*}{-0.45} & \multirow[t]{2}{*}{7.54} & -0.68 & -0.61 & -1.39 & 0.06 & -0.05 & 0.17 & -0.21 \\
\hline & & & {$[-0.73]$} & {$[-0.67]$} & {$[-1.6]$} & {$[1.04]$} & {$[-1.14]$} & {$[1.53]$} & {$[-2.63]$} \\
\hline \multirow[t]{2}{*}{2} & \multirow[t]{2}{*}{-0.44} & \multirow[t]{2}{*}{4.34} & -0.68 & -0.61 & -1.03 & 0.03 & 0.04 & 0.07 & 0.11 \\
\hline & & & {$[-1.38]$} & {$[-1.29]$} & {$[-2.38]$} & {$[1.21]$} & {$[2.09]$} & {$[1.32]$} & {$[2.66]$} \\
\hline \multirow[t]{2}{*}{3} & \multirow[t]{2}{*}{0.07} & 3.63 & -0.19 & -0.13 & -0.44 & 0.02 & -0.02 & 0.02 & -0.11 \\
\hline & & & {$[-0.51]$} & {$[-0.37]$} & {$[-1.41]$} & {$[1.05]$} & {$[-1.09]$} & {$[0.7]$} & {$[-3.63]$} \\
\hline 4 & 0.03 & 3.35 & -0.22 & -0.17 & -0.37 & -0.03 & 0 & -0.14 & -0.03 \\
\hline & & & {$[-0.66]$} & {$[-0.53]$} & {$[-1.31]$} & {$[-1.87]$} & {$[-0.21]$} & {$[-4.38]$} & {$[-0.96]$} \\
\hline 5 & -0.38 & 4.35 & -0.65 & -0.53 & -0.65 & -0.04 & 0 & -0.18 & -0.11 \\
\hline & & & {$[-1.38]$} & {$[-1.26]$} & {$[-1.69]$} & {$[-2.4]$} & {$[-0.17]$} & {$[-5.48]$} & {$[-2.89]$} \\
\hline
\end{tabular}

This table reports the portfolio performance characteristics of the '5-1' (HML) $\left|\beta_{F E A R S}\right|$ portfolio across different market capitalization (MCap) quintiles. Every beginning of month, I sort the stocks according to the past month's $\left|\beta_{F E A R S}\right|$ loading from lowest (1) to highest (5) (based on equation (12) ) and form the '5-1' portfolio as the difference between the two extreme portfolios. Panel A (B) shows portfolio returns in positive (negative) sentiment states. For each '5-1' portfolio, I then analyze the following characteristics: Monthly mean and standard deviation of simple returns (in percentage terms). The Alpha $(\alpha)$ columns report monthly Jensen's alpha with respect to the CAPM, the Fama-French (1993) three-factor model and the full model specification (FF-5, MOM, LIQ as well as Sigma). The pre- and post-formation investor attention loadings are estimated with daily portfolio returns, controlling with the full model specification. $\beta_{F E A R S}$ is the beta to the raw investor sentiment measure while $\beta_{F-F E A R S}$ denotes the sensitivity to the factor-mimicking portfolio. Robust Newey-West (1987) $t$-statistics are reported in square brackets. The sample period is from January 2004 to September 2015.

Table XXII '5-1' $\left|\beta_{F E A R S}\right|$ PF characteristics across across MCap quintiles. 